Vanadium / Air Redox Flow Battery 
This work was financially supported by Agentschap NL.

\section{Committee Members}

Prof. Dr. G. van der Steenhoven (Chairman) University of Twente

Prof. Dr.-Ing. M. Wessling (Promoter) University of Twente

Dr. M. Saakes

Magneto Special Anodes B.V.

The Netherlands

Dr. Ir. D. C. Nijmeijer

University of Twente

Prof. Dr. M. Skyllas-Kazacos

University of New South Wales

Australia

Prof. Dr. G. Mul

University of Twente

Dr. B. A. Boukamp

University of Twente

Prof. Dr. W. Schuhmann

Ruhr-Universität Bochum

Germany

This PhD-Thesis has been typeset using $\mathrm{LT}_{\mathrm{E}} \mathrm{X}$ (TEXLive-2009 distribution) using Kile Version 2.0.85 (http://kile.sourceforge.net) distributed under the GPL public license.

Title: $\quad$ Vanadium / Air Redox Flow Battery

ISBN: $\quad$ 978-90-365-3225-9

DOI: $\quad 10.3990 / 1.9789036532259$

(C)2011 Seyed Schwan Hosseiny, Enschede, 2011

All rights reserved 


\title{
Vanadium / Air Redox Flow Battery
}

\author{
DISSERTATION
}

\author{
to obtain \\ the degree of doctor at the University of Twente, \\ on the authority of the rector magnificus, \\ Prof. Dr. H. Brinksma, \\ on account of the decision of the graduation committee, \\ to be publicly defended \\ on Friday the $15^{\text {th }}$ of July 2011 at 14.45
}

by

\section{Seyed Schwan Hosseiny}

born on the $24^{\text {th }}$ of August 1979

in Mashhad, Iran 
This dissertation has been approved by:

Prof. Dr.-Ing. M. Wessling

-Promoter 
For Mina Amiry and Seyed Jamal Hosseiny, my parents Thank you so much for all your support and love 



\section{Contents}

Contents

1 Electrochemical Energy Storage and Conversion $\quad 1$

1.1 Introduction . . . . . . . . . . . . . . . . . . . 1

1.2 Primary Batteries . . . . . . . . . . . . . . . . 9

1.3 Secondary Batteries . . . . . . . . . . . . . . . . 10

1.4 Redox Flow Batteries . . . . . . . . . . . . . . . . . . 11

1.4.1 Bromine Polysulphide Redox Flow Battery . . . . . . . . . . . 14

1.4.2 Zinc Bromide Redox Flow Battery . . . . . . . . . . . . . 15

1.4.3 Vanadium Redox Flow Batteries . . . . . . . . . . . . . 15

1.5 Hybrid Systems . . . . . . . . . . . . . . . . . . 17

1.6 Membranes for Vanadium Redox Flow Battery . . . . . . . . . . . 23

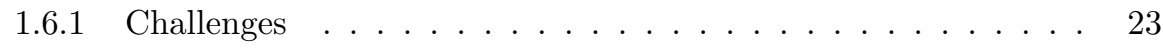

1.6.2 Membranes ......................... 28

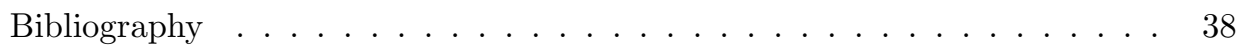

2 Principles of Electrochemical Characterization Techniques $\quad 45$

2.1 Cyclic Voltammetry . . . . . . . . . . . . . . . 46

2.2 Impedance Spectroscopy . . . . . . . . . . . . . . . . . . . . 48

2.3 Battery Characterization . . . . . . . . . . . . . . 54

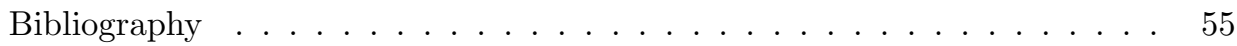

3 Modular Vanadium/Air Redox Flow Battery $\quad 57$

3.1 Introduction . . . . . . . . . . . . . . . . 58

3.2 Experimental . . . . . . . . . . . . . . . . 59 
3.2.1 Modular Vanadium/Air-RFB System . . . . . . . . . . . . . . . 59

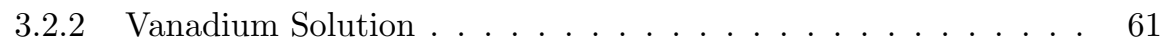

$3.2 .3 \quad$ MEA for Charging . . . . . . . . . . . . . . . . . . . . . . . . . . 61

3.2 .4 MEA for Discharging . . . . . . . . . . . . . . 63

3.3 Results and Discussions . . . . . . . . . . . . . . . . 65

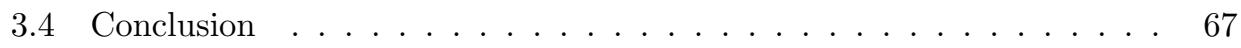

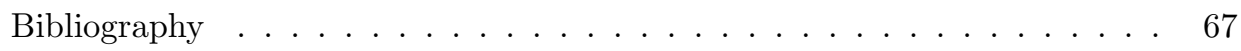

4 Unitized Vanadium/Air Redox Flow Battery $\quad 69$

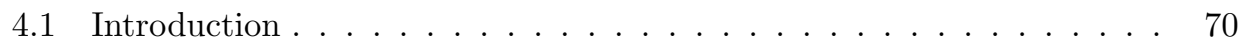

4.2 Experimental . . . . . . . . . . . . . . . . 73

4.2.1 Membrane Electrode Assembly (MEA) . . . . . . . . . . 73

4.2.2 Unitized Vanadium/Air-RFB Operation Conditions . . . . . . 73

4.3 Results and Discussions _ . . . . . . . . . . . . . . . 74

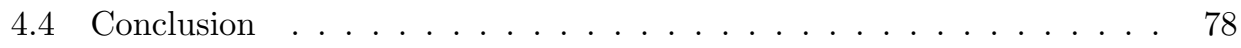

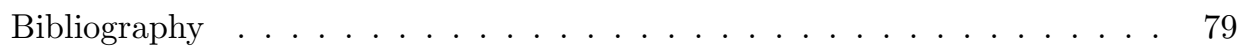

5 Crosslinked Sulphonated Poly(Ether Ether Ketone) for Redox Flow $\begin{array}{ll}\text { Battery Applications } & 81\end{array}$

5.1 Introduction . . . . . . . . . . . . . . . . . . . 82

5.2 Experimental . . . . . . . . . . . . . . . . . 87

$5.2 .1 \quad$ Membrane Preparation . . . . . . . . . . . . . . 87

5.2 .2 Proton Conductivity . . . . . . . . . . . . . . . 87

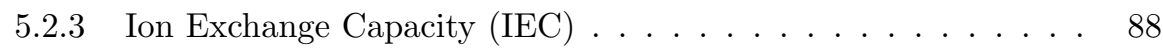

5.2 .4 Water Uptake . . . . . . . . . . . . . . . . . . . 88

5.2 .5 Permeability of Vanadium Ions . . . . . . . . . . . 88

5.2 .6 Fourier Transform Infra-red Spectroscopy . . . . . . . . . . 89

5.3 Results. . . . . . . . . . . . . . . . . . . . . 89

5.3 .1 Crosslinking SPEEK . . . . . . . . . . . . . . . . . . . 89

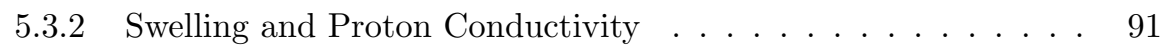

5.3 .3 Vanadium Permeability . . . . . . . . . . . . . 96

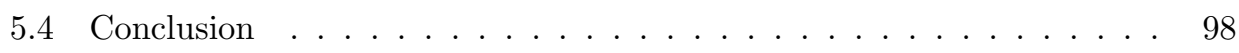

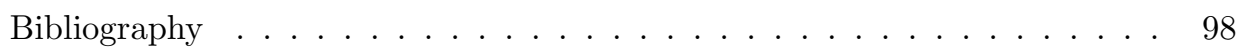

6 Appendix to Chapter 5 101

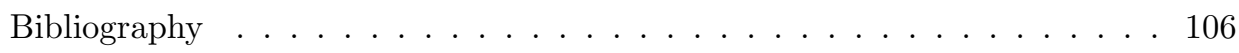

$\begin{array}{lll}7 & \text { Bifunctional Oxygen/Air Electrodes } & 109\end{array}$

7.1 Introduction . . . . . . . . . . . . . . . . . . . . . . . 110 
7.1.1 Electrocatalysts for Oxygen Reduction Reaction . . . . . . . . 111

7.1.2 Electrocatalysts for Oxygen Evolution Reaction . . . . . . . . . 112

7.2 Catalyst Support . . . . . . . . . . . . . . . . . . . . 112

7.3 Bifunctional Oxygen / Air Electrode (BOAE) . . . . . . . . . . . . 114

7.4 Experimental . . . . . . . . . . . . . . . 115

7.4.1 Chemicals and Materials . . . . . . . . . . . . . . 115

7.4.2 Electrode Preparation . . . . . . . . . . . . . . . . 115

7.4.3 Cyclic Voltammetry . . . . . . . . . . . . . . 115

7.4 .4 X-Ray Diffraction . . . . . . . . . . . . . 116

7.4.5 Accelerated Lifetime Tests . . . . . . . . . . . . . . . . 116

7.4.6 High Resolution Scanning Electron Microscopy and Energy-

Dispersive X-Ray Spectroscopy . . . . . . . . . . . . . 116

7.5 Results and Discussion . . . . . . . . . . . . . . 117

7.6 Conclusion . . . . . . . . . . . . . . . . . . . 124

Bibliography ............................ 124

$8 \mathrm{Pt} / \mathrm{Ir} / \mathrm{V}$ -

$\begin{array}{lr}\text { A Multifunctional Electrocatalyst? } & \mathbf{1 2 7}\end{array}$

8.1 Introduction . . . . . . . . . . . . . . . . . . . . . . 128

8.2 Hydrogen Evolution Reaction (HER) . . . . . . . . . . . . . . . . 128

8.3 Carbon Monoxide Tolerance . . . . . . . . . . . . . . . . . . 131

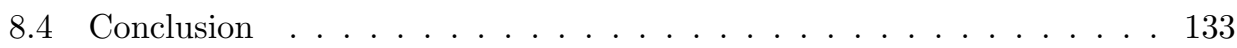

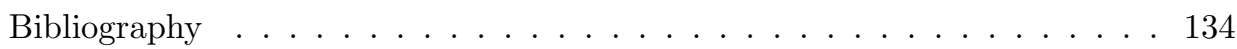

9 Summary and Outlook 137

9.1 Summary . . . . . . . . . . . . . . . . . 138

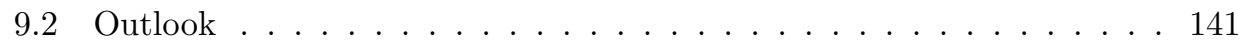

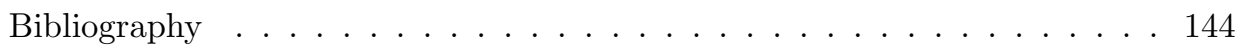

$\begin{array}{ll}\text { List of Symbols } & 147\end{array}$

$\begin{array}{ll}\text { List of Tables } & 149\end{array}$

$\begin{array}{ll}\text { List of Figures } & 151\end{array}$

$\begin{array}{ll}\text { Samenvatting } & 155\end{array}$

$\begin{array}{lr}\text { Acknowledgments } & 159\end{array}$ 


\section{Electrochemical Energy Storage and Conversion}

\subsection{Introduction}

The world electric energy consumption has been growing since 1990 by an average of $1.9 \%$ per year and has reached 17110 billion $\mathrm{kWh}$ in 2007[1], while it will be increasing by yet another half of this value until 2030[2]. For electrical energy production fossil fuels have always been a very important source. Today about two-thirds of the worlds total electric power is generated from fossil fuels [3]. Currently the world's oil consumption is about $1.2 * 10^{10}$ liter per day where the resources have the capacity of $1.6 * 10^{14}$ liter [3]. Although these values show that the sources are finite, there was no significant shortage in the use of fossils [4]. However, $\mathrm{CO}_{2}$ emitting power generation technologies using fossil fuels for electricity production will be slowly reduced by many countries in order to reduce the green house gas $\mathrm{CO}_{2}$. This has been a great motivation for many researchers to investigate new energy sources and to develop new technologies to produce "clean" electrical energy. Figure 1.1 depicts the number of scientific publication found by using the combined keywords "renewable electrical energy" [5]. 


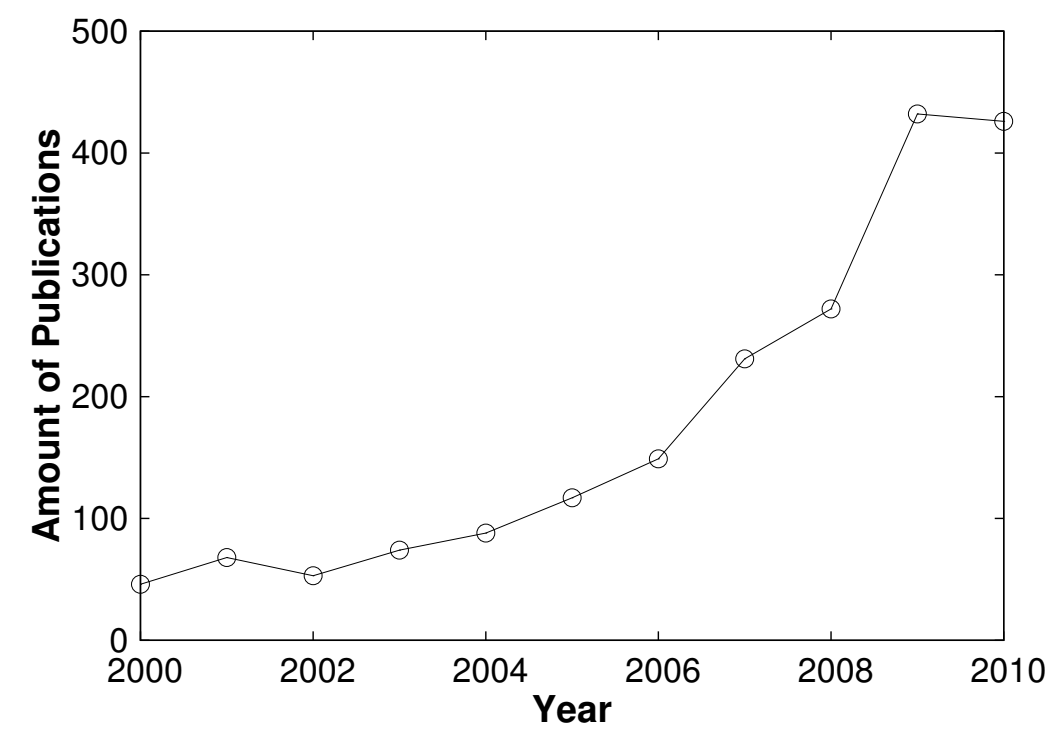

Figure 1.1 Amount of scientific publications per annum for the combined keyword search "renewable electrical energy" on ISI Web of Knowledge.

Among the new and reinvented technologies, solar and wind energy (SWE) as renewable energy carriers have been built out to a great extend. Although the energy production by SWE is still less than $1 \%$ of the total energy consumption the growth rate is approximately $30 \%$ per annum in recent years. Extrapolating this, a factor of about 200 will be reached in two decades and will exceed the factor of 2000 in three decades. According to this prediction SWE would exceed the world total consumption of total energy in only 20 to 30 years [6]. However, with the development of SWE also the development of a suitable energy storage system has become of great interest. SWE can not supply the power continuously and without any variation, since they depend on time-dependent weather condition. The produced energy needs to be stored efficiently to use it in times of higher demand or during fluctuation of the supply. Stationary electrical energy systems are required where electrical energy storage systems will find numerous other applications including portable devices and transport vehicles. In the last decades a number of energy storage systems has been developed like Fuel Cells [7], Pumped Hydro Storage (PHS) [8], Compressed Air Energy Storage System (CAES) [9], Super Conducting Magnetic Energy Storage(SCMES) [10], Capacitors and Super Capacitors [11] and Redox Flow Batteries [12]. Yet many of these systems require certain conditions or have particular drawbacks. PHS and CAES for instance need a special terrain to be built on in order to store energy. In times of 
electrical energy demand, the water is allowed to flow down to the lower reservoir where turbines will convert the kinetic energy into electrical energy. Others show cost and environmental issues, like the SCEM and are not capable for long duration applications like the fly wheel [13]. However, there are two fields of technology which have been investigated and developed intensively since their inventions, namely the battery and fuel cell technology.

In the late 1700s and early 1800s the basis of electrochemical energy storage and conversion (EESC) systems was manifested by Luigi Galvani and Alessandro Volta. Figure 1.2 depicts the first battery system, the Volta pile, comprising alternatively silver (or copper) and zinc plates separated by blotting paper soaked in brine (electrolyte) to increase the electrolyte conductivity.

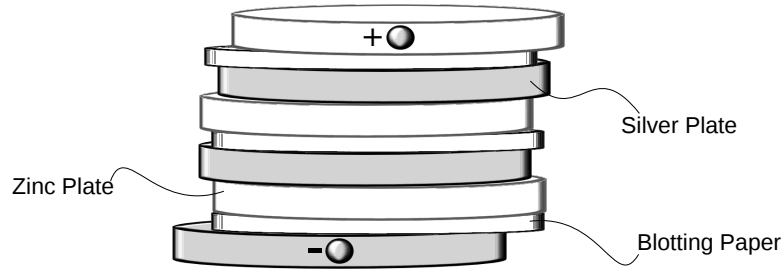

Figure 1.2 Schematic of a Volta Pile with alternating zinc and silver plates.

During the last decades, a wide range of EESC systems was developed and commercialized. Nowadays, EESC systems belong to our daily life and are used for a wide range of applications like starting, lightning and ignition (SLI) of emergency units, portable electronic devises, spacecraft, electronic vehicles etc. But also for applications like power quality management and electrification of automobiles EESC systems have taken a critical role. There are two main types of EESC systems (Figure 1.3). 


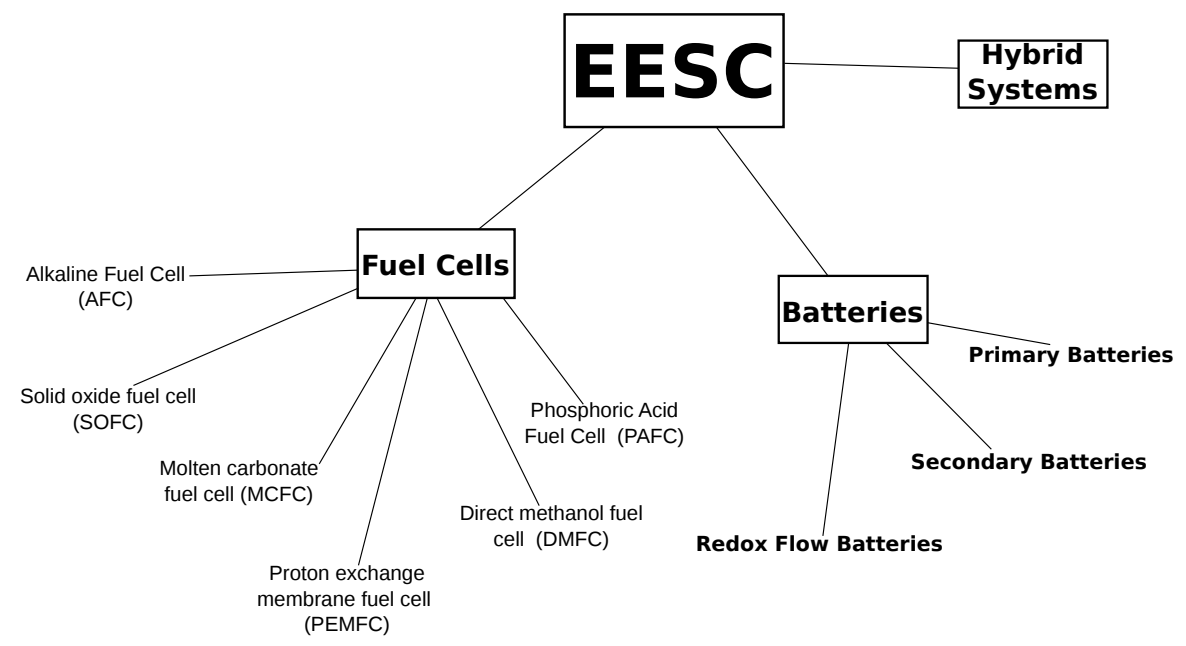

Figure 1.3 Electrochemical Energy Storage and Conversion Systems with the sub-systems of fuel cells, batteries and hybrid systems.

In fuel cells, chemical energy is converted into electrical energy by feeding the cell with a chemical fuel (hydrogen or methanol, for instance) which is then turned through a catalytic reactions into energy and chemical reaction products. Fuels cells will deliver electrical energy as long as they are fed with fuel. The reaction product cannot be recycled into their original chemical nature. Figure 1.4 depicts the general schematic of a fuel cell. A fuel cell contains in the general case 2 compartments, which are separated by a membrane electrode assembly (MEA). It is the heart of this technology since all chemical reactions and electron transfer occur at the MEA (Figure 1.4). 


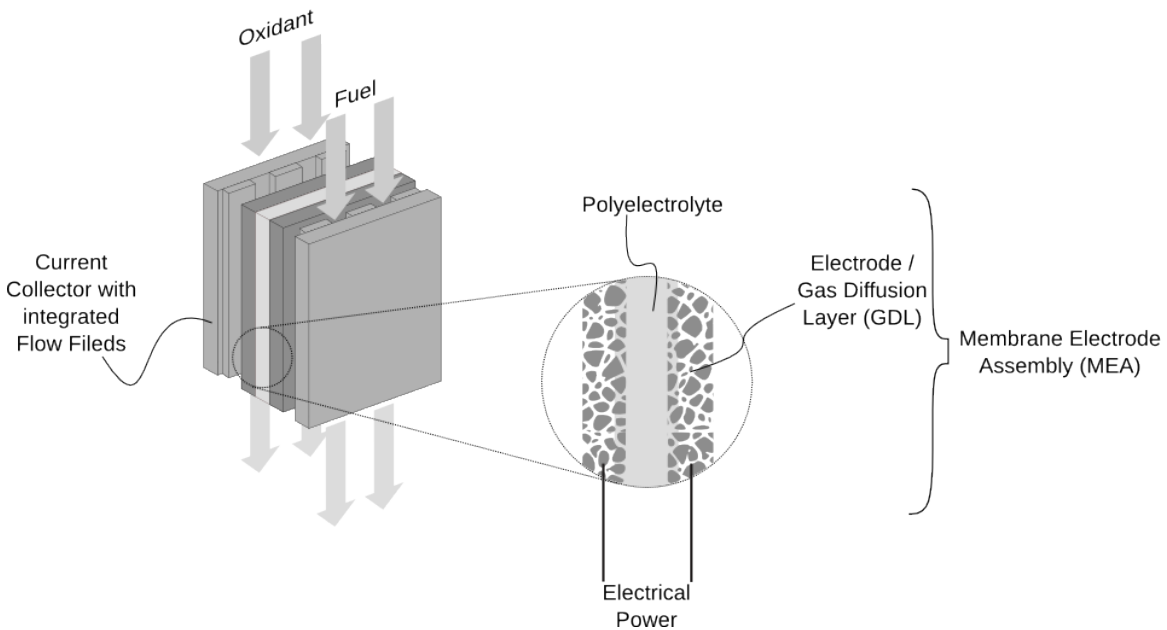

Figure 1.4 General schematics of a fuel cell sowing a MEA comprising of a polyectrolyte membrane glued between two electrodes.

A MEA consists (in the general case) of a polyelectrolyte membrane laminated between two porous electrodes (gas diffusion layers, GDL). The electrodes are generally coated with a catalyst in order to decrease the overpotential of the electrochemical reactions. The polyelectrolyte membrane is responsible for a) separation of the two compartments prohibiting the fuel and oxidant not to mix with each other b) conducting ionic charge carriers in order to balance the net charge in the two compartments during operation. The most investigated fuel cells are depicted in Figure 1.3, of which the operation conditions (temperature and fuel) are depicted in Figure 1.5. 


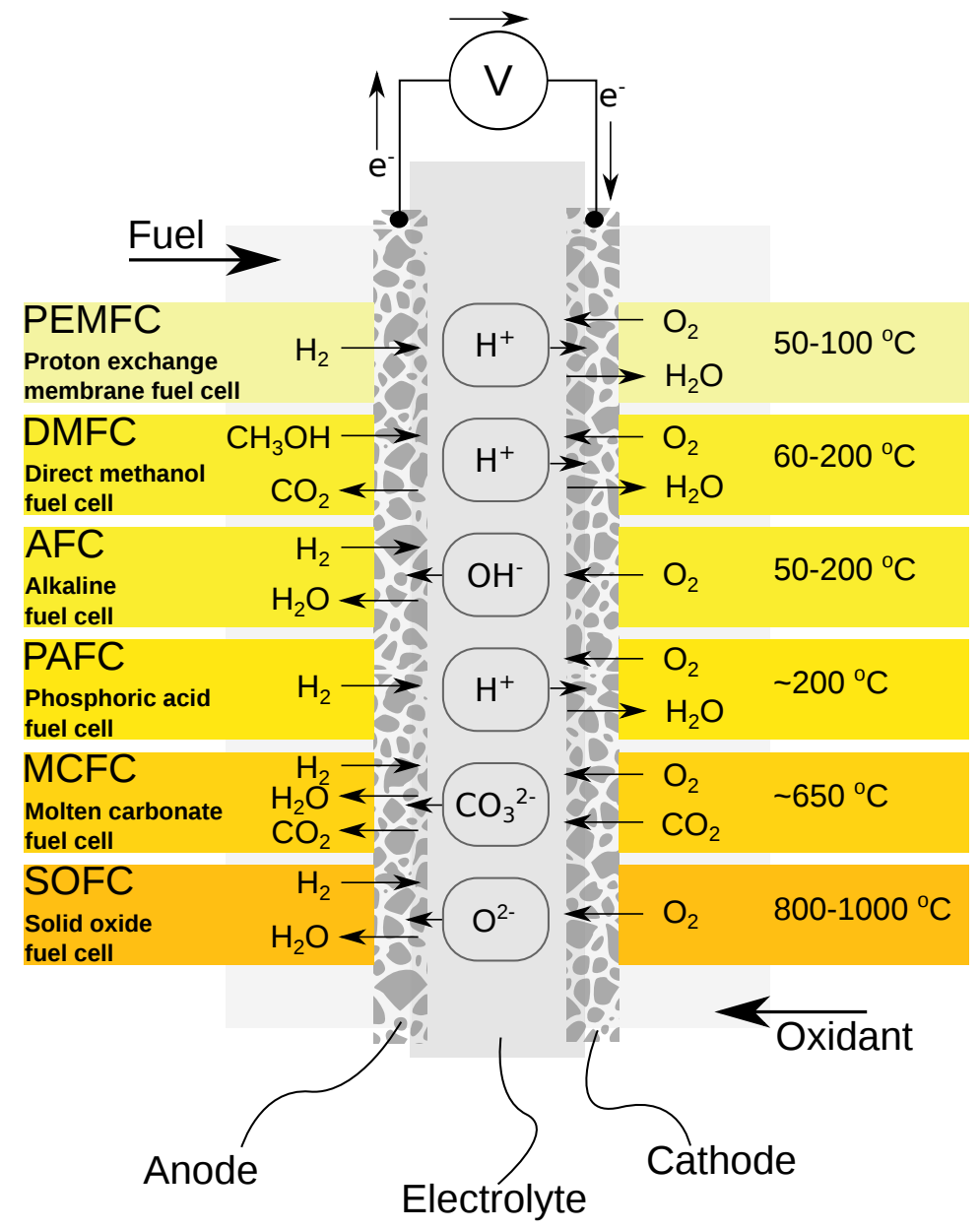

Figure 1.5 Most investigated fuel cells with operation conditions as fuel, oxidant, reactions and operation temperature. The information inside this figure were collected from [14].

Proton exchange membrane fuel cell (PEMFC)

The PEMFC employs a proton exchange membrane (PEM) in order to conduct protons between two gas diffusion layers. The chemical reactions are depicted in Equation $1.1,1.2,1.3$.

Anode

$$
2 H_{2} \rightarrow 4 H^{+}+4 e^{-}
$$


Cathode

$$
\mathrm{O}_{2}+4 \mathrm{H}^{+}+4 e^{-} \rightarrow 2 \mathrm{H}_{2} \mathrm{O}
$$

Overall Reaction

$$
2 \mathrm{H}_{2}+\mathrm{O}_{2} \rightarrow 2 \mathrm{H}_{2} \mathrm{O}
$$

During this reaction heat is as well generated. Although the reactions inside the cell need a temperature of over $\sim 80^{\circ} \mathrm{C}$ the produced thermal energy needs to be controlled to avoid damages on the polyelectrolyte membrane [15]. However, the relatively low operation temperature made this technology attractive for mobile application and

automotive vehicles [14]. Disadvantageous are the low density of the fuel (hydrogen), platinum requirement as catalyst and the low carbon monoxide tolerance of the platinum $[14,16]$.

Direct methanol fuel cell (DMFC)

In the DMFC technology hydrogen was replaced as a fuel by methanol. This is a major advantage compared with the PEMFC, since methanol is liquid and can be transported easily. Also the DMFC uses a proton exchange membrane as separator. Although using methanol as fuel protons are still needed in order to recombine with oxygen and electrons to water and electrical energy. The reaction occurring in the cell are depicted in Equation 1.4, 1.5 and the overall reaction in Equation 1.6.

Anode

$$
\mathrm{CH}_{3} \mathrm{OH}+\mathrm{H}_{2} \mathrm{O} \rightarrow \mathrm{CO}_{2}+6 \mathrm{H}^{+}+6 e^{-}
$$

Cathode

$$
\frac{3}{2} \mathrm{O}_{2}+6 \mathrm{H}^{+}+6 e^{-} \rightarrow 3 \mathrm{H}_{2} \mathrm{O}
$$

Overall Reaction

$$
\mathrm{CH}_{3} \mathrm{OH}+\frac{3}{2} \mathrm{O}_{2} \rightarrow \mathrm{CO}_{2}+2 \mathrm{H}_{2} \mathrm{O}
$$

However, the main disadvantage of the DMFC is the slow rate of anodic oxidation on platinum [17]. Another drawback is the so called methanol crossover where methanol diffuses through the proton exchange membrane to the oxidant side. This leads to a decrease in efficiency. To overcome this issue, the maximum methanol concentration 
of the methanol is kept under $2 \mathrm{M}[17]$.

Alkaline fuel cell (AFC)

The alkaline fuel cell has been developed as one of the earlier fuel cells by the NASA [18]. Also in this fuel cell type hydrogen is needed as fuel. Yet not protons are transferred as charge carrier in the AFC but hydroxyl-ions from the cathode to the anode. The electrolyte is a solution of $\mathrm{KOH}$. Due to that the polyelectrolyte membrane applied in the AFC needs to be anion conductive. The use of an alkaline environment brought one major advantage, namely the independency of noble metal catalyst as in the case of PEMFC and DMFC [17]. The reactions in the AFC are depicted in Equation 1.7 to 1.9.

Anode

$$
2 \mathrm{H}_{2}+4 \mathrm{OH}^{-} \rightarrow 4 \mathrm{H}_{2} \mathrm{O}
$$

Cathode

$$
\mathrm{O}_{2}+2 \mathrm{H}_{2} \mathrm{O}+4 e^{-} \rightarrow 4 \mathrm{OH}^{-}
$$

Overall Reaction

$$
2 \mathrm{H}_{2}+\mathrm{O}_{2} \rightarrow 2 \mathrm{H}_{2} \mathrm{O}
$$

However, the main drawbacks are the adsorption of $\mathrm{CO}_{2}$ from the air by the liquid alkaline electrolyte solution $(\mathrm{KOH}) \cdot \mathrm{CO}_{2}$ adsorbed in the electrolyte will react with the hydroxyl-ions and forms $\mathrm{K}_{2} \mathrm{CO}_{3}$, which precipitates within the electrode pores. This may cause a blocking of the gas diffusion layers. Furthermore this reaction will decrease the concentration of the hydroxyl-ions leading to a decrease in cell efficiency $[17,19]$. To overcome the issue of the liquid $\mathrm{KOH}$ electrolyte research has focused the development of anion exchange membranes for AFC in order to provide the suitable medium for the hydroxylions to travel. A recent review on anion exchange membranes for AFCs depicts the work in this field [19].

Other fuel cells

Other fuel cells like the PAFC, MCFC and SOFC will not be described here in detail since these do not apply a polyelectrolyte membrane due to the elevated temperatures $[17,14]$. 
Batteries are different: in batteries the electrical energy is also gained by conversion of chemical energy. However, the chemical nature can be regained after discharge through a re-charging process (in case of secondary batteries). Hence, the chemical reactants must be contained within the limited space of the battery. This also limits in turn the amount of electrical energy stored per unit volume of the battery. If the chemical reactants are in the liquid state, they can be stored outside the actual electrochemical reactor and the liquid can be pumped through the reactor. Such batteries are called flow batteries.

This chapter focuses on a)depicting different EECS systems and b) the use of polyelectrolyte membranes used for battery applications, in particular vanadium based redox flow batteries. After the first battery system, which was developed more than 100 years ago, we are facing now the usage of batteries almost every day and in every situation. During these years, the field of battery research and development has grown very rapidly and can be demonstrated at this stage by three different fields:

- Primary Batteries (disposable, single use)

- Secondary Batteries (rechargeable)

- Redox Flow Batteries (rechargeable, flow through)

\subsection{Primary Batteries}

Primary batteries, also called disposable batteries, still use the basic idea of a voltaic pile. Here the electrochemical energy produced by the decomposition of electrode material and electrolyte will break down once the electrode or the electrolyte are degraded. And since this procedure is irreversible the battery need to be replaced by a new battery. In a primary battery the electrochemical reaction is not reversible. Table 1.1 presents some of the customary primary battery systems. However, such systems are expensive and environmental unfriendly due to its disposable character. 
Table 1.1 Some customary primary battery systems [20]

\begin{tabular}{llr}
\hline Battery system & Cell Reaction & Potential (V) \\
\hline Leclanché & $\mathrm{Zn}+2 \mathrm{MnO}_{2}+2 \mathrm{NH}_{4} \mathrm{Cl} \rightarrow$ & 1.5 \\
& $\mathrm{ZnCl}_{2}+\mathrm{Mn}_{2} \mathrm{O}_{3}+2 \mathrm{NH}_{3(a q)}+$ & \\
& $\mathrm{H}_{2} \mathrm{O}$ & \\
& $\mathrm{Zn}+2 \mathrm{MnO}_{2} \rightarrow \mathrm{ZnO}+\mathrm{Mn}_{2} \mathrm{O}_{3}$ & 1.5 \\
Manganese alkaline & $\mathrm{Zn}+\mathrm{Ag}_{2} \mathrm{O}+\mathrm{H}_{2} \mathrm{O} \rightarrow \mathrm{Zn}(\mathrm{OH})_{2}$ & 1.6 \\
Silver oxide/zinc & $+2 \mathrm{Ag}$ \\
& $\mathrm{Zn}+\frac{1}{2} \mathrm{O}_{2} \rightarrow \mathrm{ZnO}$ \\
Air/zinc (alkaline) & $\mathrm{Li}+\mathrm{Mnn}^{4+} \mathrm{O}_{2} \rightarrow \mathrm{LiMn}^{3+} \mathrm{O}_{2}$ & 1.45 \\
Lithium/manganese dioxide & $4 \mathrm{Li}+2 \mathrm{SOCl}_{2} \rightarrow 4 \mathrm{LiCl}+\mathrm{S}+$ & 3.5 \\
Thionyl chloride & $\mathrm{SO}_{2}$ & 3.9 \\
& & \\
\hline
\end{tabular}

\subsection{Secondary Batteries}

Facing a time of energy crises and environmental protection, ways to store energy efficiently and in large quantities with reversible systems has inspired the field of battery technology. Secondary batteries present such a reversible system: they do not need to be replaced after every discharge cycle, due to the reversible electrochemistry of the charge and discharge reaction of the system. Many secondary batteries have been developed and commercialized of which some are depicted in Table 1.2.

Table 1.2 Some customary secondary battery systems [20]

\begin{tabular}{llc}
\hline Battery system & Cell Reaction & Potential (V) \\
\hline Lead-acid & $\mathrm{Pb}+\mathrm{PbO}_{2}+2 \mathrm{H}_{2} \mathrm{SO}_{4} \leftrightarrow 2 \mathrm{PbSO}_{4}+2 \mathrm{H}_{2} \mathrm{O}$ & 2 \\
Nickel/cadmium & $\mathrm{Cd}+2 \mathrm{NiOOH}+2 \mathrm{H}_{2} \mathrm{O} \leftrightarrow 2 \mathrm{Ni}(\mathrm{OH})_{2}+\mathrm{Cd}(\mathrm{OH})_{2}$ & 1.3 \\
Nickel/metal hydride & $\mathrm{H}_{2}+2 \mathrm{NiOOH} \leftrightarrow 2 \mathrm{Ni}(\mathrm{OH})_{2}$ & 1.3 \\
Lithium-ion & $\mathrm{Li}_{x} \mathrm{C}_{6}+\mathrm{Li}_{1-x} \mathrm{Mn}_{2} \mathrm{O}_{4} \leftrightarrow \mathrm{C}_{6}+\mathrm{Li}_{x} \mathrm{Mn}_{2} \mathrm{O}_{4}$ & 3.6 \\
\hline
\end{tabular}

Table 1.3 Secondary batteries as large scale energy storage systems [13]

\begin{tabular}{ll}
\hline Battery system & Drawbacks \\
\hline Lead-acid & Limited life cycle $(500-1000)$, Low energy density, Low temperature performance \\
Nickel/cadmium & High cost $(\$ 1000 / \mathrm{kWh})$, Toxicity, Memory effect \\
Sodium-Sulfate & High operation temperature $\left(300-350{ }^{\circ} \mathrm{C}\right)$ \\
\hline
\end{tabular}


Secondary systems are not only environmental friendly but also inexpensive compared with a primary battery. However, secondary batteries do also have a specific lifetime and need to be replaced after certain charge-discharge cycles, depending on the chargedischarge conditions. Another disadvantage is that the currently applied secondary batteries show drawbacks in the field of large scale energy storage, as summarized Table 1.3 for three large scale systems.

\subsection{Redox Flow Batteries}

Redox flow batteries are a relatively new technology to store large quantities of energy. Such a system increases the flexibility, minimizes the environmental risk and improves the response time to a demand. Rather than having the electroactive materials being stored inside the cell housing of the battery, and being limited to the volume of the secondary battery, in redox flow batteries the electroyte can be circulated into and out of a reservoir tank. The tank volume gives the extent of energy storage. The concept of a redox flow battery is depicted in Figure 1.6. The main element of Figure 1.6 is the electrochemical cell, where the redox reaction of the battery takes place. The electrochemical cell is mainly composed of two half cells, separated by a ion exchange membrane. The electrodes are included in the half cells. 


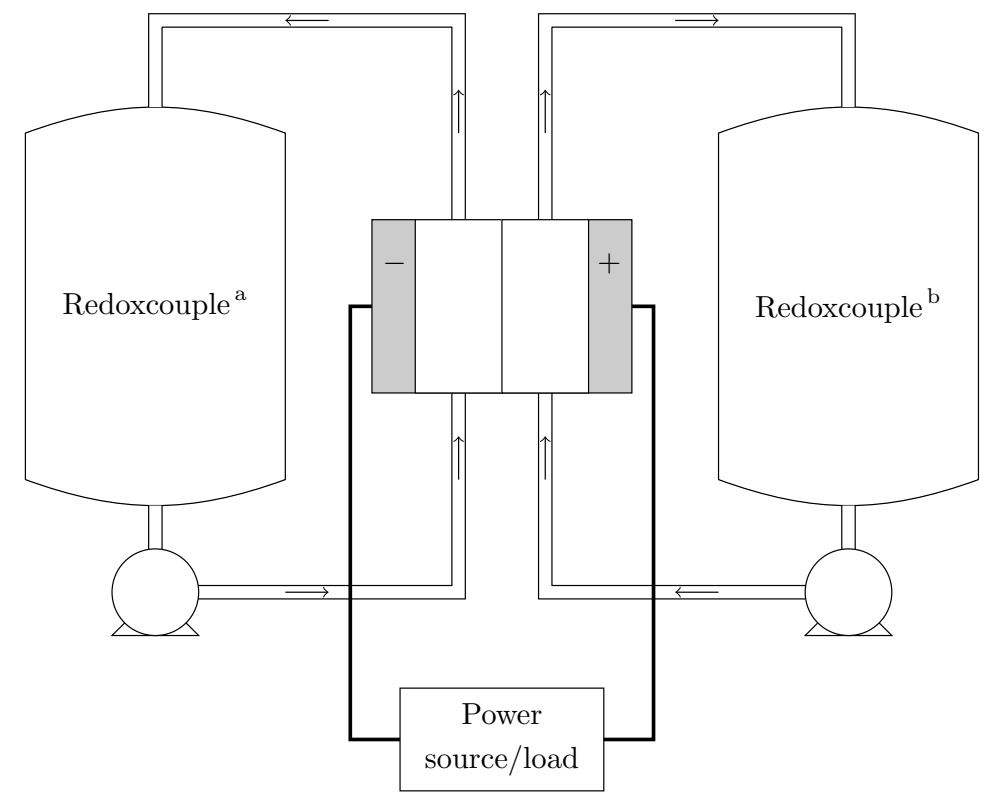

Figure 1.6 Overview of a redox flow battery, showing two storage containers for the redox couples, one electrochemical cell in which charge and discharge reactions occur and a power source and load, respectively.

To run the system, the electrolyte flows through the electrochemical cell containing the oxidized and reduced species. The membrane, electrodes and the electrolyte need to fulfill different tasks. In the following the most investigated redox flow battery types will be described in detail. In the past many systems have been developed to achieve a stable and cheap system to store large quantities of energy. Table 1.4 summarizes the systems and their characteristics. 


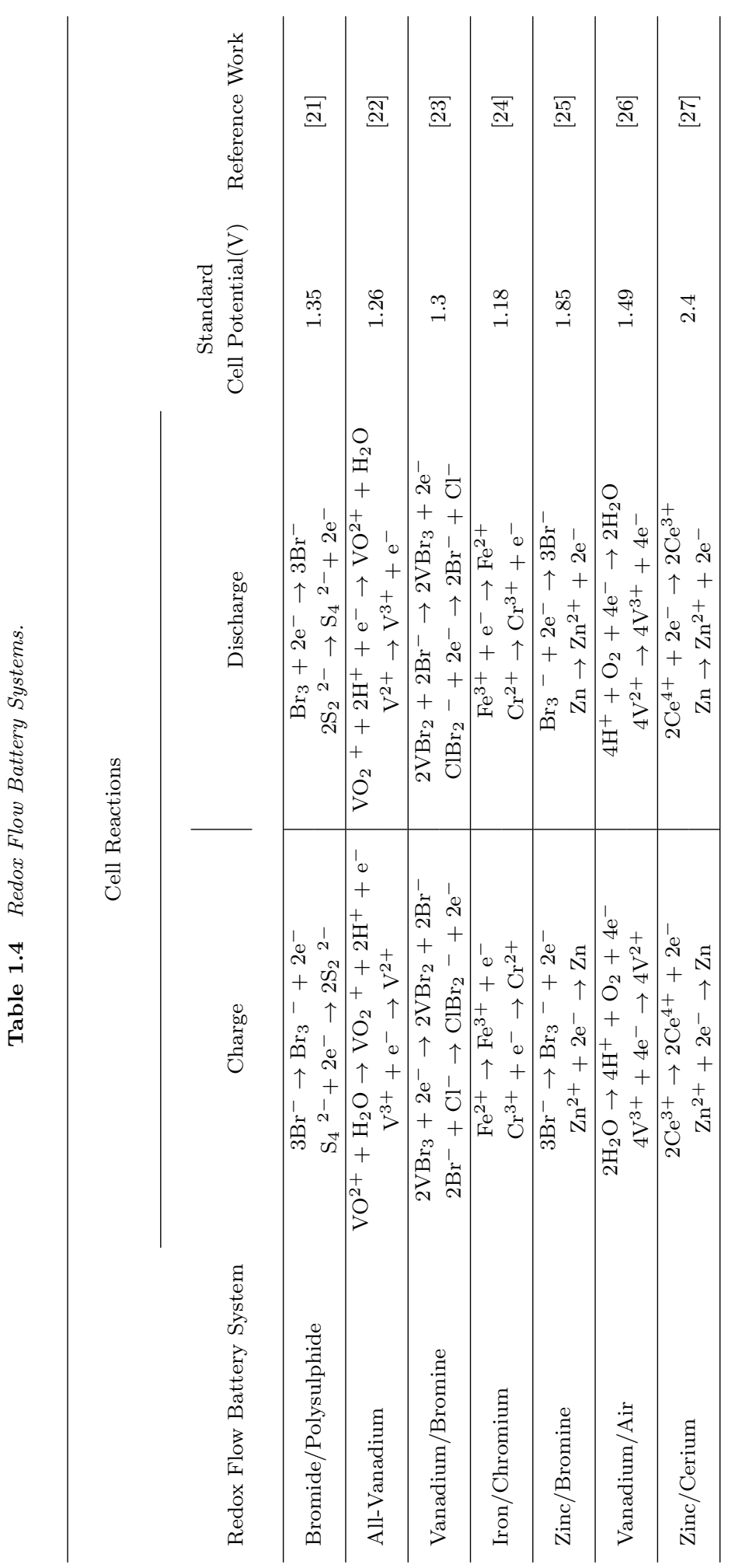


All of the above mentioned systems can be up-scaled increase the power of the cells. This happens usually by increasing the size of the electrodes, stacking the systems with bipolar electrodes (10-200) or connecting the systems in series (higher voltage) or parallel (higher current). To increase the storage capacity (Ah) the concentration of the redox system and the volume of the electrolyte solution can be increased. Power and storage capacity are separated and can be influenced independently. This is the most important feature of such systems. A redox flow battery system will be characterized in the following terms:

Voltage efficiency

$$
\eta_{V}=\frac{V_{\text {discharge }}}{V_{\text {charge }}} * 100 \%
$$

Coulomb efficiency

$$
\eta_{C}=\frac{Q_{\text {discharge }}}{Q_{\text {charge }}} * 100 \%
$$

Energy efficiency

$$
\eta_{E}=\frac{E_{\text {discharge }}}{E_{\text {charge }}} * 100 \%
$$

\subsubsection{Bromine Polysulphide Redox Flow Battery}

The Bromine Polysulphide Redox Flow Battery (Bromine Polysuphide-RFB) uses the abundant and good soluble (aqueous media) redox couples sodium bromide and sodium polysulphite. Due to the wide access to these couples, the Bromine PolysuphideRFB was investigated extensively and many efforts were taken to develop large systems (the largest, unfortunately never finished project was the Regenesys System with a capacity aim of $120 \mathrm{MWh}[28,29]$ ). During charge (Equation 1.10) and discharge (Equation 1.11) the following reactions take place:

$$
\begin{aligned}
3 \mathrm{Br}^{-} & \rightarrow \mathrm{Br}_{3}^{-}+2 e^{-} \\
S_{4}^{2-}+2 e^{-} & \rightarrow 2 S_{2}^{2-} \\
\mathrm{Br}_{3}^{-}+2 e^{-} & \rightarrow 3 \mathrm{Br}^{-} \\
2 S_{2}^{2-} & \rightarrow S_{4}^{2-}+2 e^{-}
\end{aligned}
$$

It has been reported, that the Bromine Polysuphide-RFB shows major challenges 
which need to be overcome in order to develop an efficient battery. these challenges are: a)the cross contamination of the redox couples b) maintaining a fixed composition of the redox couples solution c) sulfur capturing in the membrane and d) $\mathrm{H}_{2} \mathrm{~S}$ and $\mathrm{Br}_{2}$ gas evolution reaction [23]. Furthermore studies showed, that the electrodes of the Bromine Polysuphide-RFB need to show catalytic activity in order to enhance the redox reactions (positive electrode $=\mathrm{Pt} / \mathrm{C}$, negative electrode $=\mathrm{Ni} / \mathrm{C}$ ) [30]. This implies, that although the Bromine Polysuphide-RFB is economic due to the abundant redox couples, the overall price for such a system will be determinated by the electrodes and the high electrolyte maintenance costs.

\subsubsection{Zinc Bromide Redox Flow Battery}

The Zinc Bromide Redox Flow Battery (Zinc Bromide-RFB) was invented by EXXON in the early 1970s [13]. It has already reached the commercialization state, where some companies already can offer pre-assembled and complete stand alone systems. The Zinc Bromide-RFB has an interesting concept to store energy. During charging, aqueous zinc bromide is reduced at the negative electrode and deposited on the electrode surface. On the positive electrode the oxidation of $\mathrm{Br}^{-}$occurs forming $\mathrm{Br}_{2}$. To capture the $\mathrm{Br}_{2}$ to avoid the contact to the deposited $\mathrm{Zn}$ electrode and the gas formation, a organic phase containing complexing agents, such as quaternary ammonium salts is introduced to the electrolyte solution. Bromine will be captured in the organic phase and is stored as an emulsion in the storage tanks in a non volatile and "non toxic" form [31] where it is separated by gravity due to the different density. Another interesting point about the Zinc Bromide-RFB is that the system does not require a polyelectrolyte membrane, making the system more economic. However, challenges with homogeneous $\mathrm{Zn}$ deposition and better complexing agents have to be overcome [23].

\subsubsection{Vanadium Redox Flow Batteries}

The all vanadium redox flow battery (Vanadium-RFB) is an electrochemical energy storage system invented by Maria Skyllas-Kazacos in 1984. It consists of two electrochemical half cells, separated by an ion exchange membrane (Figure 1.7). 


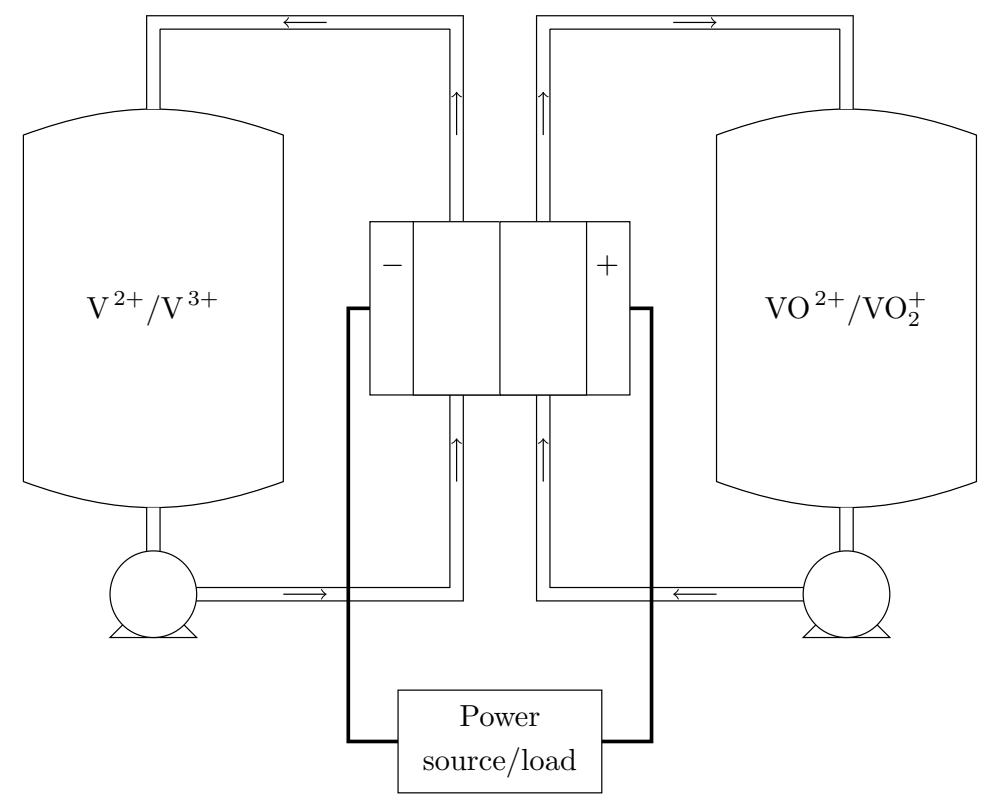

Figure 1.7 Overview of a vanadium redox flow battery.

Since vanadium can exist in 4 different oxidation states, the positive half cell employs $\mathrm{VO}^{2+} / \mathrm{VO}_{2}^{+}$where the negative half cell contains $\mathrm{V}^{2+} / \mathrm{V}^{3+}$. When the vanadium battery is charged, the $\mathrm{VO}^{2+}$ ions in the positive half-cell are converted to $\mathrm{VO}_{2}^{+}$ions when electrons are removed from the positive terminal of the battery. Similarly in the negative half-cell, electrons are converting the $\mathrm{V}^{3+}$ ions into $\mathrm{V}^{2+}$. During discharge this process is reversed. Equation (1.12 and 1.13) summarize the electrochemical reactions during charging and discharging.

\section{Charging}

$$
\begin{aligned}
\mathrm{VO}^{2+} & \rightarrow \mathrm{VO}_{2}^{+}+e^{-} \\
V^{3+}+e^{-} & \rightarrow V^{2+}
\end{aligned}
$$

\section{Discharging}

$$
\begin{aligned}
\mathrm{VO}_{2}^{+}+e^{-} & \rightarrow \mathrm{VO}^{2+} \\
V^{2+} & \rightarrow V^{3+}+e^{-}
\end{aligned}
$$

The Vanadium-RFB potential is calculated by the redox potentials of the half cell 
reactions and is presented by Equation (1.14).

$$
\begin{aligned}
& E_{(\text {Vanadium }-R F B)}=E_{\left(V^{2+/ 3+}\right)}^{0}-E_{\left(V^{2+} / V_{2}^{+}\right)}^{0} \\
& E_{(\text {Vanadium }-R F B)}=0.26 \mathrm{~V}-(-1.00 \mathrm{~V}) \\
& E_{(\text {Vanadium }-R F B)}=1.26 \mathrm{~V}
\end{aligned}
$$

The Vanadium-RFB is a special type of redox flow system, where the crossover of the vanadium redox couples through the ion exchange membrane (separator) will not damage the battery system as it would be the case for several other systems like Iron-Chromium, Zinc-Bromine and Zinc-Cerium. However, crossover still remains a critical issue of the ion exchange membrane in the Vanadium-RFB next to other critical issues like water cross-over, conductivity and chemical stability.

\subsection{Hybrid Systems}

Hybrid systems are energy conversion/storage systems which combine the battery technology with the fuel cell technology. However, there is not a clear definition for hybrid systems. The development of such hybrid systems has been triggered by certain challenges in both fuel cells and redox flow batteries. The advantage of the hybrid systems however is very individual and depends on the system configuration. Some interesting hybrid systems will be described briefly in the following.

\section{Fuel Cell Bio Reactor}

The fuel cell bio reactor [32] belongs to the systems using the first approach to produce electrical energy and to store it as chemical compounds. The fuel cell bio reactor consists of two half cells separated by an ion exchange membrane. On the membrane, facing the anode compartment, a platinum coated porous electrode is glued by thermal pressing. The cathode compartment contains as intermediate storage media an iron salt solution in the oxidation state $\mathrm{Fe}^{2+} / \mathrm{Fe}^{3+}$. The main storage is performed by an iron oxidizing microorganism, converting the electricity by oxidizing $\mathrm{Fe}^{2+}$ and reduction of $\mathrm{CO}_{2}$ and $\mathrm{O}_{2}$ into chemical compounds. The reactions are depicted in Equation 1.15, 1.16 and 1.17.

\section{Anode}

$$
\frac{1}{2} H_{2} \rightarrow H^{+}+e^{-}
$$




\section{Cathode}

$$
F e^{3+}+e^{-} \rightarrow F e^{2+}
$$

Electricity conversion into Chemicals

$$
\begin{array}{r}
\mathrm{Fe}^{2+}+\text { Acidithiobacillus ferro-oxidans }+\mathrm{CO}_{2}+\mathrm{O}_{2} \\
\rightarrow \text { Chemical compounds }+\mathrm{Fe}^{3+}
\end{array}
$$

The performance of the cell has been described according to low OCP, which reached $274 \mathrm{mV}$. This very low potential is probably due to the efficiency of the microorganism. Both reactions (hydrogen oxidation and iron reduction) are fast in nature. The increase of the microorganism density could have a positive influence on the cell performance as well the ability to produce more efficient $\mathrm{Fe}^{3+}$. However, none of the issues has been discussed in the patent and also no solution have been suggested. Figure 1.8 depicts the bioreactor fuel cell set up, as described in the patent.

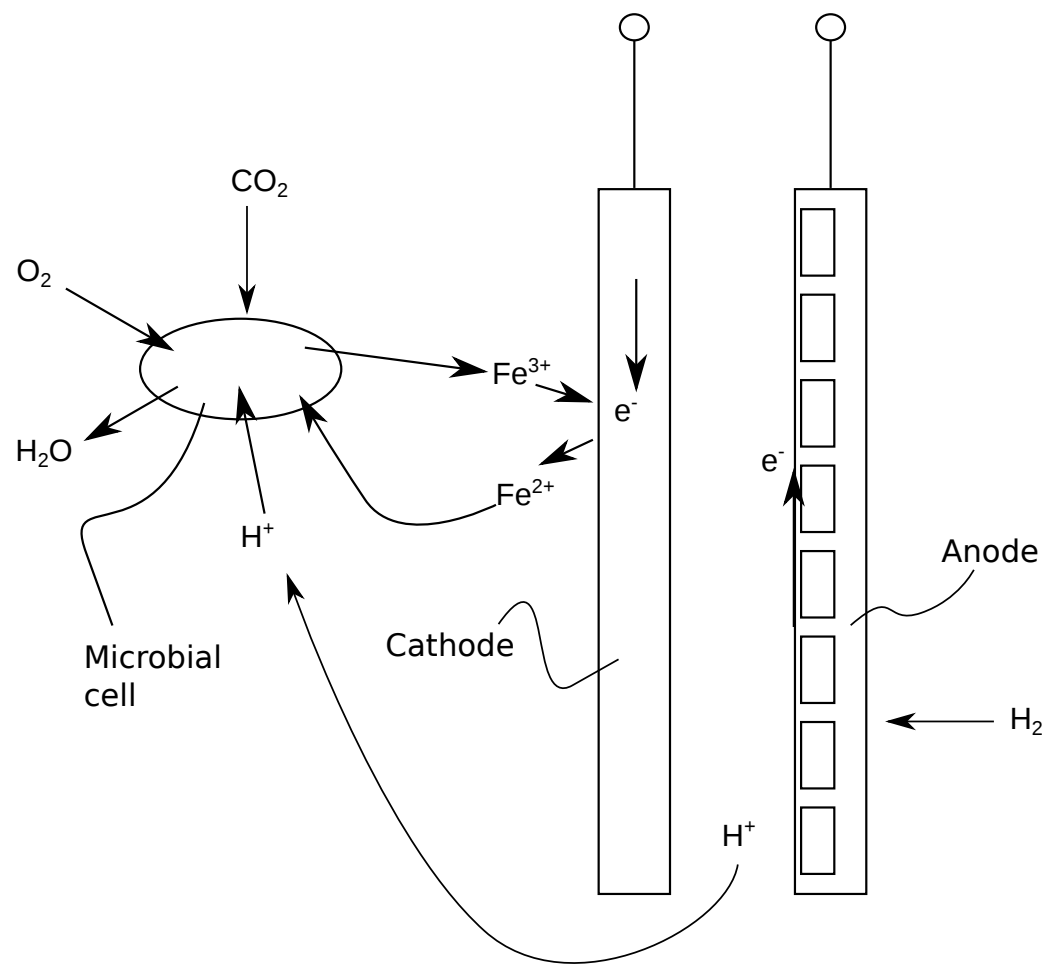

Figure 1.8 Schematic of the Fuel Cell Bio Reactor [32] using $\mathrm{H}_{2}$ as a chemical energy source on the anode side and a iron salt solution as "intermediate" storage media on the cathode side. 


\section{Redox Fuel Cell}

The redox fuel cell [33] unitizes two fuel cell reactions with two different redox couples to produce electrical energy. Figure 1.9 describes the rather complex cell design. The electrical energy delivering cell is assembled by two half cells separated via a polyelectrolyte membrane. In the anode side $\mathrm{Fe}^{2+}$ is oxidized to $\mathrm{Fe}^{3+}$ in order to deliver electrons. These will pass through an external circuit to the cathode side where oxygen is reduced by a $\mathrm{HNO}_{3}$ acidic solution of $\mathrm{VO}^{2+} / \mathrm{VO}_{2}^{+}$at the electrode. The second part of the system is a reactor in which the depleted $\mathrm{Fe}^{3+}$ is fed in order to produce $\mathrm{Fe}^{2+}$. This happens by oxidizing methane and water on a platinum catalyst. The electrode specific reactions and the reaction for the $\mathrm{Fe}^{2+}$ reactor are depicted in Equation 1.18, 1.19 and 1.20, respectively.

\section{Anode}

$$
4 \mathrm{Fe}^{3+}+4 e^{-} \rightarrow 4 \mathrm{Fe}^{2+}
$$

\section{Cathode}

$$
\mathrm{O}_{2}+4 \mathrm{H}^{+}+4 e^{-} \rightarrow 2 \mathrm{H}_{2} \mathrm{O}
$$

Electricity conversion into chemicals

$$
\mathrm{Fe}^{3+}+\mathrm{CH}_{4}+2 \mathrm{H}_{2} \mathrm{O} \rightarrow \mathrm{CO}_{2}+\mathrm{Fe}^{2+}+8 \mathrm{H}^{+}
$$

The system reached a OCP of $0.48 \mathrm{~V}$. However, this system needs a high pressurized $\mathrm{CH}_{4}$ tank, which increases the complexity of the system. Furthermore the system potential is limited due to the high redox potential of the $\mathrm{Fe}^{3+} / \mathrm{Fe}^{2+}$ which is 0.32 volt higher than the potential for the $\mathrm{CH}_{4}$ oxidizing reaction. This is the reason for the fairly low OCP of $0.48 \mathrm{~V}$. Finding a redox couple with a lower redox potential would lead to a higher OCP.

\section{Bifunctional Redox Flow Battery}

The bifunctional redox flow battery (Bifunctional-RFB) combines a fuel cell with a redox flow battery. Figure 1.10 depicts the set up [34, 35]. 


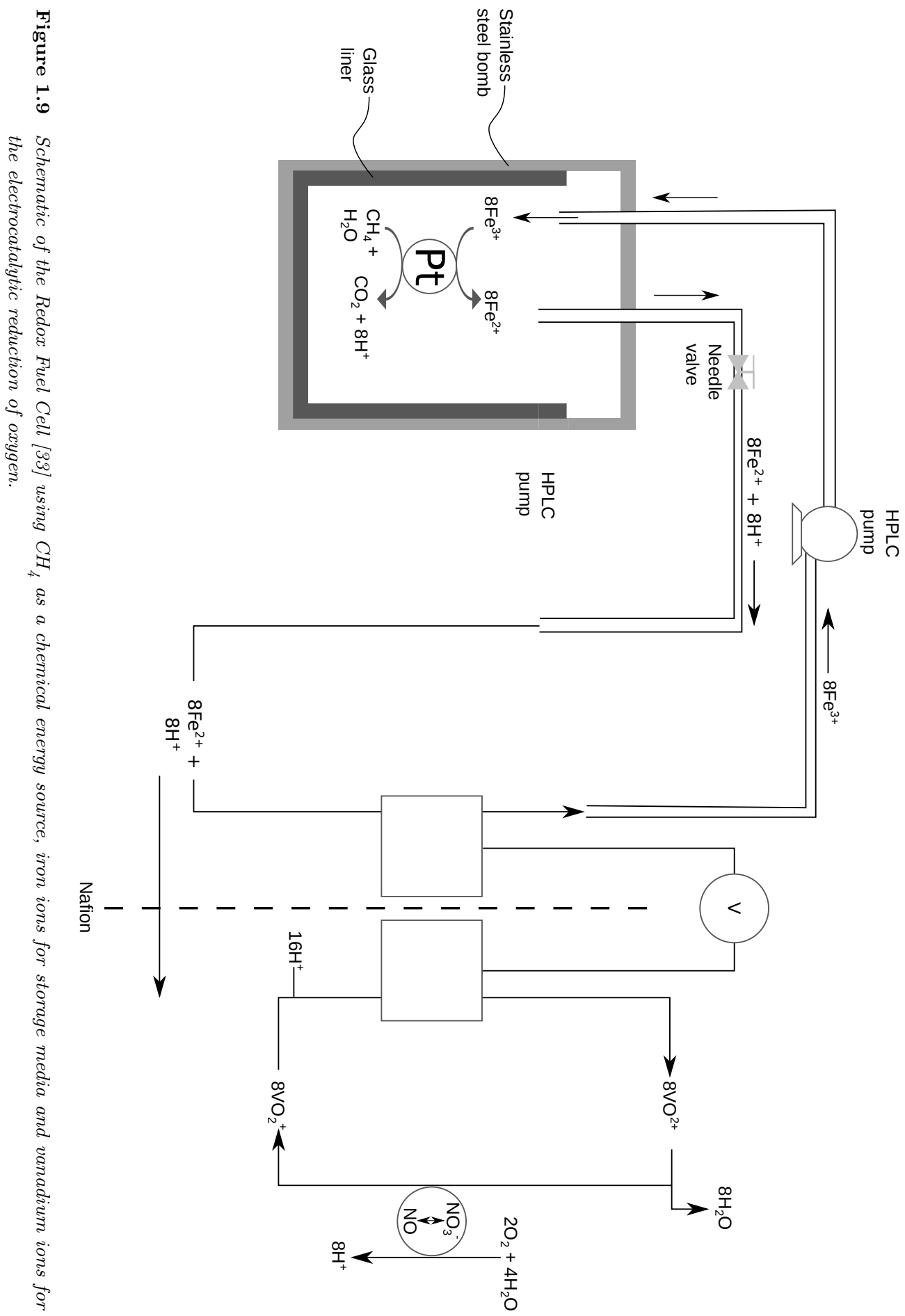



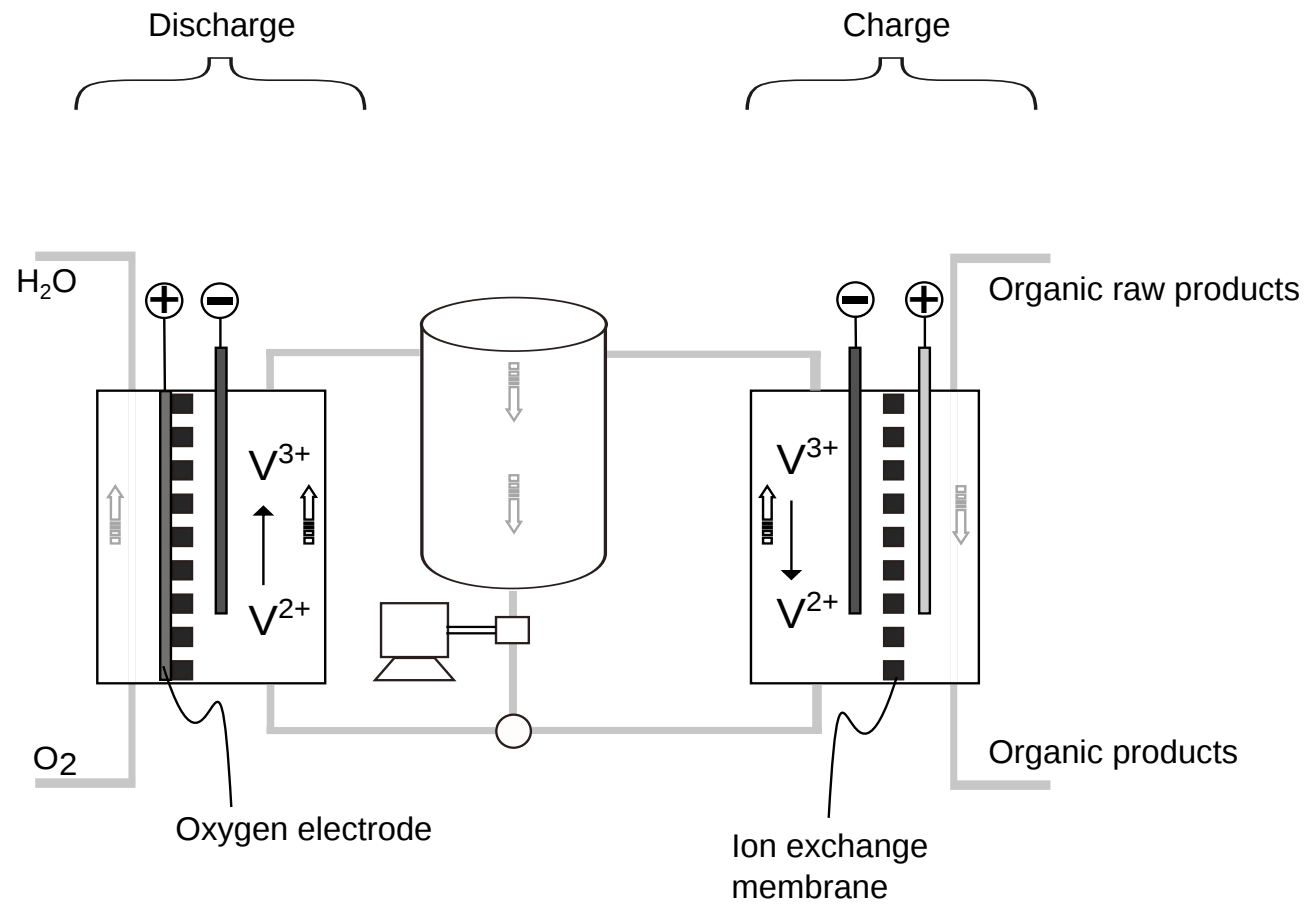

Figure 1.10 Schematic of the Bifunctional-RFB [34, 35] using raw chemicals as fuel and vanadium ions as storage media.

The system consists of one storage tank, a cell for charging and a cell for discharging the battery. Both cells are independent and are separated into two half cells by a polyelectrolyte membrane. During charging raw organic material is used as fuel to be oxidized at the anode by applying a potential. At the same time at the cathode $\mathrm{V}^{3+}$ is circulating in order to be reduced to $\mathrm{V}^{2+}$. Similar to the all vanadium redox flow battery this $\mathrm{V}^{2+}$ solution can be stored and used in times of demand, where it has to be pumped into the cell for discharge. Here the $\mathrm{V}^{2+}$ is circulating through the anode compartment to deliver the stored electrical energy by being oxidized. On the cathode side oxygen reduction takes place. The cell reactions are depicted in Equation 1.21 to 1.24 .

\section{Charging (Anode)}

Raw Chemicals $\rightarrow$ Oxidized Chemicals $+e^{-}$

\section{Charging (Cathode)}

$$
V^{3+}+e^{-} \rightarrow V^{2+}
$$




\section{Discharging (Anode)}

$$
4 V^{2+} \rightarrow 4 V^{3+}+4 e^{-}
$$

Discharging (Cathode)

$$
\mathrm{O}_{2}+4 \mathrm{H}^{+}+4 e^{-} \rightarrow 2 \mathrm{H}_{2} \mathrm{O}
$$

The system shows a rather high $\eta_{C}$ of $66-87 \%$ and delivers furthermore small chemical carbon based molecules. Yet, the system is also dependent on fuel as raw organic material and has a complex cell design, where the weight will be one of the main issues for portable applications.

\section{Mixed Reactant Direct Liquid Redox Flow Battery}

Ilicic et al. [36] reported the mixed reactant direct liquid redox fuel cell (Mixed Reactant Direct Liquid-RFB) with a redox couple cathode (Figure 1.11), which is a fusion of a methanol fuel cell and a redox flow battery.

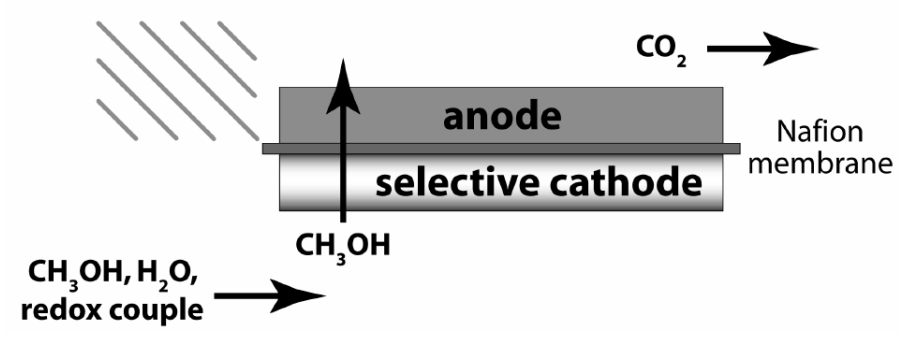

Figure 1.11 Schematic of a Mixed Reactant Direct Liquid-RFB [36].

In this system the charging occurs by methanol oxidization on the anode to $\mathrm{CO}_{2}$ and $\mathrm{H}_{2} \mathrm{O}$, where the electrons flow via through an external circuit to reduce $\mathrm{Fe}^{3+}$ to $\mathrm{Fe}^{2+}$ at the cathode. The reduction of $\mathrm{Fe}^{3+}$ to $\mathrm{Fe}^{2+}$ allows the energy storage in form of a stable ion. The discharge follows by oxidizing the $\mathrm{Fe}^{2+}$ to $\mathrm{Fe}^{3+}$ at the same side of the cell which is now functioning as anode. The gained electrons from the $\mathrm{Fe}^{2+}$ ion oxidation will now travel back through an external circuit to the other half cell to reduce oxygen. The complete charge/discharge reactions are depicted by Equation 1.25, to Equation 1.28. 


\section{Charging (Anode)}

$$
\mathrm{CH}_{3} \mathrm{OH}+\mathrm{H}_{2} \mathrm{O} \rightarrow \mathrm{CO}_{2}+6 \mathrm{H}^{+}+6 e^{-}
$$

\section{Charging (Cathode)}

$$
6 \mathrm{Fe}^{3+}+6 e^{-} \rightarrow 6 \mathrm{Fe}^{2+}
$$

\section{Discharging (Anode)}

$$
4 \mathrm{Fe}^{2+} \rightarrow 4 \mathrm{Fe}^{3+}+4 e^{-}
$$

\section{Discharging (Cathode)}

$$
4 \mathrm{H}^{+}+\mathrm{O}_{2}+4 e^{-} \rightarrow 2 \mathrm{H}_{2} \mathrm{O}
$$

To lower the weight and minimize the storage space, methanol is added to the iron solution. Methanol can permeate by diffusion through the membrane to the anodic side and react there at the electrode membrane interface. However, direct liquid redox fuel cell with a redox couple cathode has a low OCV of 0.77 . This value is too low to be of any interests for mobile applications, which need a minimum potential of about $1 \mathrm{~V}$. Furthermore, the need of methanol and the production of $\mathrm{CO}_{2}$ are contradictory to the aim of a green energy source and puts the user back in the dependence of a fuel.

\subsection{Membranes for Vanadium Redox Flow Battery}

\subsubsection{Challenges}

Since the discovery of the Vanadium-RFB in 1984 by Maria Skyllas-Kazacos the Vanadium-RFB has been going a long way and has recently reached the state of commercialization. However, there is still research on improving the system in terms of stability and performance. One main research area beside the electrode and the electrolyte is dedicated to the polyelectrolyte membrane research. Polyelectrolyte membranes used as separator in the Vanadium-RFB have the important task to separate efficiently the half cells and being anion or proton conductive to equilibrate the ionic charge during charge and discharge procedures. Beside ion conductivity and 
separation properties, the membrane has also to withstand the harsh conditions inside the Vanadium-RFB since the vanadium electrolyte solvent will be 3-6 M sulfuric acid and the $\mathrm{VO}_{2}^{+}$produced during charging has very strong oxidative properties. Because of these limitations the polyelectrolyte membranes still decrease the performance or the life time of such a Vanadium-RFB. The properties affecting performance and life-time of the membrane are depicted in Figure 1.12.

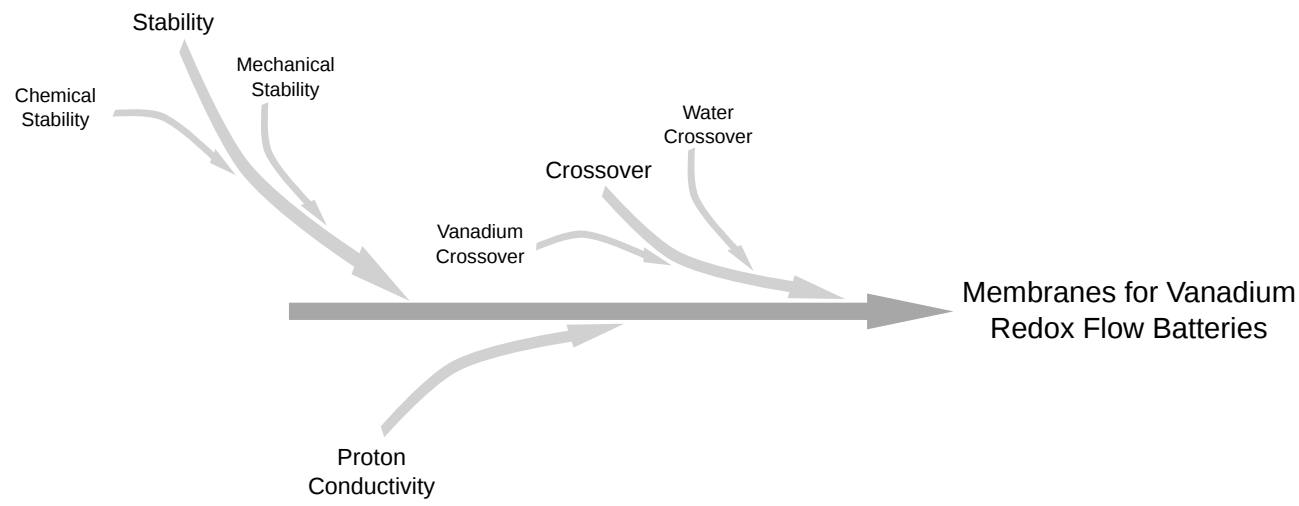

Figure 1.12 Issues which need to be overcome in order to develop a suitable membrane for vanadium redox flow batteries.

\section{Cross-Over}

The phenomena of cross-over in the Vanadium-RFB describes the undesired permeation of chemical species $\left(\mathrm{H}_{2} \mathrm{O}\right.$ and vanadium ions) through the ion exchange membranes.

Vanadium and Water Cross-Over The unique chemistry of the Vanadium-RFB prevents the system from irreversible degradation since vanadium will be applied in both half cells of the system: this avoids any irreversible mixing of chemically different species and downgrading of the electrolyte quality. Yet the crossover of vanadium will influence the cell performance, since undesired self discharge can take place if the following reaction happen by cross over of vanadium ions (1.29).

$$
\begin{aligned}
& V^{2+}+\mathrm{VO}_{2}^{+} \rightarrow V^{3+}+\mathrm{VO}^{2+} \\
& V^{3+}+\mathrm{VO}_{2}^{+} \rightarrow 2 \mathrm{VO}^{2+}
\end{aligned}
$$

Looking at the vanadium chemistry it appears that $\mathrm{VO}_{2}^{+}$and $\mathrm{VO}^{2+}$ show a rather complicated dissociation reaction in sulfuric acid. Suhkar et al.[37] showed that a 
vanadium redox flow battery applying $2 \mathrm{M}$ vanadium solution in the negative and 2 molar vanadium solution in the positive half cell, both using a sulfuric acid with $5 \mathrm{M}$ total sulfate content as a solvent, will have the following composition at a state of charge of $50 \%$.

\section{Positive half cell:}

$$
1 \mathrm{MVOSO}_{4}+0.4 \mathrm{MVO}_{2}^{+}+0.6 \mathrm{MVO}_{2} \mathrm{SO}_{4}^{-}+3.4 \mathrm{MHSO}_{4}^{-}+3.6 \mathrm{MH}^{+}
$$

\section{Negative half cell:}

$$
1 M V^{3+}+1 M V^{2+}+2.5 M \mathrm{HSO}_{4}^{-}+2.5 M \mathrm{SO}_{4}^{2-}+2.5 M \mathrm{H}^{+}
$$

This variation in dissociation behavior leads to different ionic strength, which will multiple diffusive fluxes. This presents an issue in the VRB since the concentration of electrolyte will change leading to concentration of electrolyte in one half cell and dilution of electrolyte in the other half cell $[38,37,39]$. By this an osmotic pressure difference will establish, leading to more vanadium crossover and a faster self discharge behavior. For that it is important to understand the water crossover in the Vanadium-RFB to improve its performance. The two ways of water transfer have been investigated recently by Sun and Sukkar et al. [39, 37] in which it was shown that the vanadium crossover and the water crossover are related to each other. Figure 1.13 depicts the dependence of the water transfer according to vanadium-proton crossover and osmotic pressure difference.

Furthermore, Heintz et al. studied sorption isotherm of vanadium ions with $\mathrm{H}_{3} \mathrm{O}^{+}[40]$. It was reported that all vanadium species are highly soluble in presence of $\mathrm{H}_{3} \mathrm{O}^{+}$in the proton exchange membranes used in the study. However, the diffusion coefficients of various vanadium species through cation exchange membranes which are more of interest regarding to the crossover phenomena, were quantified by a mathematical model based on a Maxwell-Stefan description by Heinz et al. [41]. According to their results it was suggested, that monoselective proton exchange membranes will decrease the vanadium crossover drastically while showing a low electrical resistance and by this increase the efficiency of a Vanadium-RFB. 
Anion Exchange Membrane

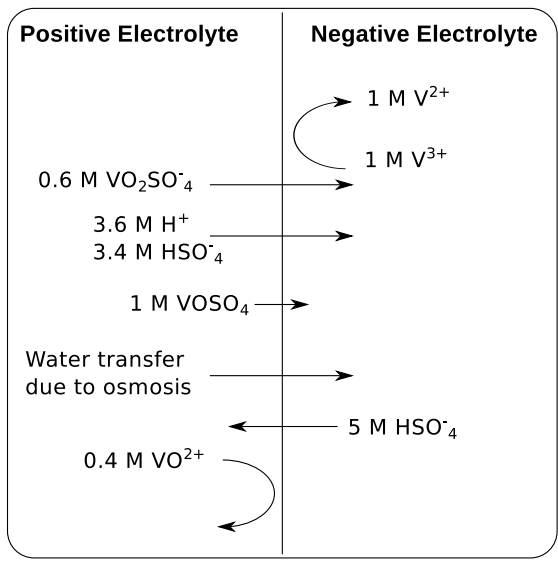

Net Water

Transfer

Net Vanadium

Transfer
Cation Exchange Membrane
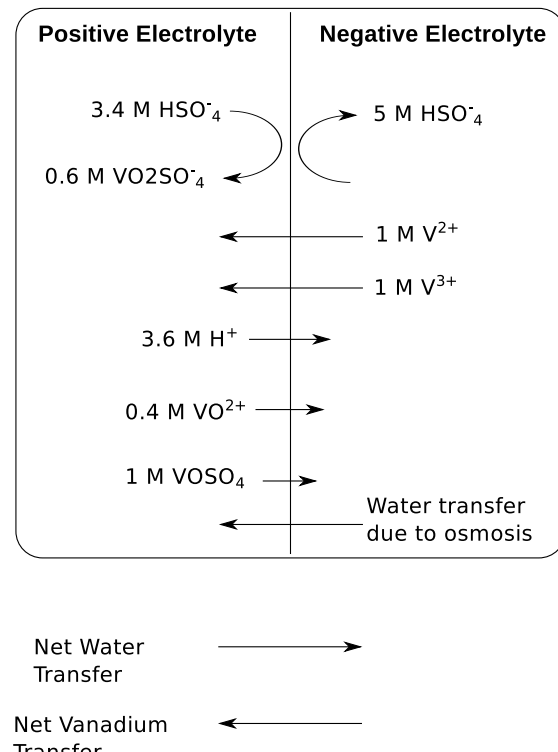

Transfer

Figure 1.13 Expected water and ion transfer for anion and cation exchange membranes applied in a $50 \%$ state of charge all vanadium redox flow battery [37].

\section{Ion Conductivity}

The development of efficient membranes for the vanadium redox flow battery has been also facing the issue of the ion conductivity in the past. The ion conductivity of a membrane in a Vanadium-RFB system describes the ability to conduct protons or anions (e.g. $\mathrm{SO}_{4}^{2-}$ ), in both directions during charge and discharge in order to balance the charge differences occurring during these reactions. Since the ion conductivity of such a polyelectrolyte determines partly the resistance and the voltage drop inside the electrochemical cell, a suitable polyelectrolyte need to have sufficient ion conductivity in order to achieve a good performing and efficient redox flow battery. The ion conductivity of a polyelectrolyte results from fixed charged groups on the polymer backbone of the membrane. According to the charge of the fixed groups the ions are transported through the ionic domains inside the membrane. Fixed negative charges in the ionic domains will promote the conduction of positive charges (cation exchange membranes) and positively charged fixed groups will promote the conduction of negatively charged ions (anion exchange membranes). Not only the ion conductivity needs to be reasonable but also the crossover of the vanadium ions through the membrane needs to be low to avoid self-discharge. Cases are reported in 
which a Nafion membrane resulted in a lower or equal energy efficiency compared with lower ion conductive membranes $[42,43,44]$. This was the case where the developed polyelectrolytes showed a lower vanadium permeability than the Nafion.

\section{Chemical Stability}

During charge in the positive half cell a vanadium redox flow battery produces $\mathrm{VO}_{2}^{+}$ ions, which have a very strong oxidizing potential. Since the vanadium ion is in its highest oxidation state $(5+)$, it will act as a electron acceptor to fall back in the more stable oxidation state of $4+$. Furthermore, the vanadium solution, needs to have a high acidity due to the poor vanadium solubility in neutral solution. The membranes applied in the vanadium redox flow battery need to be chemically stable at these harsh conditions. Many pathways have been described in the literature to enhance the chemical stability of ion exchange membranes for other type of energy conversion and storage systems, like for fuel cells. Although the stability issue of membranes for the vanadium redox flow battery was noticed by the scientific literature, it never was picked up as a major topic in order to quantify and understand degradation pathways. Even though $\mathrm{VO}_{2}^{+}$is claimed mostly as the major degradation agent other states like $\mathrm{V}^{2+}$ might also have a high degradation potential, since $\mathrm{V}^{2+}$ is a very strong reducing agent. Finally, to the best of our knowledge, no scientific work has been done on the long term stability of polyelectrolytes in contact with such strong reducing agents as $\mathrm{V}^{2+}$. The majority of publications on vanadium redox flow batteries deal with the application of (a) sulfonated perfluorinated polymers like Nafion, (b) partly sulfonated fluorinated polymers as well as (c) sulfonated polyarylenes with conjugated bonds. For the latter, here we mention sulphonated poly(ether ether ketone) as an example. The sulfonation of the precursor polymer will also set limits to the stability (chemical and mechanical). Little work has been done in the field of anion exchange membranes as compared to the amount of work done on cation exchange membranes (mostly sulfonated polymers). In the scientific literature only a few anion exchange membranes have been prepared and tested for the vanadium redox flow battery application. In conclusion, a suitable membrane for the vanadium redox flow battery needs to be stable in $\mathrm{VO}_{2}^{+}$and $\mathrm{V}^{2+}$ and should have low crossover for vanadium species. Also more work needs to be done on the chemical stability of polyelectrolytes for vanadium redox flow batteries in order to understand degradation procedures to be able to engineer a cheap, conductive but stable membrane for this promising energy storage application. 


\subsubsection{Membranes}

Several commercially available ion exchange membranes from Asahi Glass (Selemion and Flemion), Dow Chemicals (Dow XUSI 3204.01), Asahi Chemicals (K142) and Du Pont(Nafion) [45] have been applied and tested in the past for the Vanadium-RFB application. Two of the above mentioned membranes (Flemion and Nafion) were identified as a suitable membrane for the Vanadium-RFB. But these ion exchange membranes are fairly expensive and show a quite high vanadium cross over. Researchers have been screening several material classes in order to produce a cheap, stable, proton conductive and selective membrane with little vanadium cross over. Next to cation exchange membranes (CEM), also anion exchange membranes (AEM) as well as amphotheric ion exchange membranes (AIEM) have been studied. The usage of anion exchange and amphotheric ion exchange membranes is possible since only a charge transfer by ions is necessary to equilibrate the overall charge of the system. In the case of the anion exchange membranes e.g. $\mathrm{SO}_{4}^{2-}$ will travel through the membrane during charge and discharge in order to equilibrate the charge. However, although AEM reject cations protons will be able to move as well through the membrane due to their small size [46]. In the case of amphoteric ion exchange membrane both (protons and anions) species are allowed to permeate through the membrane back and forward during charge/discharge cycles.

\section{Cation Exchange Membranes (CEM)}

The CEM is the most reported membrane for the Vanadium-RFB application in the scientific literature due to the high transport rates for protons. However, the vanadium species are mobile as well and will also permeate through the CEM. According to that the challenge is to apply a high proton conductive but a low vanadium permeable membrane for the Vanadium-RFB in order to achieve a highly efficient system. Nafion is the most studied CEM for energy applications [47] due to its chemical stability and excellent proton conductivity. Nafion is a sulfonated perfluorinated polymer with a copolymer molecule structure (Figure 1.14). The polymer consists of a strong hydrophobic backbone and regularly spaced shorter perfluoro vinylether side chains, each terminated with a strong hydrophilic sulfonic acid group. Nafion shows a good phase separation between the hydrophilic and hydrophobic phases, leading to a very well interconnected hydrophilic phase due to the highly flexible fluorocarbon backbone of the polymer. It is also due to the fluorocarbon backbone that this polymer shows excellent chemical stability. Since the hydrophilic groups are responsible for the 
proton conductivity by dissociation in contact with protic and polar solvents, Nafion shows among a large list of commercial polymers not only chemical stability but also good proton conductivity.

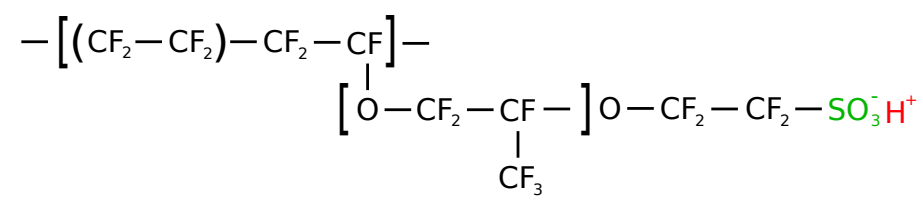

Figure 1.14 Nafion chemical structure

The two major disadvantages of Nafion for vanadium redox flow battery applications are the costs and the vanadium crossover. The high costs are mainly due to the complex production method and low production volumes to date [48]. Vanadium permeation is due to the well interconnected hydrophilic and broad channels [49]. Figure 1.15 depicts the difference of a swollen Nafion membrane compared with a glassy polyelectrolyte (in this case sulfonated poly (ether ether ketone) (SPEEK)). The visualization expresses the highly permeable phase separation of Nafion and the dead end and narrow channels of sPEEK which do not contribute as effectively to the ion conductivity. 

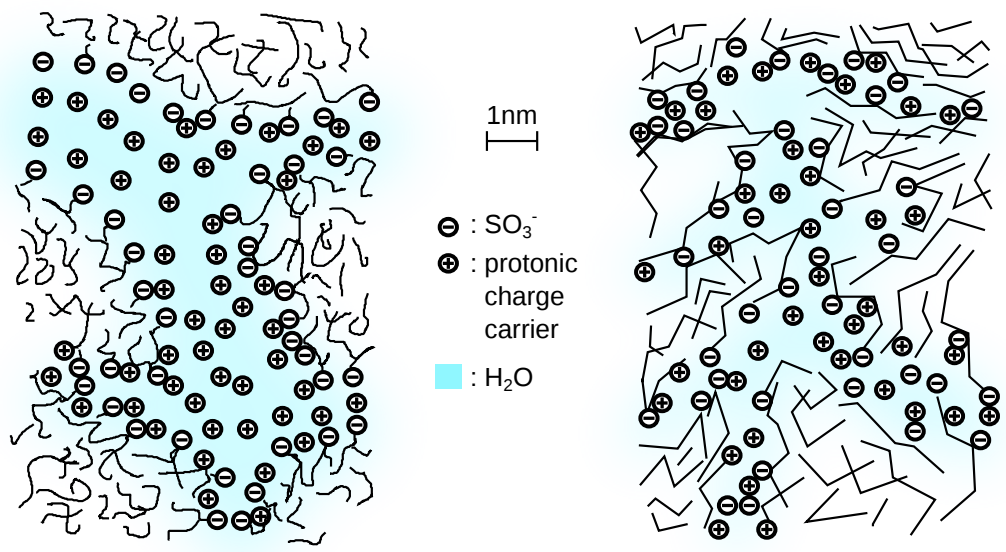

- wide channels

- more separated

- narrow channels

- less branched

- good connectivity

- small $\mathrm{SO}_{3}-\mathrm{SO}_{3}$ separation

- $\mathrm{pK}_{\mathrm{a}} \sim-6$

- less separated
- highly branched
- dead-end connectivity
- large $\mathrm{SO}_{3}^{-} / \mathrm{SO}_{3}^{-}$
- $\mathrm{pK}_{\mathrm{a}} \sim-1$

Figure 1.15 Redrawn schematics of the microstructures of Nafion and a sulfonated poly ether ketone [50].

This leads to the two main issues of Nafion in Vanadium-RFB:

- Self discharge and low energy efficiency due to vanadium permeation (cross-over)

- Dilution and concentrating of the electrolyte solutions, due to high levels of water transfer

On the search for alternatives for Nafion, considerable work has been done on modification methods of CEMs. The following methods were applied to CEMs in order to produce low vanadium permeable CEMs:

- Soaking of porous non conductive membranes with polyelectrolytes $[51,52,53$, $54,55]$

- Synthesis of organic / inorganic composite membrane

- In-situ sol gel

- Blending of the polyelectrolyte with inorganic particles 
- Modification with polyelectrolyte multilayers

Two major modifications have proved the decrease of vanadium crossover and showed long term stability in a running vanadium redox flow battery. These methods are described in the following.

Synthesis of Organic / Inorganic Composite Membrane Composite ion exchange membranes with inorganic materials such as silica $[56,57,58]$, zirconia $[59,60]$, silica titanium oxide [61], zeolites [62] and silicon-aluminum oxide [63] have been in the focus of the research in the field of direct methanol fuel cells in order to reduce the methanol crossover. Especially Nafion has been modified by these inorganic nanoparticles to introduce winding pathways for methanol, since the cross over of methanol presents a serious issue in direct methanol fuel cells. The cross over phenomena of methanol is caused by two different effects (1) the protonic drag of methanol, where the methanol is easily transported together with protons through the membrane (2) the diffusion through the water filled channels. Since these effects may also be the origin of vanadium crossover, research was done into incorporation of inorganic particles into CEMs suitable for vanadium redox flow batteries. Xi et al. [64] for example, employed successfully a Nafion $/ \mathrm{SiO}_{2}$ (prepared by the sol gel route) membrane to the Vanadium-RFB system. The results showed that the incorporation of the $\mathrm{SiO}_{2}$ decreased efficiently the vanadium crossover. This was attributed to the filling of the polar clusters of Nafion by silica nanoparticles. This results in a better coulomb and energy efficiency but also in lower self-discharge rate of the Vanadium-RFB.

Modification with Polyelectrolyte Multilayers Layer by Layer (LbL) deposition of polyelectrolytes represents a surface modification method. In the LbL, polyelectrolyte membranes which has to be modified on the surface (in this case Nafion) will be immersed first in a positively charged polyelectrolyte solution followed by a washing step with deionized water (Figure 1.16). 


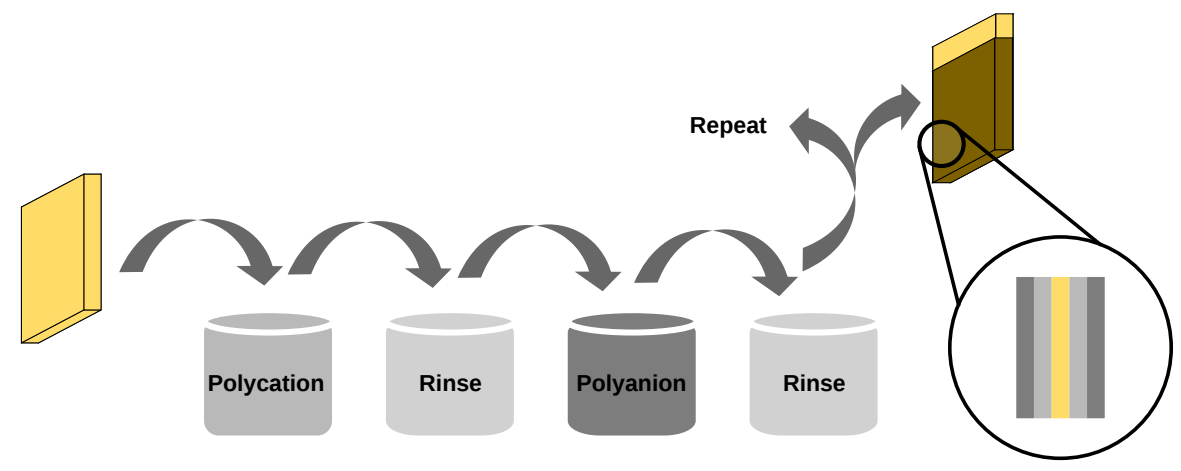

Figure 1.16 Layer by Layer surface modification.

After the washing step the same membrane is immersed into a negatively charged polyelectrolyte solution. Repeating these steps a mono layer of self assembled cationic and anionic charged layers will accumulate on the surface, which is stabilized by ionic interactions. By this simple method the modification of a polyelectrolyte membranes by thin stacked oppositely charged thin layer polyelectrolytes thin films can be achieved, within the nanoscale [65, 66]. In DMFC applications LbL modified membranes are mainly applied to decrease the methanol cross-over [56]. However, in Vanadium-RFB, it has been observed [67] that LbL modified Nafion membranes show a lower vanadium cross-over and with that an increase of coulomb and energy efficiency but also a lower self-discharge rate.

However, research has to be done as well CEM material in order to reduce the vanadium cross over and the price. New materials and modified CEMs used in VanadiumRFB application are listed in Table 1.5. 


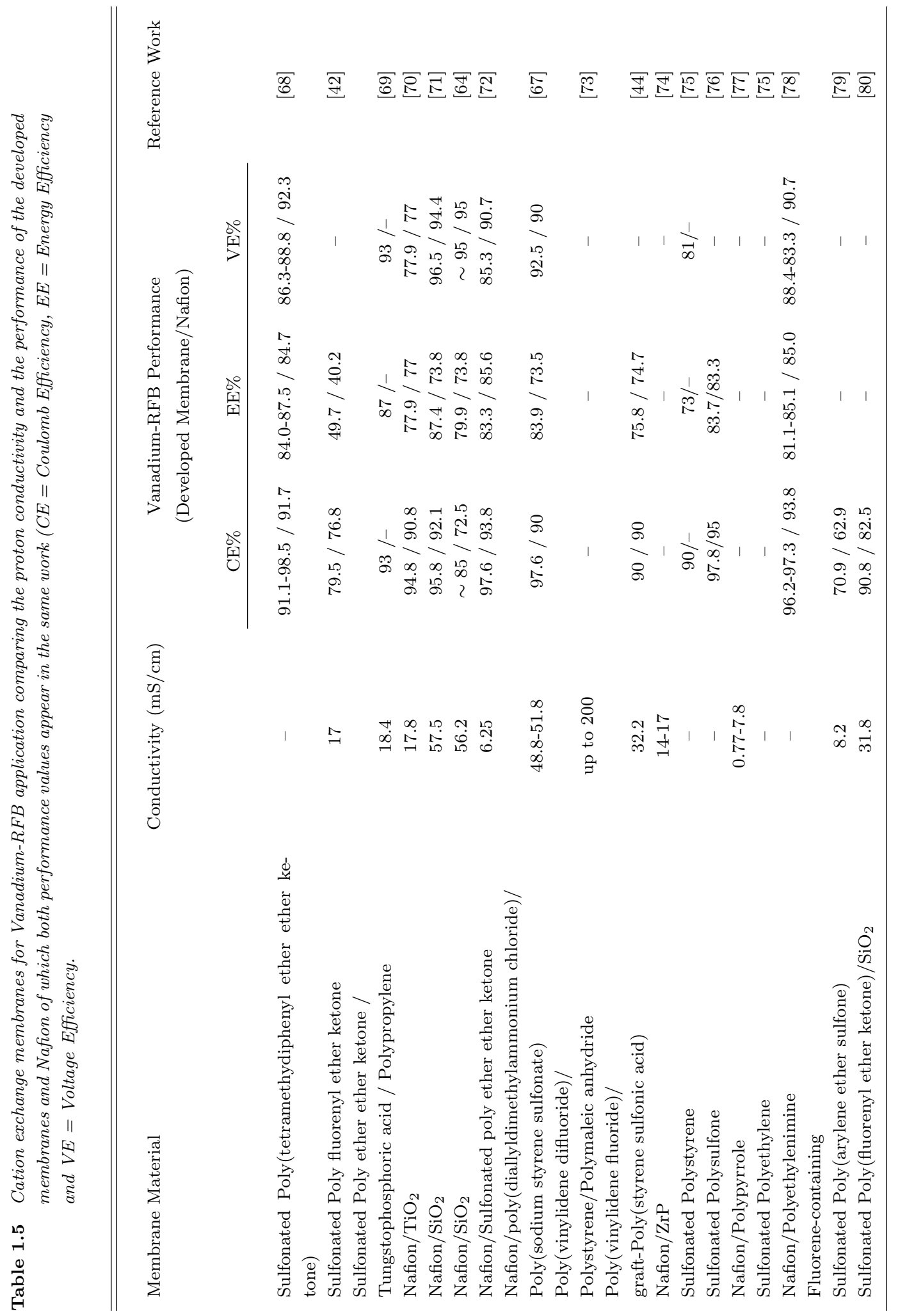




\section{Anion Exchange Membranes (AEM)}

Anion exchange membranes (AEM) are membranes which have positively charged functional groups. These membranes allow the transport of anions, while rejecting cations. A recent review summarizes the properties of AEMs for the use in alkaline fuel cells [19]. However, the properties of the AEMs initiated some work in the field of polyelectrolyte membrane separators for the Vanadium-RFB to obtain low vanadium cross over and low water cross over. Since the AEMs are positively charged only anions can pass: the cross over of positively charged vanadium ions will be decreased drastically. However although positively charged vanadium ions are rejected by the $\mathrm{AEM} \mathrm{VOSO}_{4}$ and $\mathrm{VO}\left(\mathrm{SO}_{4}\right)_{2}^{2-}$ which are neutral and negatively charged, respectively [81] may travel through the AEM as well. Due to the decreased cross over of the vanadium species, the water cross over will be minimized as well, since it is dependent on the vanadium cross over. Even though the AEM rejects cations, protons will diffuse through the membrane since their exclusion by the anion exchange membrane is less effective. In fact, it is desired to use a so-called proton-leaking AEM so that proton transport happens through 'leakage' as well as vanadium rejection. The chemical stability seems to be less under the harsh conditions in the VanadiumRFB [82] compared with CEMs. These issues might have been the reason for the little research on AEMs for Vanadium-RFB application. 


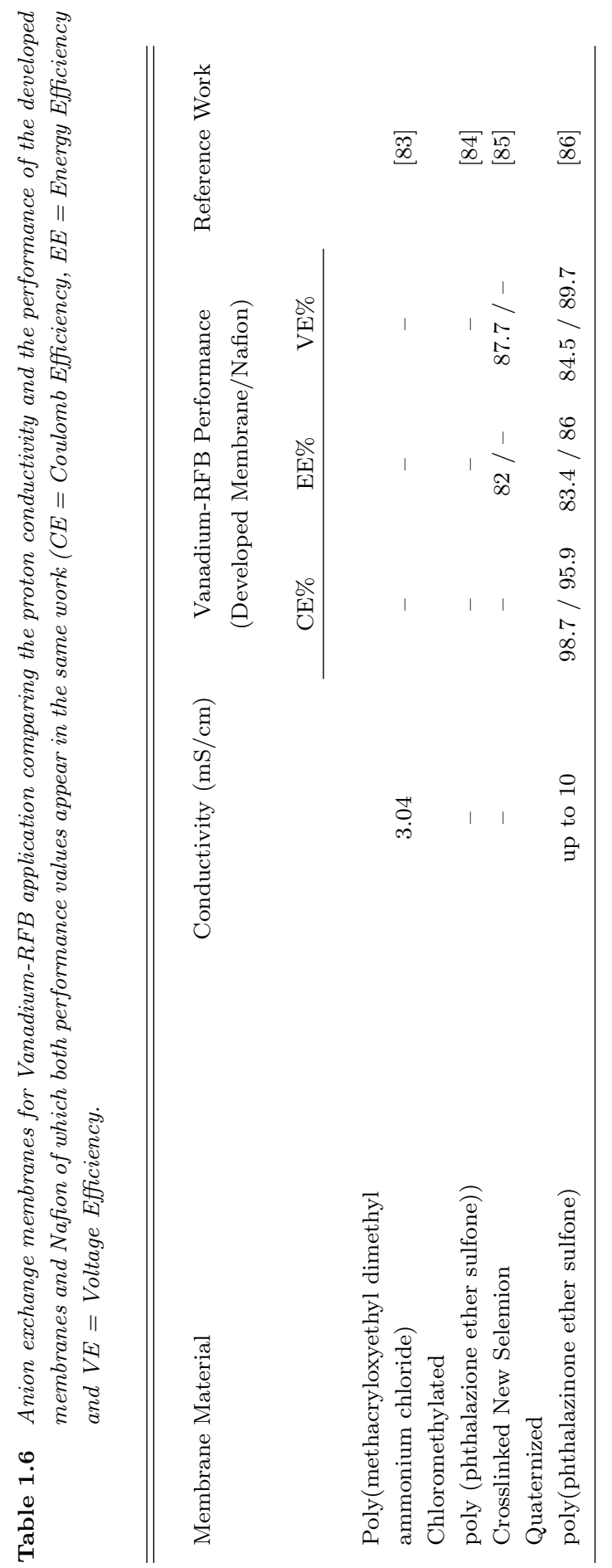




\section{Amphotheric Ion Exchange Membranes (AIEM)}

The amphoteric ion exchange membranes (AIEM) contain cationic as well as anionic exchange groups as first proposed in 1932 by Sollner [87]. The advantage of AIEM is that the adjustment of the composition and the external conditions allows the control the ion exchange properties. Due to that, AIEMs show high potential in different applications [88]. However, only one research group has been investigating the AIEM in the Vanadium-RFB [88]. The study show that due to the adjustments of the cation and anion exchange group composition, the vanadium as well the water crossover could be decreased drastically leading to an open circuit potential which is 100 times more stable than using Nafion 117 as CEM for the VRB. The adjustment of the oppositely charged and fixed groups of the polyelectrolyte will decrease, as proved, the vanadium permeability for the same reason as in the case of the LbL modified membranes. Unfortunately the presented work does not include any CE, EE and VE measurements. The same group investigated the amphoteric membranes prepared by grafting [43]. Here the result showed clearly that the application of a membrane bearing positive and negative charges can indeed increase the performance of the Vanadium-RFB. This is also due to the 130 to 200 times lower vanadium permeability. The membrane stability in the Vanadium-RFB was tested up to $\sim 45$ cycles. The values for the voltage efficiency, energy efficiency and coulomb efficiency showed more deviation in the last cycles from cycle number 30. However, this was not commented in the publication, which might be to our opinion an instability of the membrane itself. 


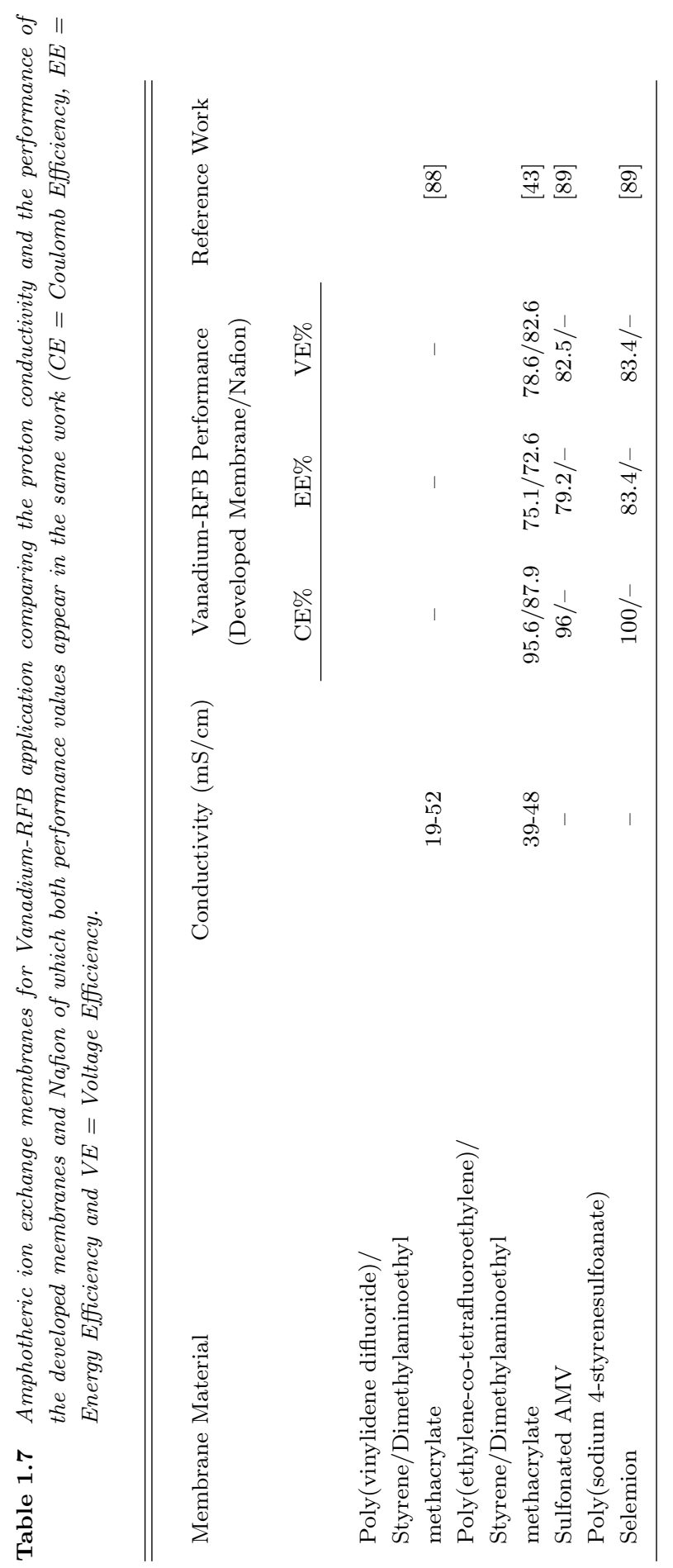




\section{Bibliography}

[1] Attaviriyanupap, P. (2010) Engineering Journal 14, 57-70.

[2] Administration, E. I. Annual energy outlook 2009 Technical report U.S. Department of Energy (2009).

[3] Dresselhaus, M. S. and Thomas, I. L. November 2001 Nature 414(6861), 332337.

[4] Friedlingstein, P., Houghton, R. A., Marland, G., Hackler, J., Boden, T. A., T. J. Conway, T. J., Canadell, J. G., Raupach, M. R., Ciais, P., and Quere, C. L. December 2010 Nature Geosci 3(12), 811-812.

[5] Isi web of knowledge (2011).

[6] H. J. Schellnhuber, (ed.) (2010) Global Sustainibility, Cambridge University Press.

[7] Steven, G. C. and Miller, J. F. (2006) Journal of Power Sources 159(1), 73 80 .

[8] Bueno, C. and Carta, J. (2006) Renewable and Sustainable Energy Reviews $\mathbf{1 0}(\mathbf{4}), 312-340$.

[9] Najjar, Y. and Jubeh, N. (2006) Proceedings of the Institution of Mechanical Engineers, Part A: Journal of Power and Energy 220(6), 581-588.

[10] Xue, X. D. (2006) Superconductor Science and Technology 19(6), R31.

[11] Kondoh, J., Ishii, I., Yamaguchi, H., Murata, A., Otani, K., Sakuta, K., Higuchi, N., Sekine, S., and Kamimoto, M. (2000) Energy Conversion and Management 41(17), $1863-1874$.

[12] Skyllas-Kazacos, M., Rychick, M., and Robins, R. (1988) US Patent 4,786,567.

[13] Chen, H., Cong, T. N., Yang, W., Tan, C., Li, Y., and Ding, Y. (2009) Progress in Natural Science 19(3), 291 - 312.

[14] Kirubakaran, A., Jain, S., and Nema, R. (2009) Renewable and Sustainable Energy Reviews 13(9), 2430 - 2440.

[15] Lasbet, Y., Auvity, B., Castelain, C., and Peerhossaini, H. (2006) Journal of Power Sources 156(1), $114-118$. 
[16] Sopian, K. and Daud, W. R. W. (2006) Renewable Energy 31(5), 719 - 727.

[17] A. J. Bard, D. Inzelt, and F. Scholz, (ed.) (2008) Electrochemical Dictionary, Springer Berlin Heidelberg.

[18] Tischer, R. P. (1966) Electrochimica Acta 11(9), 1309 - 1323.

[19] Merle, G., Wessling, M., and Nijmeijer, K. (2011) Journal of Membrane Science DOI: 10.1016/j.memsci.2011.04.043.

[20] Kiehne, H. (2003) Battery Technology Handbook, Expert Verlag RenningenMalsheim, Germany.

[21] Price, A., Bartley, S., Male, S., and Cooley, G. (1999) Power Engineering Journal 13(3), 122-129.

[22] Skyllas-Kazacos, M., Rychick, M., and Robins, R. (1988) US Patent 4,786,567.

[23] deLeon, C. P., Frias-Ferrer, A., and Gonzalez, G. (2006) Journal of Power Sources 160(1), 716-732.

[24] Hagedorn, N. H. Nasa redox storage system development project, Technical Report DOEI/NASA/II 2726-24 NASA TM-83677 NASA (1984).

[25] Lex, P. and Jonshagen, B. June 1999 Power Engineering Journal 13(3), 142 -148 .

[26] Hosseiny, S. S., Saakes, M., and Wessling, M. (2010) Electrochemistry Communications, DOI:10.1016/j.elecom.2010.11.025.

[27] Clarke, R., Dougherty, B., Harrison, S., Millington, J., and Mohanta, S. (2007) WO $2007 / 044852$.

[28] Schaber, C., Mazza, P., and Hammerschlag, R. (2004) The Electricity Journal $\mathbf{1 7}(\mathbf{6}), 21-29$.

[29] Perrin, M., Saint-Drenan, Y., Mattera, F., and Malbranche, P. (2005) Journal of Power Sources 144(2), 402 - 410.

[30] Ge, S. H., Yi, B. L., and Zhang, H. M. (2004) Journal of Applied Electrochemistry 34, 181-185.

[31] Cedzynska, K. (1995) Electrochimica Acta 40(8), 971 - 976. 
[32] Karamanev, D. G., Porfirievich, V., and Vassilev, P. (2009) US Patent 2009/0305083 A1.

[33] Bergens, S. H., Gorman, C. B., Palmore, G. T., and Whitesides, G. M. September 1994 Science 265(5177), 1418-1420.

[34] Wen, Y., Cheng, J., Ma, P., and Yang, Y. (2008) Electrochimica Acta 53(9), $3514-3522$.

[35] Wen, Y., Cheng, J., Xun, Y., Ma, P., and Yang, Y. (2008) Electrochimica Acta 53(20), $6018-6023$.

[36] Ilicic, A., Dara, M., Wilkinson, D., and Fatih, K. (2010) Journal of Applied Electrochemistry 40, 2125-2133.

[37] Sukkar, T. and Skyllas-Kazacos, M. (2003) Journal of Membrane Science 222(12), 249-264.

[38] Mohammadi, T., Chieng, S. C., and Skyllas Kazacos, M. (1997) Journal of Membrane Science 133(2), 151-159.

[39] Sun, C., Chen, J., Zhang, H., Han, X., and Luo, Q. (2010) Journal of Power Sources 195(3), 890-897.

[40] Wiedemann, E., Heintz, A., and Lichtenthaler, R. N. April 1998 Journal of Membrane Science 141(2), 207-213.

[41] Wiedemann, E., Heintz, A., and Lichtenthaler, R. N. (1998) Journal of Membrane Science 141(2), 215-221.

[42] Chen, D., Wang, S., Xiao, M., and Meng, Y. April 2010 Journal of Power Sources 195(7), 2089-2095.

[43] Qiu, J., Zhai, M., Chen, J., Wang, Y., Peng, J., Xu, L., Li, J., and Wei, G. (2009) Journal of Membrane Science 342(1-2), 215-220.

[44] .Luo, X., Lu, Z., Xi, J., Wu, Z., Zhu, W., Chen, L., and Qiu, X. November 2005 The Journal of Physical Chemistry B 109(43), 20310-20314.

[45] Mohammadi, T. and Skyllas-Kazacos, M. (1995) Journal of Membrane Science 107(1-2), 35-45.

[46] Lorrain, Y., Pourcelly, G., and Gavach, C. (1997) Desalination 109(3), 231 239. 
[47] Mauritz, K. A. and Moore, R. B. (2004) Chemical Reviews 104(10), 4535-4586.

[48] Gubler, L., Grsel, S. A., and Scherer, G. G. (2005) Fuel Cells 5(3), 317-335.

[49] Jia, C., Liu, J., and Yan, C. (2010) Journal of Power Sources 195(13), 4380 4383.

[50] Kreuer, K. D. (2001) Journal of Membrane Science 185(1), 29 - 39.

[51] Mohammadi, T. and Skyllas-Kazacos, M. (1995) Journal of Membrane Science 98(1-2), 77-87.

[52] Chieng, S., Kazacos, M., and Skyllas-Kazacos, M. December 1992 Journal of Membrane Science 75(1-2), 81-91.

[53] Tian, B., Yan, C. W., and Wang, F. (2004) Journal of Membrane Science 234(12), 51-54.

[54] Miyake, S. (2002) US Patent, No. US 64617r2 B1.

[55] Mohammadi, T. and Skyllas-Kazacos, M. (1995) Journal of Power Sources 56(1), 91-96.

[56] Jiang, R., Kunz, H. R., and Fenton, J. M. (2006) Journal of Membrane Science 272(1-2), $116-124$.

[57] Jung, D. H., Cho, S. Y., Peck, D. H., Shin, D. R., and Kim, J. S. (2002) Journal of Power Sources 106(1-2), 173 - 177.

[58] Antonucci, P. L., Arico, A. S., Creti, P., Ramunni, E., and Antonucci, V. (1999) Solid State Ionics 125(1-4), 431 - 437.

[59] Bauer, F. and Willert-Porada, M. (2004) Journal of Membrane Science 233(12), $141-149$.

[60] Arbizzani, C., Donnadio, A., Pica, M., Sganappa, M., Varzi, A., Casciola, M., and Mastragostino, M. (2010) Journal of Power Sources 195(23), 7751 - 7756.

[61] Daiko, Y., Klein, L. C., Kasuga, T., and Nogami, M. (2006) Journal of Membrane Science 281(1-2), $619-625$.

[62] Yildirim, M. H., Curoś, A. R., Motuzas, J., Julbe, A., Stamatialis, D. F., and Wessling, M. (2009) Journal of Membrane Science 338(1-2), 75 - 83. 
[63] Ismail, A., Othman, N., and Mustafa, A. (2009) Journal of Membrane Science 329(1-2), $18-29$.

[64] Xi, J., Wu, Z., Qiu, X., and Chen, L. (2007) Journal of Power Sources 166(2), 531-536.

[65] Decher, G. (1997) Science 277(5330), 1232-1237.

[66] Chao, L. and Charles, M. R. July 1991 Nature 352(6330), 50-52.

[67] Xi, J., Wu, Z., Teng, X., Zhao, Y., Chen, L., and Qiu, X. (2008) Journal of Materials Chemistry 18(11), 1232-1238.

[68] Mai, Z., Zhang, H., Li, X., Bi, C., and Dai, H. (2011) Journal of Power Sources 196(1), $482-487$.

[69] Jia, C., Liu, J., and Yan, C. (2010) Journal of Power Sources 195(13), 4380 4383.

[70] Teng, X., Zhao, Y., Xi, J., Wu, Z., Qiu, X., and Chen, L. (2009) Journal of Membrane Science 341(1-2), 149-154.

[71] Teng, X., Zhao, Y., Xi, J., Wu, Z., Qiu, X., and Chen, L. (2009) Journal of Power Sources 189(2), 1240-1246.

[72] Luo, Q., Zhang, H., Chen, J., You, D., Sun, C., and Zhang, Y. (2008) Journal of Membrane Science 325(2), 553-558.

[73] Qiu, J., Zhao, L., Zhai, M., Ni, J., Zhou, H., Peng, J., Li, J., and Wei, G. (2008) Journal of Power Sources 177(2), 617-623.

[74] Sang, S., Q.Wu, and Huang, K. (2007) Journal of Membrane Science 305(1-2), $118-124$.

[75] Skyllas-Kazacos, M. and Grossmith, F. (1987) Journal of The Electrochemical Society 134(12), 2950-2953.

[76] Kim, S., Yan, J., Schwenzer, B., Zhang, J., Li, L., Liu, J., Yang, Z. G., and Hickner, M. A. (2010) Electrochemistry Communications 12(11), 1650 - 1653.

[77] Zeng, J., Jiang, C., Wang, Y., Chen, J., Zhu, S., Zhao, B., and Wang, R. (2008) Electrochemistry Communications 10(3), 372-375.

[78] Luo, Q., Zhang, H., Chen, J., Qian, P., and Zhai, Y. (2008) Journal of Membrane Science 311(1-2), 98-103. 
[79] Chen, D., Wang, S., Xiao, M., and Meng, Y. (2010) Energy Conversion and Management 51(12), 2816 - 2824.

[80] Chen, D., Wang, S., Xiao, M., Han, D., and Meng, Y. (2010) Journal of Power Sources 195(22), $7701-7708$.

[81] Rahman, F. and Skyllas-Kazacos, M. (1998) Journal of Power Sources 72(2), $105-110$.

[82] Zhang, S., Yin, C., Xing, D., Yang, D., and Jian, X. (2010) Journal of Membrane Science 363(1-2), 243 - 249.

[83] Qiu, J., Li, M., Ni, J., Zhai, M., Peng, J., Xu, L., Zhou, H., Li, J., and Wei, G. (2007) Journal of Membrane Science 297(1-2), 174-180.

[84] Xing, D., Zhang, S., C.Yin, Yan, C., and Jian, X. (2009) Materials Science and Engineering: $B$ 157(1-3), $1-5$.

[85] Hwang, G.-J. and Ohya, H. August 1997 Journal of Membrane Science 132(1), 55-61.

[86] Xing, D., Zhang, S., Yin, C., Zhang, B., and Jian, X. (2010) Journal of Membrane Science 354(1-2), $68-73$.

[87] Sollner, K. (1932) Biochemische Zeitschrift 244, 370 - 381.

[88] Qiu, J., Zhang, J., Chen, J., Peng, J., Xu, L., Zhai, M., Li, J., and Wei, G. (2009) Journal of Membrane Science 334(1-2), 9-15.

[89] Mohammadi, T. and Skyllas-Kazacos, M. (1996) Journal of Power Sources 63(2), 179-186. 
Chapter

\section{Principles of Electrochemical}

\section{Characterization Techniques}

This chapter describes the electrochemical measurements which have been applied within this thesis. The descriptions of the electrochemical methods are mainly taken from $[1,2,3]$ if not differently mentioned.

Electrochemical characterization techniques are based on measuring an electrical signal. Hereby the electrochemical instrument generates and measures the input/output signals which are voltage or current. In general, a electrochemical characterization cell will comprise various electrodes, frequently three and more. Figure 2.1 depicts an electrochemical cell consisting of a working electrode, counter electrode and a reference electrode. 


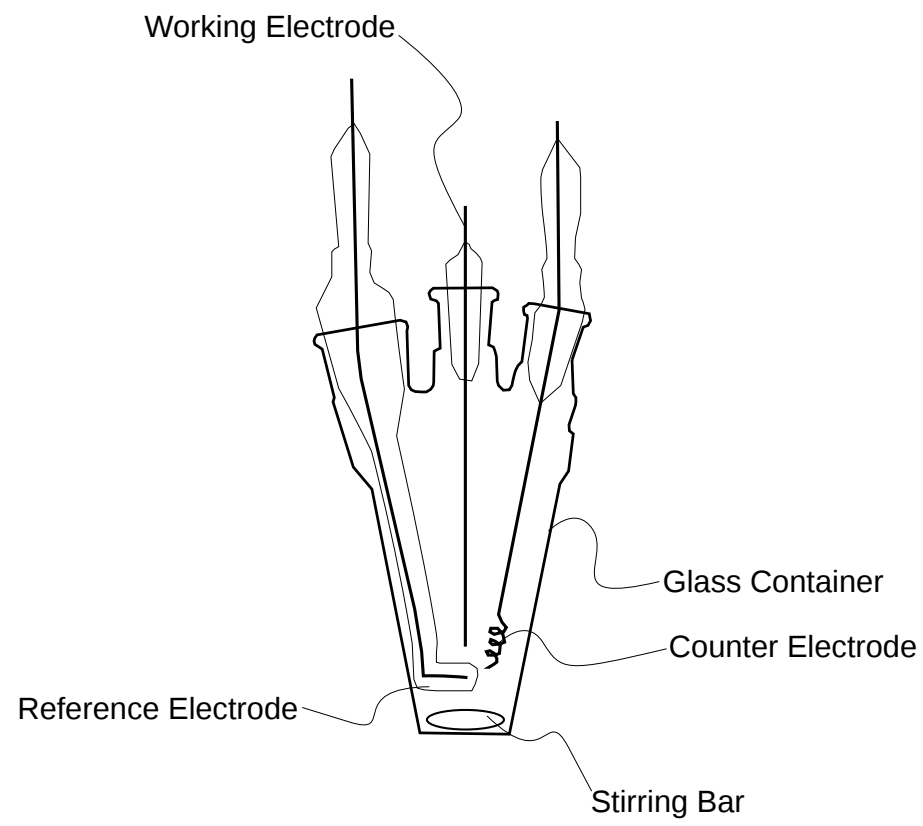

Figure 2.1 Schematic of an electrochemical cell for most electrochemical characterization methods.

The characteristics of the input signal will influence reactions occurring at the working electrode and the counter electrode. Between the working and counter electrode the input current will be imposed, where the working electrode represents the electrode of interest. The potential will be monitored relative to the reference electrode, which is placed close to the working electrode.

\subsection{Cyclic Voltammetry}

In cyclic voltammetry a potential will be cycled between a chosen low and high potential and the resulting current will be recorded. The potential/current plot resulting from this measurements is called cyclic voltammogram. The scan rate $(\mathrm{mV} / \mathrm{s})$ with which the potential is carried out can be controlled in a wide range and will be carried out linearly. In this thesis, CV was used to visualize the catalytic activity of a catalyst which can be applied as working electrode. The investigated reactions are oxygen reduction reaction $(\mathrm{ORR})$ and oxygen evolution reaction (OER) in a potential range of $0.2 \mathrm{~V}$ to $1.6 \mathrm{~V}$ vs. $\mathrm{Ag} / \mathrm{AgCl}$. Figure 2.2 depicts a sketch of a $\mathrm{CV}$ on a platinum electrode in $\mathrm{H}_{2} \mathrm{SO}_{4}$ [4]. 


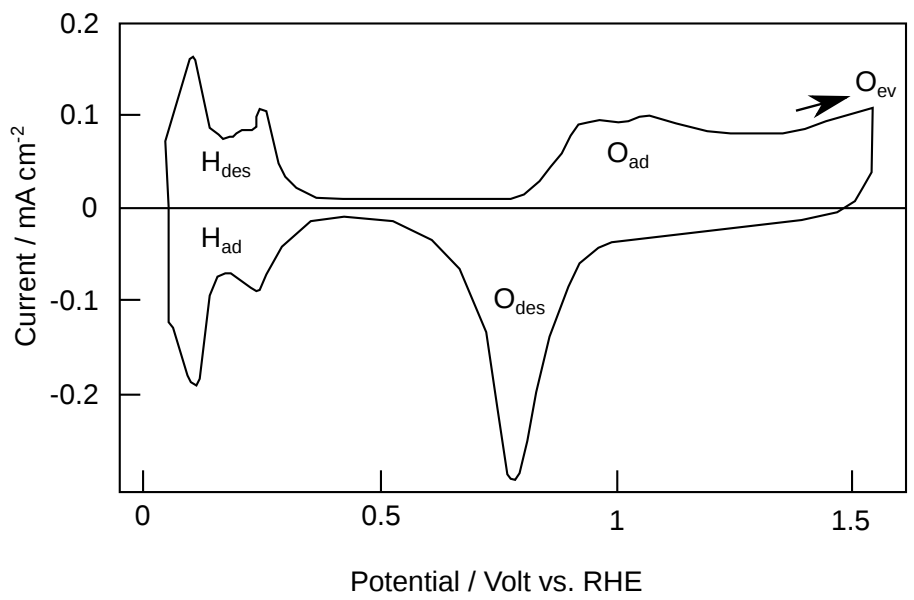

Figure 2.2 Redrawn schematic representation of a cyclic voltammogram of Pt in acidic media [4].

Here $\mathrm{H}_{a d}$ and $\mathrm{H}_{\text {des }}$ stand for the hydrogen adsorption and hydrogen desorption. In the figure $\mathrm{O}_{a d}$ and $\mathrm{O}_{d e s}$ represent the oxygen adsorption and oxygen desorption. Oxygen evolution $\left(\mathrm{O}_{e v}\right)$ will appear on blank platinum after $\mathrm{O}_{a d}$ at higher potentials. However, $\mathrm{O}_{d e s}$ and $\mathrm{O}_{e v}$ correspond to the desired reactions ORR and OER. As depicted in Figure 2.2 OER occurs in this case in highly anodic regions $>1.23 \mathrm{~V}$ vs. RHE where ORR occurs in less anodic regions between 0.8-0.6 V vs RHE. For that only these regions will be of relevance for the Chapter 7 where only the forward scan (for OER) or the backward scan (ORR) will be showed and discussed.

Furthermore CV was applied to calculate the electrochemical surface area (ECSA, $\mathrm{m}^{2} / \mathrm{g}$ catalyst) of the prepared catalyst. For that the electrolyte solution in the electrochemical cell is purged with $\mathrm{CO}$ to be adsorbed by the catalyst reactive sides [5]. Figure 2.3 depicts a sketch of the $\mathrm{CO}$ stripping voltammogram. 


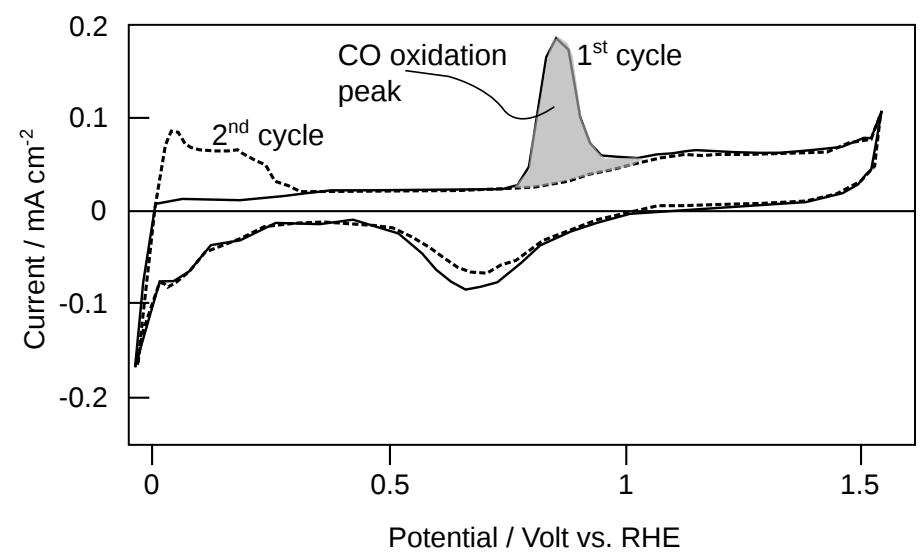

Figure 2.3 Redrawn schematic representation of a CO stripping cyclic voltammogram [6].

The CO oxidation peak is coloured grayed for better visualization. To gain information about the ECSA the adsorbed CO was removed by CV. The obtained CV shows a typical shape as depicted in Figure 2.3. To calculate the charge invested for $\mathrm{CO}$ oxidation $\left(\mathrm{Q}_{C O}\right)$ the area under the $\mathrm{CO}$ oxidation peak is integrated within the integration limits $\mathrm{E}_{1}(\mathrm{~V})=0.3$ and $\mathrm{E}_{2}(\mathrm{~V})=1$ using the second scan as the base line. It is assumed that the $\mathrm{CO}$ occupation on the catalyst surface occur by producing a mono layer. To oxidized a monolayer of CO from an area of $1 \mathrm{~cm}^{2}(\mathrm{Pt})$ a charge of $0.484 \mathrm{mC}$ has to be invested [6]. With this and the loading of the applied catalyst $\left(\mathrm{L}_{P t}\right.$ in $\left.\mathrm{g} / \mathrm{m}^{2}\right)$ the ECSA can be calculated as follows

$$
\operatorname{ECSA}\left(\mathrm{m}^{2} / g\right)=\frac{Q_{C O}\left(\mathrm{mC} / \mathrm{cm}^{2}\right)}{L_{P t}\left(\mathrm{~g} / \mathrm{m}^{2}\right) * 0.484\left(\mathrm{mC} / \mathrm{cm}^{2}\right)}
$$

Figure 2.3 also shows the appearance of the hydrogen adsorption peak in the $2^{\text {nd }}$ cycle. $\mathrm{CO}$ adsorption in the first cycle was blocking any hydrogen adsorption. The analysis of exactly these peaks indicate how susceptible an electro-chemically catalytic is for $\mathrm{CO}$ poisoning and how active the surface is towards $\mathrm{CO}$ oxidation.

\subsection{Impedance Spectroscopy}

The ability of any electrically conducting material to resist the electrical current is called electrical resistance. By Ohm's law it is defined as follows (Equation 2.2):

$$
R=\frac{E}{I}
$$


where $\mathrm{R}$ is the electrical resistance in Ohms, $\mathrm{E}$ is the potential in Volts, and $\mathrm{I}$ is the current in Amperes. This relationship is valid for only one element namely the resistor. Electrochemical systems, including e.g. electrode surface reactions, double layer formation, mass transport limitation and charge transfer resistance and ohmic resistance [6] have different time scales and resistance measurement would result in a combined resistance value from which the different systems could not be distinguished. Electrochemical impedance spectroscopy is yet an other method to measure the ability of a system to resist the electrical current, without being limited to only one electrical circuit element. Using an alternating electrical excitation signal (potential) with a sinusoidal shape, which is expressed as in Equation 2.3 presented where $E_{m}$ is the maximum amplitude and $\omega$ is the frequency in Hertz $\left(\mathrm{s}^{-1}\right)$, time constants of different systems can be taken into account. The result of such an alternating sinusoidal excitation (current) will also be of a sinusoidal nature (Equation 2.4), with $I_{m}$ being the maximum amplitude and $\phi$ the phase of the current.

$$
\begin{aligned}
& E(t)=E_{m} \sin (2 \pi \omega t) \\
& I(t)=I_{m} \sin (2 \pi \omega t+\phi)
\end{aligned}
$$

Combining these two expressions according to Ohm's law, the impedance (Z) of a system can be calculated.

$$
Z=\frac{E_{t}}{I_{t}}
$$

The resulting current of the applied sinusoidal potential provide information about the impedance of the cell. The way to analyze the input and output signal is simply over the amplitude of the alternating excitation signals and the phase shifts (Figure 2.4). 


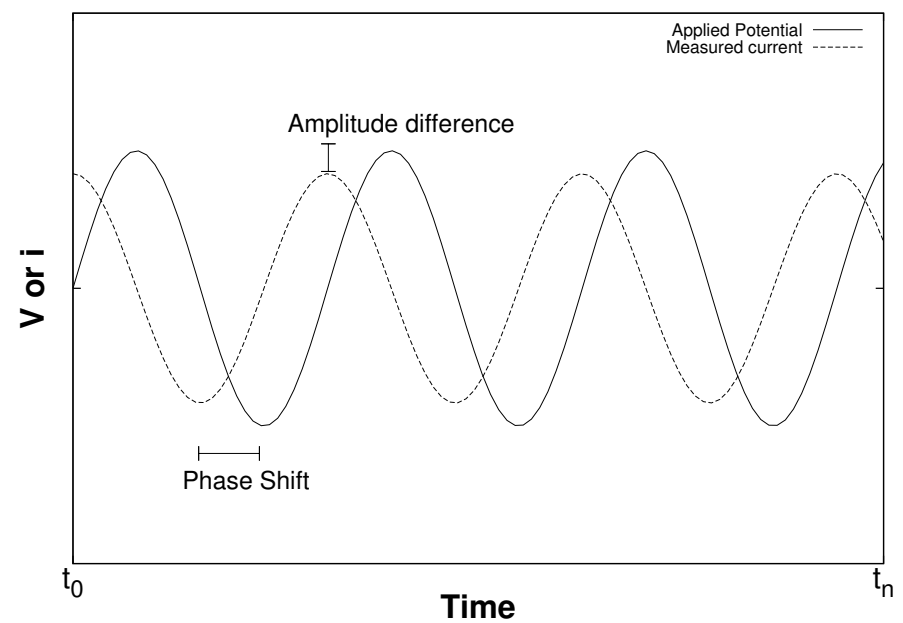

Figure 2.4 Example of current respond during impedance spectroscopy to illustrate phase shift and magnitude.

To do so, complex exponentials will be introduced. $Z$ can now be written in complex number notation as

$$
z=x+j y
$$

where $x$ corresponds to the real part and with

$$
j=\sqrt{-1}
$$

$y$ being the imaginary part one can re-write

$$
\begin{aligned}
& E(t)=E_{m} * e^{j w t} \\
& I(t)=I_{m} * e^{j \phi} * e^{j w t}
\end{aligned}
$$

where $e^{j \phi}$ corresponds to the phase and $e^{j w t}$ corresponds to the rotation vector. With that now $Z$ can also be re-written again as

$$
Z=\left(\frac{E_{m}}{I_{m}}\right) * e^{-j \phi}
$$

If $Z$ has the magnitude of $|Z|$ and a phase of $\Theta$

$$
Z=|Z| * e^{j \Theta}
$$


one can proceed by applying Euler's formula to re-write $Z$ as

$$
\begin{array}{r}
Z=|Z| \cos x+|Z| j \sin x \\
Z=\operatorname{Real}(Z)+\text { Imaginary }(Z)
\end{array}
$$

The advantage of impedance spectroscopy is, that different elements (e.g. resistive, capacitive etc.) can be analyzed using the imaginary and real part of the system respond, which then can be assigned to different electrochemical phenomena. In the following part some electrical elements will be presented in a Nyquist plot (imaginary part of $|Z|$ against the real part). The Nyquist plot of a simple resistor will result in just one point in the graph since a resistor does not have any imaginary part and is not frequency dependent. The impedance for a capacitor looks different and is depicted in Figure 2.5. That shows, that a capacitor has a low impedance (imaginary) at high frequencies and a high at low frequencies. This can be explained as in Equation 2.6 where $\mathrm{C}$ is the capacitance in farad, and $Z_{C}$ is the capacitative impedance.

$$
\begin{array}{r}
I(t)=C \frac{d E(t)}{d t} \\
E(t)=E_{m} * e^{j w t} \\
d E(t) / d t=E_{m} * j w * e^{j w t} \\
I(t)=C * E_{m} * j w * e^{j w t} \\
Z_{C}=\frac{E}{I}=\frac{1}{j w C}=\frac{-j}{w C}
\end{array}
$$

The combination of these simple elements in series will produce the following impedance Nyquist plot (Figure 2.5), where $Z_{R}$ ist the impedance of the resistor. 


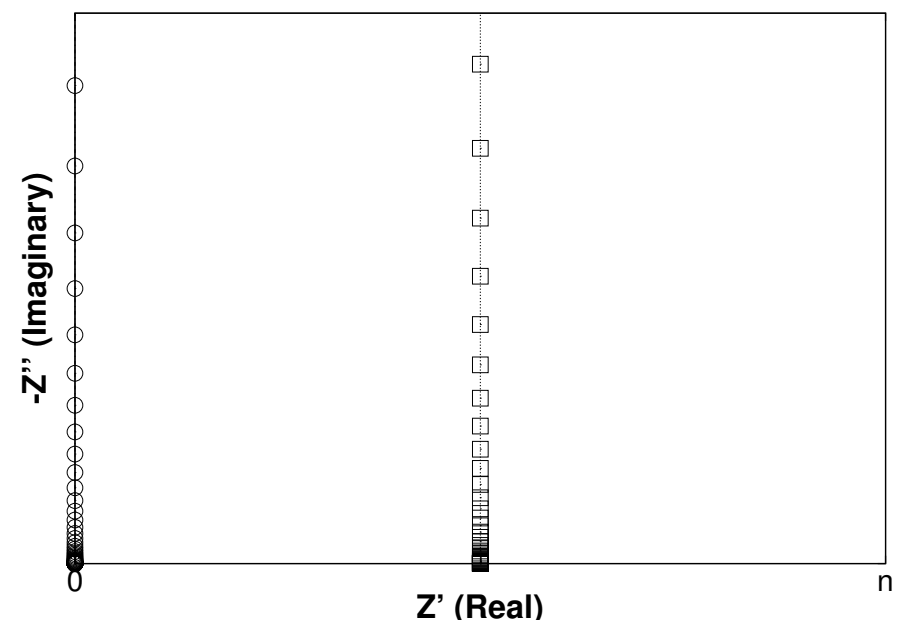

Figure 2.5 Nyquist plot of a capacitor ( $O$ ) and a circuit consisting of an $R-C$ element in series configuration ( $\square$ ).

In this case the impedances are added

$$
Z=Z_{R}+Z_{C}=R-\frac{-j}{w C}
$$

Taking an parallel R-C network we will observe this as a respond (Figure 2.6).

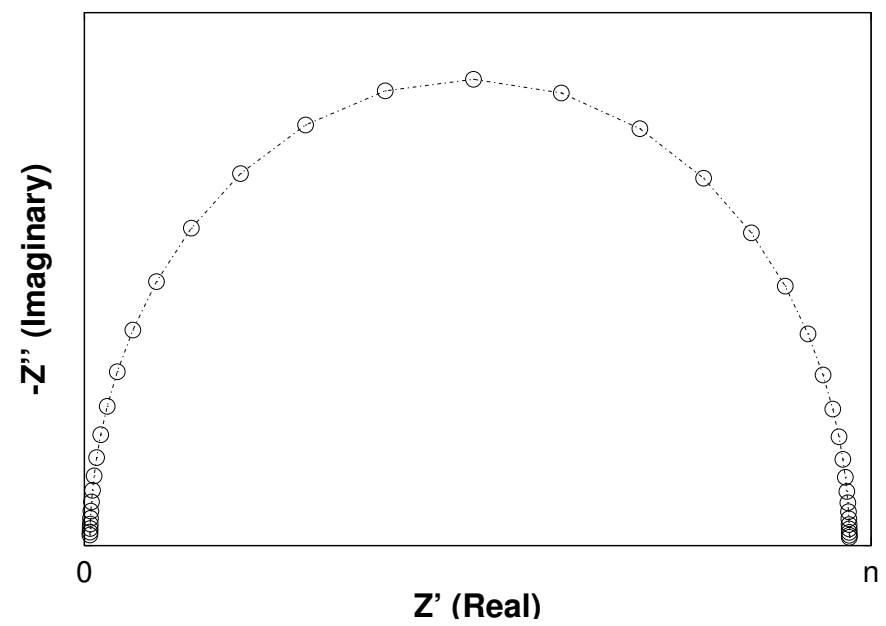

Figure 2.6 Nyquist plot of a $R$-C circuit in parallel configuration

In the upper case the analysis is, that at high frequencies the resistor is not visible, 
that means that the capacitor has such a low impedance, that the current can pass, without seeing the resistor. At low frequencies however, the current has to go through the resistor, since the impedance of the capacitor will increase, by this also the resistor can be analyzed from the circuit. For our work, we used impedance spectroscopy to determine the ionic conductivity of proton exchange membranes. The impedance of the membrane was modeled according to an equivalent circuit and the data were extracted. As a model we chose a simple model from the literature [7]. Where $R_{1}$ is the membrane resistance and $\left(R_{2} C P E_{1}\right)$ (CPE stands for constant phase element) is the time constant used to model for a non ideal electrode behavior. This nonideal behavior is mainly described by the CPE because microscopic material properties. This is for example the electrode/solid electrolyte interface, which may not be smooth, containing a large number of defects in terms of surface defects like kinks and notches.

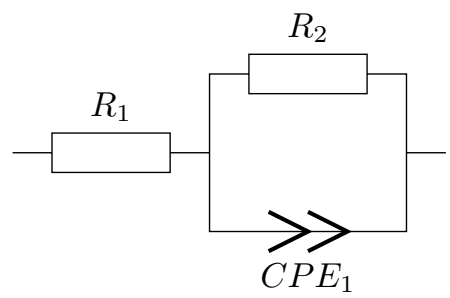

Figure 2.7 Equivalent circuit used to fit impedance data [7].

The measurements were done through plane. The membranes were first wetted in $1 \mathrm{M} \mathrm{H}_{2} \mathrm{SO}_{4}$ until no weight gain was dedected. The soaked membranes were to clamped between two inert Pt electrodes in which state a impedance measurement was performed (Figure 5.8). 


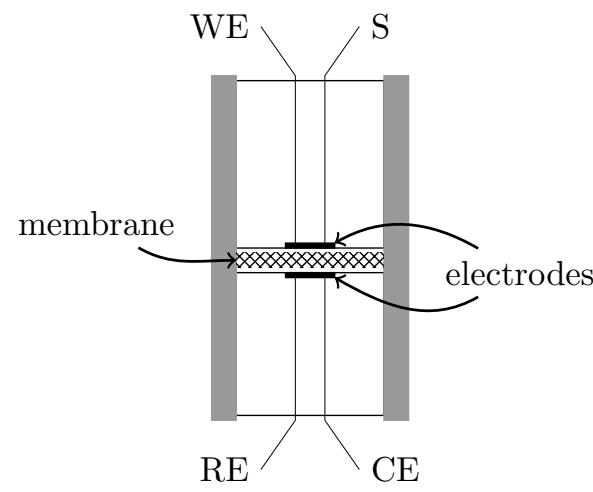

(A)

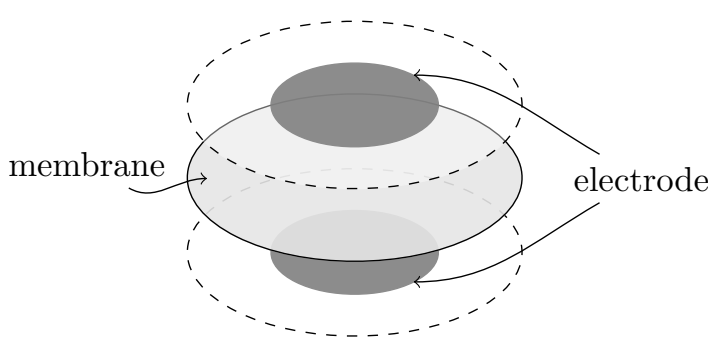

(B)

Figure 2.8 Scheme for measurement cell, the membrane is clamped between two electrodes (area $=$ $0.23 \mathrm{~cm}^{2}$ ) in a two electrode system $W E=$ working electrode, $C E=$ counter electrode, $S=$ sense electrode (second reference electrode), $R E=$ reference electrode

The conductivity was calculated in two steps (1) fitting the frequency response to the equivalent circuit to extract the membrane resistance (Figure 2.7) (2) calculating the conductivity $(\mathrm{S} / \mathrm{cm})$ from the resistance data according to Equation 5.3. Where $\sigma_{H^{+}}$is the proton conductivity in $(\mathrm{S} / \mathrm{cm}), l$ the membrane thickness in $(\mathrm{cm}), a$ the electrode area in $\left(\mathrm{cm}^{2}\right)$ and $R$ the membrane resistance in $\Omega$.

$$
\sigma_{H^{+}}=\frac{l}{a * R}
$$

\subsection{Battery Characterization}

The vanadium redox flow battery described in this thesis was investigated by galvanostatic techniques in order to determine the battery performance. Performance parameters are:

- $\eta_{V}$ in $\%$

- $\eta_{E}$ in $\%$

- $\eta_{C}$ in $\%$

- Specific energy (SE) in Wh/kg 
The voltage efficiency was calculated by Equation 2.9. This was only the case in a fast charge, slow discharge runs.

$$
\eta_{V}=\frac{V_{d i s}}{V_{c h}} * 100 \%
$$

The energy efficiency was also calculated by a numerical integration (Equation 2.10).

$$
\eta_{E}=\frac{I_{\text {dis }} * \int_{t_{0}}^{t_{n}} V_{\text {discharge }} d t}{I_{\text {ch }} * \int_{t_{0}}^{t_{n}} V_{\text {charge }} d t} * 100 \%
$$

The coulombic efficiency was calculated by Equation 2.11.

$$
\eta_{C}=\frac{t_{d i s} * I_{d i s}}{t_{c h} * I_{c h}} * 100 \%
$$

The specific energy of the vanadium electrolyte was calculated by equation 2.12 .

$$
S E=\frac{\frac{M * F}{3600} * O C P}{V * \rho} \text { in } W h / k g
$$

Where $\mathrm{M}$ is the molarity of the vanadium solution, $\mathrm{F}$ is the Faraday constant, OCP is the average open circuit potential, $\mathrm{V}$ is the volume of the vanadium solution in liter and $\rho$ in $\mathrm{kg} / \mathrm{l}$ is the density of the vanadium solution.

\section{Bibliography}

[1] Monk, P. (2005) Fundamentals of Electroanalytical Chemistry, John Wiley \& Sons Ltd.

[2] E. Barsoukov and J. R. Macdonald, (ed.) (2005) Impedance Spectroscopy, John Wiley \& Sons, Inc.

[3] Bard, A. J. and Faulkner, L. R. (2001) Electrochemical Methods Fundamentals and Applications, John Wiley \& Sons, Inc.

[4] Rand, D. and Woods, R. (1972) Journal of Electroanalytical Chemistry and Interfacial Electrochemistry 35(1), 209 - 218.

[5] Chetty, R., Xia, W., Kundu, S., Bron, M., Reinecke, T., Schuhmann, W., and Muhler, M. (2009) Langmuir 25(6), 3853-3860.

[6] Zhang, J. (2008) PEM Fuel Cell Electrocatalysts and Catalyst Layers, SpringerVerlag London.

[7] Compan, V., Riande, E., Fernandez-Carretero, F., Berezina, N., and Sytcheva, A.-R. (2008) Journal of Membrane Science 318, 255 - 263. 


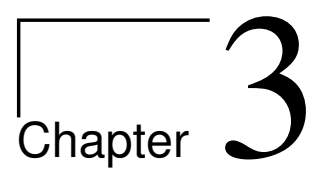

Modular Vanadium/Air Redox Flow Battery 


\subsection{Introduction}

Large scale energy storage systems have been developed during the last decade in the form of redox flow batteries based on different redox couples like Polysulfide / Polybromide (Regenesys) [1], the all vanadium system [2], the Iron-Chromium system [3] and the Zinc-Bromide system [4]. The main advantage of redox flow batteries is the uncoupling of the energy storage capability (Wh) and the power (W) generated. In this way complete freedom is generated in terms of energy storage (Wh) and power generation (W). So far, redox flow batteries were always developed for stationary applications since the specific energy $(\mathrm{Wh} / \mathrm{kg}$ ) of the existing redox flow batteries is too low to be of any meaning for mobile applications. The reason is that for the commercially available redox flow batteries always two solutions are needed, Vanadium-RFB. Current development of energy storage systems like Li-ion and NiMH batteries have led to much larger values for the specific energy namely in the order of $200 \mathrm{Wh} / \mathrm{kg}$ for Li-ion batteries. Although the specific energy of these Li-ion systems has now reached the long term goal of the United States Advanced Battery Consortium (USABC), a large market introduction for electric vehicles has not yet been realized due to several remaining challenges.

It would be of interests to develop a redox flow battery with a reduced weight where one redox couple is replaced by a gaseous system. Here we introduce the Modular Vanadium/Air Redox Flow Battery (Modular Vanadium/Air-RFB) using on one side an aqueous solution of $2 \mathrm{M} \mathrm{V}^{2+} / \mathrm{V}^{3+}$ in $3 \mathrm{M} \mathrm{H}_{2} \mathrm{SO}_{4}$ and on the other side the $\left(\mathrm{O}_{2}\right) / \mathrm{H}_{2} \mathrm{O}$ couple. We focused in particular on the preparative and technical details of the MEA development. The reactions during charging and discharging are presented by Equation (3.2) and Equation (3.1), respectively.

$$
\begin{aligned}
2 \mathrm{H}_{2} \mathrm{O} & \rightarrow 4 \mathrm{H}^{+}+\mathrm{O}_{2}+4 e^{-} \\
4 V^{3+}+4 e^{-} & \rightarrow 4 V^{2+} \\
4 \mathrm{H}^{+}+\mathrm{O}_{2}+4 e^{-} & \rightarrow 2 \mathrm{H}_{2} \mathrm{O} \\
4 V^{2+} & \rightarrow 4 V^{3+}+4 e^{-}
\end{aligned}
$$

The Modular Vanadium/Air-RFB open circuit potential is calculated by the redox potentials of the half cell reactions and is presented by Equation(3.3).

$$
\begin{aligned}
& E_{(R F B)}=E_{(\text {water/oxygen })}^{0}-E_{\left(V^{2+/ 3+}\right)}^{0} \\
& E_{(R F B)}=1.23 \mathrm{~V}-(-0.26 \mathrm{~V}) \\
& E_{(R F B)}=1.49 \mathrm{~V}
\end{aligned}
$$


Such system has never been described in the scientific literature, but was disclosed as a patent elsewhere $[5,6]$. However, the system described in $[5,6]$ has a significant drawback and does not represent a stable solution for two reasons: a) on one hand, the carbon paper electrode is not a corrosion resistant support for a bifunctional oxygen/air catalyst, indeed during charging the carbon will be oxidized (corroded) due to the evolving reactive oxygen [7], b) on the other hand platinum is a very weak catalyst for oxygen evolution with a very high overpotential for this reaction [7, 8]. Wen et al. [9, 10] described in two publications a vanadium redox flow battery system, using air for discharging. During charging raw organic materials are used, leading to a dependency of raw organic material for every charging cycle. These shortcomings in the above mentioned patents and publication, have been overcome with the improved Modular Vanadium/Air-RFB system described here. A schematic of the reactions inside the electrochemical cell of the Modular Vanadium/Air-RFB is depicted in Figure (3.1). As Figure 3.1 depicts, the system consits of only one electrochemical cell. However, the system needs to operate for charge and discharge with two different MEAs, as it is indicated by the name of the system to be a modular design.

The reason for choosing two different MEAs consisting of two different electrodes is the different morphology of both metal electrodes. During charging water will be split into oxygen, which will accumulate as excess water inside the porous structure of the electrode [11]. This highly oxygenated water will pass due to the osmotic pressure difference through the membrane to the vanadium side, where it will oxidize the $\mathrm{V}^{2+}$ back to $\mathrm{V}^{3+}$. A more porous and open structured electrode material like the titanium mesh will avoid flooding and will lead to a charging of the system without compromising the performance due to undesired oxygen transport into the vanadium solution. The advantage of the high surface area of the sintered titanium used for the discharge reaction is the relatively high current density. The MEA with the titanium mesh serves for the charging reaction to avoid $\mathrm{O}_{2}$ crossover 3.1.

\section{$3.2 \quad$ Experimental}

\subsubsection{Modular Vanadium/Air-RFB System}

In Figure (3.2) the schematic flow diagram of our Modular Vanadium/Air-RFB system is depicted. It contains three different parts: (1) the electrochemical cell, (2) the gaseous circuits and the (3) liquid circuit. This system is completely controlled 


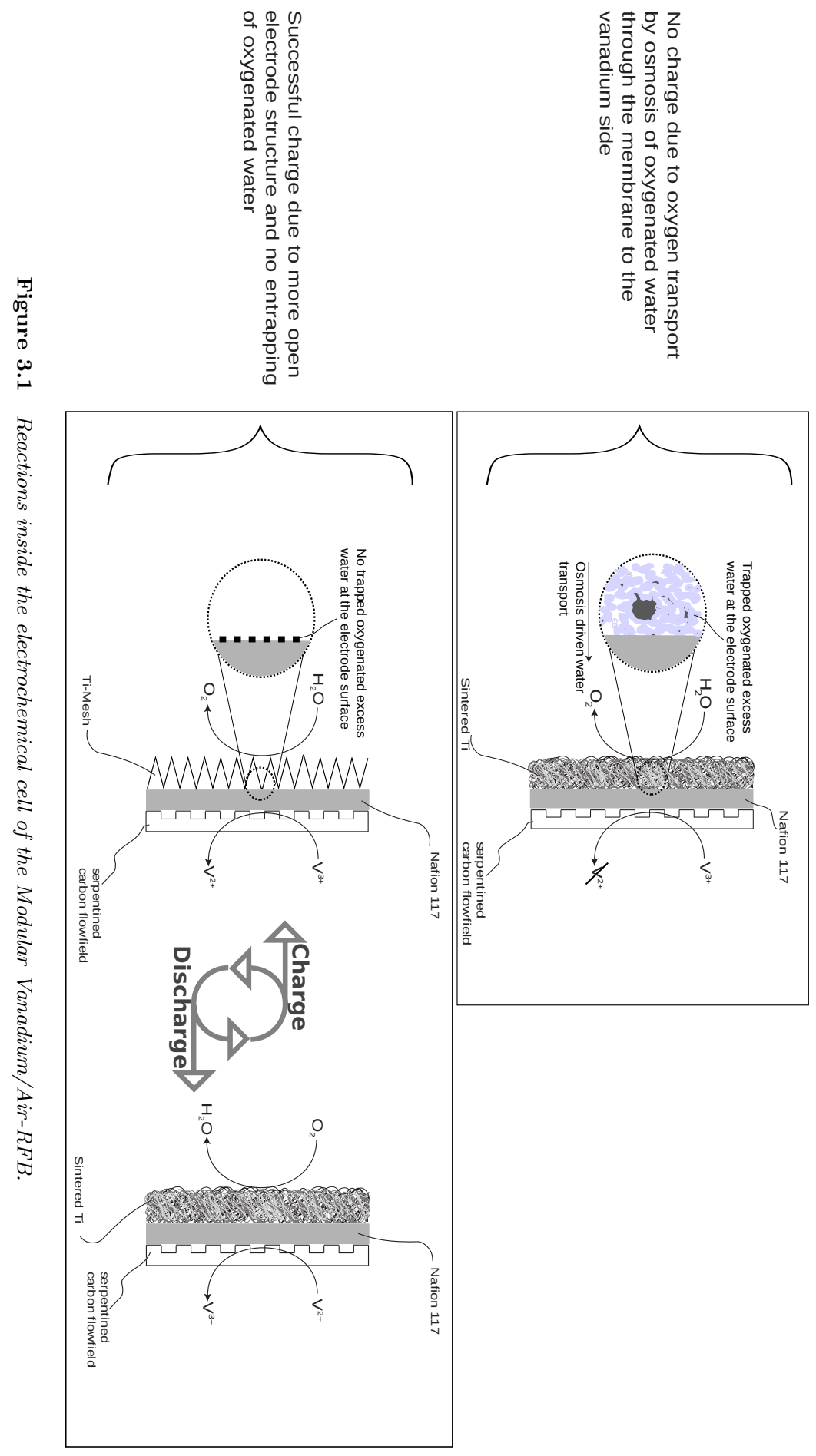


through a computer and connected to an Autolab potentiostat. As Carbon current collectors for the electrochemical cell epoxy impregnated carbon plates (MÜLLER \& RÖSSNER GmbH \& Co. KG, Germany) were used. Mass flow controllers and humidification controllers for the gaseous circuit were purchased from Bronkhorst B.V., The Netherlands. Viton(B) Tubings for the liquid circuit were purchased from Megaflex Ltd., United Kingdom. Catalyst coated electrodes were supplied by Magneto Special Anodes B.V., The Netherlands. Charging and discharging of the cell was carried out at $24 \mathrm{~A} / \mathrm{m}^{2}$ with an electrode area of $8.55 \mathrm{~cm}^{2}$. The volume of the aqueous vanadium solution was $100 \mathrm{ml}$ in total. The capacity of $100 \mathrm{ml} 2 \mathrm{M} \mathrm{V}^{2+}$ was equal to $5.36 \mathrm{Ah}$ using Faraday's law. In case of charging, the air side of the cell consisted of a MEA that was made by using a catalyst coated Ti-mesh electrode of $100 \mu \mathrm{m}$ thickness. In case of discharging, the air side of the cell consisted of a MEA that was made by using sintered $\mathrm{Ti}$ of $1.2 \mathrm{~mm}$ thickness coated with catalyst. The used catalyst was a mixed metal oxide catalyst based on $\operatorname{Pt}(70$ Mol-\%) and $\operatorname{Ir}(30 \mathrm{Mol}-\%)$. All measurements were done at $80^{\circ} \mathrm{C}$. After charging, the MEA with Ti-mesh was exchanged for the Ti-sintered electrode. This was done by pumping back the charged $\mathrm{V}^{2+}$ in its nitrogen gas controlled container. Opening the electrochemical cell and changing the titanium mesh MEA by the sintered titanium MEA made the cell ready for discharge. All tests were carried out in a controlled nitrogen atmosphere (nitrogen gas converted from liquid nitrogen in-house line) to prevent $\mathrm{V}^{2+}$ being oxidized to $\mathrm{V}^{3+}$.

\subsubsection{Vanadium Solution}

A $2 \mathrm{M}$ vanadium solution was prepared by dissolving $\mathrm{VOSO}_{4}$ (Aldrich, 99.5\%) in 3 $\mathrm{M}$ sulphuric acid. During charge and discharge the vanadium solution was circulated between reservoir and cell with a flow of $20 \mathrm{ml} / \mathrm{min}$ through the system.

\subsubsection{MEA for Charging}

For the MEA a Nafion-117 membrane was used without any post treatment. The Nafion was cut in a circular shape with a diameter of $60 \mathrm{~mm}$. For hot pressing the titanium mesh (thickness $=100 \mu \mathrm{m} ; \varnothing=33 \mathrm{~mm}$ ) electrode coated with Pt/Ir was painted on one side with a Nafion solution to ensure good adhesion between the Nafion and the Ti-mesh electrode. A $50 \mu \mathrm{m}$ aluminum spacer with the inner diameter of 33 mm was placed on top of the Membrane electrode arrangement to prevent that the electrode is pressed entirely inside the membrane during the hot pressing. The hot pressing was performed at $125^{\circ} \mathrm{C}$ under a pressure of $7.01 \mathrm{kN} / \mathrm{cm}^{2}$ for 15 minutes. 


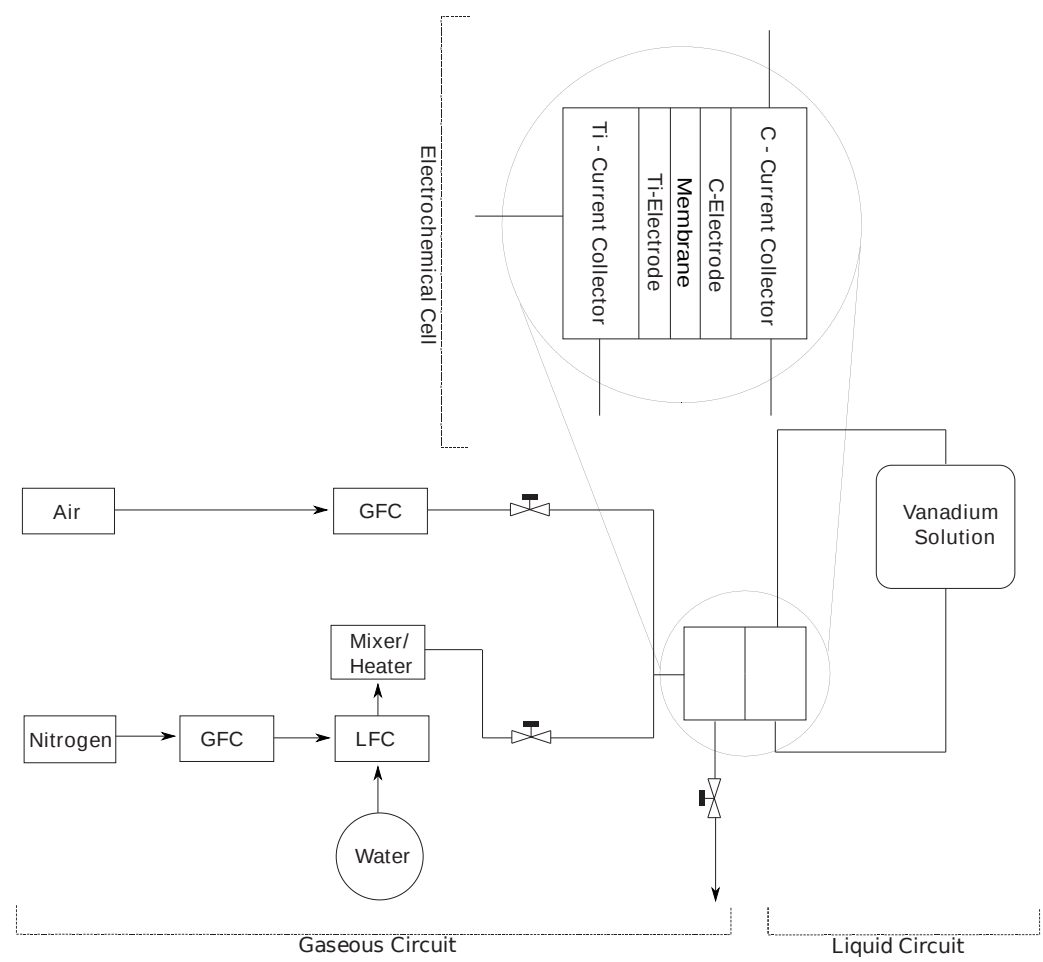

Figure 3.2 Schematic of the Modular Vanadium/Air-RFB system built at the University of Twente ( $G F C=$ Gas Flow controller; LFC=Liquid Flow Controller).

After the hot pressing the aluminium spacer was removed and the MEA was placed into the electrochemical cell for charging facing with the titanium electrode to the air side of the cell. Figure 3.3 depicts the MEA for charging, a Nafion-117 membrane hotpressed to a titanium mesh electrode. 


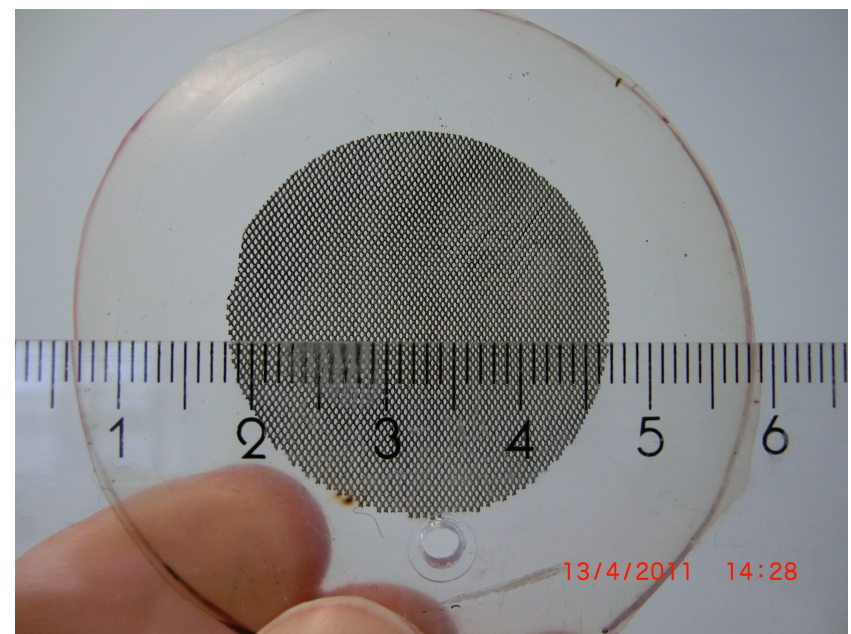

Figure 3.3 MEA for the charging procedure of the Modular Vanadium/Air-RFB, a Nafion-117 membrane hotpressed under a pressure of $7.01 \mathrm{kN} / \mathrm{cm}^{2}$ for 15 minutes to a titanium mesh (thickness $=100 \mu \mathrm{m}, \varnothing=33 \mathrm{~mm}$ ) electrode coated with Pt/Ir $(70 / 30 \mathrm{wt} \%)$.

\subsubsection{MEA for Discharging}

For the MEA a Nafion-117 membrane was used. The Nafion was cut in a circular shape with a diameter of $60 \mathrm{~mm}$. For hot pressing the sintered titanium electrode (thickness $=$ $1 \mathrm{~mm} ; \varnothing=33 \mathrm{~mm}$; porosity $=45 \%$ ) electrode coated with $\mathrm{Pt} / \mathrm{Ir}$ was painted with a Nafion solution. A $0.95 \mathrm{~mm}$ PVDF spacer with the inner diameter of $33 \mathrm{~mm}$ was placed on top of the membrane electrode arrangement for the same reason as mentioned above. The hot pressing was performed at $130{ }^{\circ} \mathrm{C}$ under a pressure of $2.34 \mathrm{kN} / \mathrm{cm}^{2}$ for 15 minutes. The pressure chosen has been set lower compared to the preparation of the charging MEA since the sintered titanium electrode would suffer from too high pressure and break under too high stress. After hot pressing the PVDF spacer was removed and the MEA was placed into the electrochemical cell for discharging facing with the titanium electrode to the air side of the cell. Figure 3.4 depicts the MEA for discharging, a Nafion-117 membrane hotpressed to a porous sintered titanium electrode, where Figure 3.5 depicts the SEM picture of the sintered titanium electrode. 


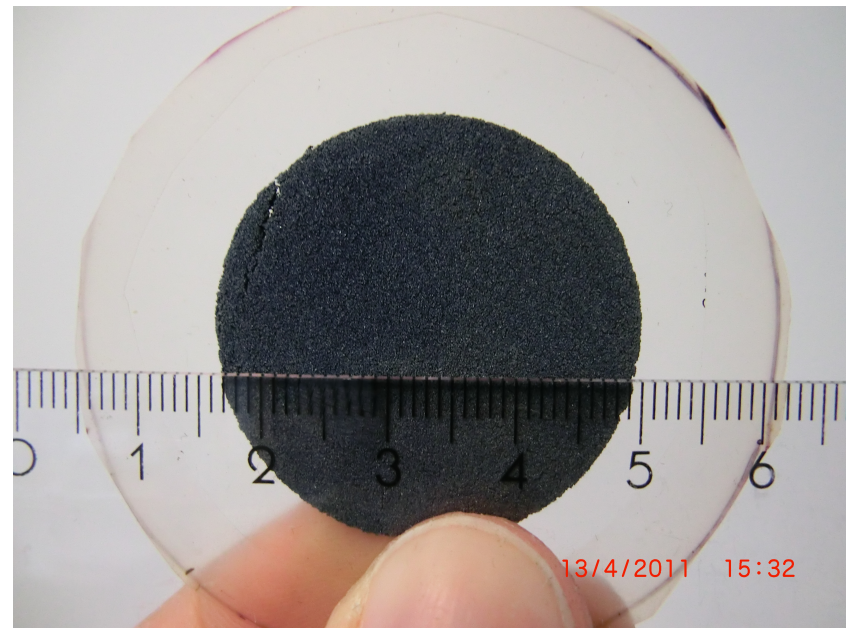

Figure 3.4 MEA for the charging procedure of the Modular Vanadium/Air-RFB, a Nafion-117 membrane hotpressed under a pressure of $2.34 \mathrm{kN} / \mathrm{cm}^{2}$ for 15 minutes to a porous sintered titanium (thickness $=1 \mathrm{~mm} ; \varnothing=33 \mathrm{~mm}$; porosity $=45 \%$ ) electrode coated with Pt/Ir (70/30 wt\%).

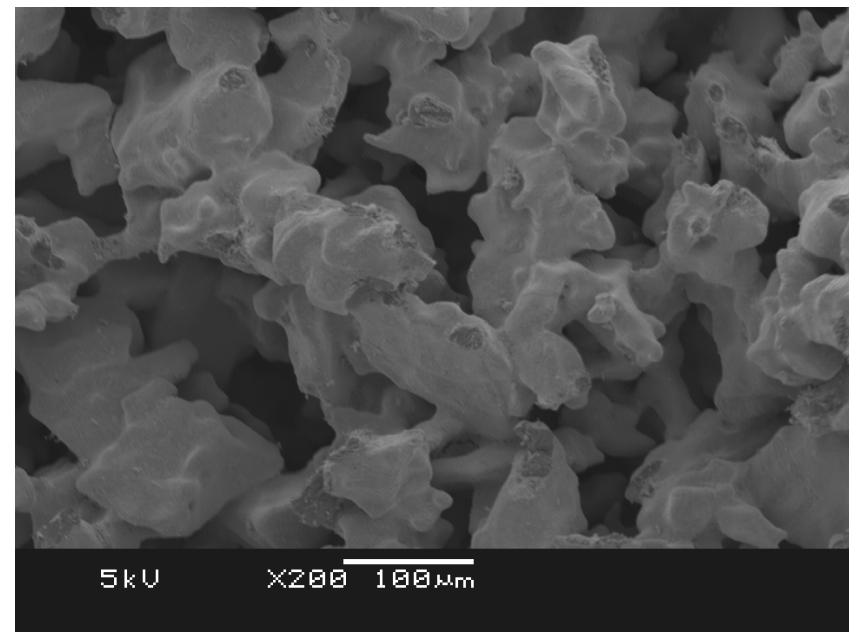

Figure 3.5 SEM picture of the sintered titanium electorde for the discharge MEA of the Modular Vanadium/Air-RFB (thickness $=1 \mathrm{~mm} ; \varnothing=33 \mathrm{~mm}$; porosity= 45\%) at a magnification of $200 X$. 


\subsection{Results and Discussions}

The open circuit voltage (OCV) of the Modular Vanadium/Air-RFB with Nafion 117 and the sintered Ti-MEA is shown Figure (3.6). The OCP of the system could not be maintained at the calculated value of $1.49 \mathrm{~V}$. A possible reason for this self-discharge might be some inlet of $\mathrm{O}_{2}$ gas in the nitrogen evacuation system. Furthermore, oxygen gas permeation through Nafion 117 can be as well a reason for the low OCP. The oxygen permeability through Nafion membranes was investigated in several studies $[12,13]$. It was observed that the oxygen permeability increases with increasing temperature. Applying a less permeable membrane material for oxygen would most likely lead to a better Modular Vanadium/Air-RFB performance.

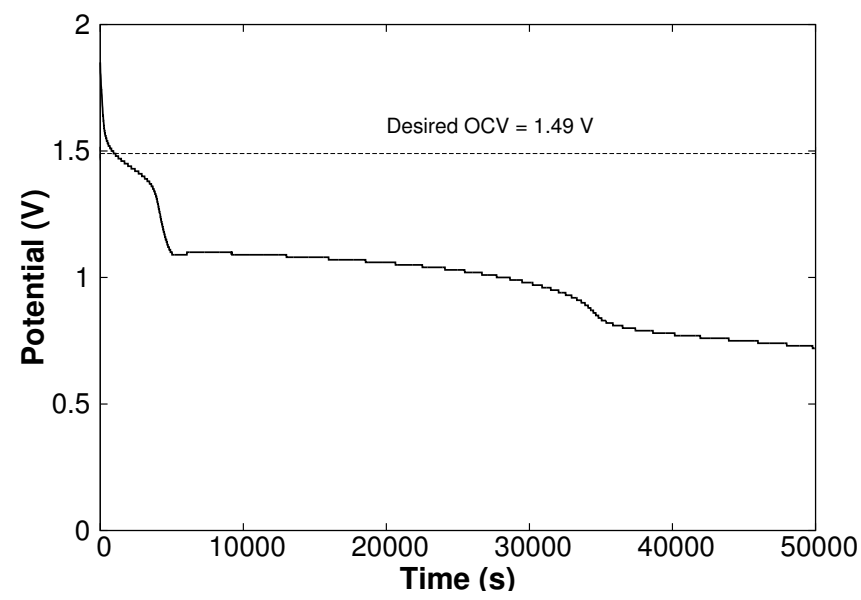

Figure 3.6 Open Circuit Potential of the Modular Vanadium/Air-RFB at $80^{\circ} \mathrm{C}$.

No vanadium crossover could be detected on the gaseous side. Figure (3.7) depicts three different charge/discharge cycles of the Modular Vanadium/Air-RFB system where the system was charged/discharged at different temperatures. These cycles are the first cycles at the given temperature and they were recorded after the cell rested for 2 hours at the given temperature. The rate capability was not determined so far for the system, but will be the focus in Chapter 4 . 


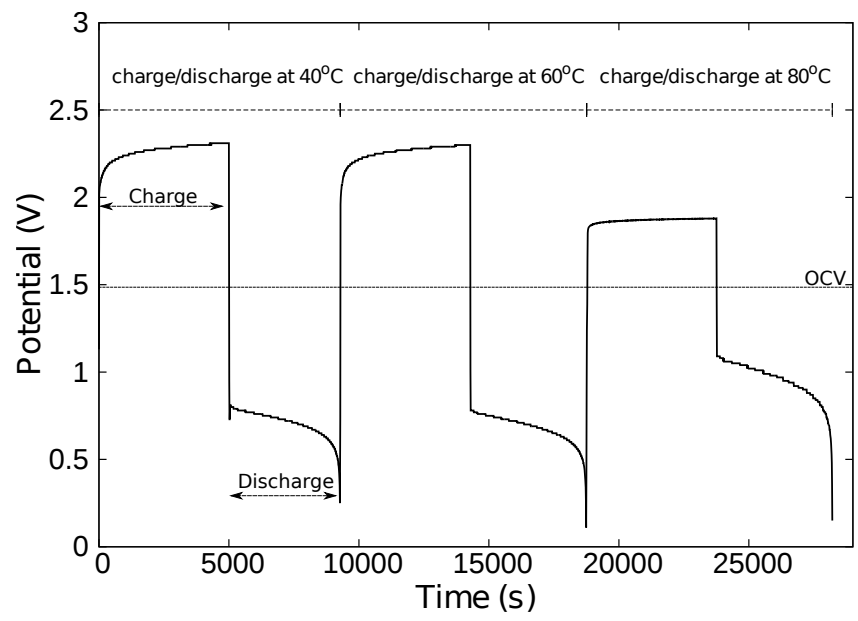

Figure 3.7 Charge-Discharge behavior of the Modular Vanadium/Air-RFB at different temperatures $\left(40^{\circ} \mathrm{C} ; 60^{\circ} \mathrm{C}\right.$ and $\left.80^{\circ} \mathrm{C}\right)$ at a charge/discharge current density of $24 \mathrm{~A} / \mathrm{m}^{2}$.

It shows that the inner voltage losses of the system are mainly due to the catalytic activity of the reversible air electrode. The voltage losses decreased by increasing the operating temperature of the system. This resulted in a better voltage efficiency due to the increase of the catalytic activity on the air side. The voltage efficiency of the Modular Vanadium/Air-RFB is calculated to be $\eta_{V}=46 \%$ for the current Modular Vanadium/Air-RFB system. The energy efficiency calculated for the data presented in Figure (3.7) is $\eta_{E}=26.67 \%$ for $40{ }^{\circ} \mathrm{C}, \eta_{E}=27 \%$ for $60{ }^{\circ} \mathrm{C}$ and $\eta_{E}=45.66 \%$ for $80{ }^{\circ} \mathrm{C}$, where the corresponding couloumb efficiencies are $\eta_{C}=85.4 \%$ for $40{ }^{\circ} \mathrm{C}, \eta_{C}=$ $89.58 \%$ for $60{ }^{\circ} \mathrm{C}$, and $\eta_{C}=89.36 \%$ for $80{ }^{\circ} \mathrm{C}$. These values show a slight decrease in couloumbic efficiency at higher temperatures indicating, that at higher temperatures more oxygen may pass through the membrane leading to a slight self discharge of the battery. The oxygen permeability of Nafion was reported elsewhere [12], to increase with increasing temperature. For the known and well studied all vanadium redox flow batteries voltage efficiencies of $91.6 \%$ and a energy efficiency up to $90 \%$ [14] at a current density of $3 \mathrm{~A} / \mathrm{cm}^{2}$ were reported. The comparatively low voltage and energy efficiency reported here can be explained by insufficient mass transfer, low catalytic activity, inner resistance and oxygen permeability through the Nafion membrane to the vanadium side. Insufficient mass transfer will occur with low pumping rates of the vanadium solution and also due to insufficient contact area between the vanadium solution and the graphite electrode. Low catalytic activities of the bi-functional air electrode are mainly due to low specific area of the catalyst at the surface of the Ti-structures. The inner resistance may increase in time due to corrosion. This has 
been observed in the current system at the titanium serpentine flow field acting as current collector, which was covered with a thin oxide layer due to the water splitting reaction while charging. However, the applied discharge current density of $24 \mathrm{~A} / \mathrm{m}^{2}$ is too low for practical applications. Therefore a new high surface area and a highly active catalyst material needs to be developed.

\subsection{Conclusion}

A new membrane electrode assembly and process is described for a Vanadium/Air Redox Flow Battery. First experiments resulted in a voltage efficiency of $46 \%$. The system showed stable behavior during charge and discharge, although the voltage losses and the ohmic losses of the system need to be decreased in order to increase the voltage efficiency. This can be done by increasing the oxidation stability of the Ti-flow field on the gaseous circuit, higher pumping rates of the vanadium redox couple solution and improving the cell design. The Modular Vanadium/Air-RFB has the potential to be an environmental friendly and viable solution to store energy efficiently in the future. The specific energy of such a system applying a discharge potential of 1 Volt with one liter of $2 \mathrm{M}$ vanadium solution will be equal to 41.2 $\mathrm{Wh} / \mathrm{kg}$, being higher than e.g. lead-acid [15] and all vanadium redox flow battery (3 M vanadium solution) $[16,17]$. The system costs will depend on the catalyst price in particular. However, compared with fuel cell technology the amount of the needed catalyst could already be decreased by half, since only the reversible air side requires a catalyst. The vanadium couple $\mathrm{V}^{2+/ 3+}$ is already reversible at graphite. Furthermore new, non-noble catalyst could decrease the system costs further.

\section{Bibliography}

[1] Price, A., Bartley, S., Male, S., and Cooley, G. (1999) Power Engineering Journal 13(3), 122-129.

[2] Skyllas-Kazacos, M., Rychick, M., and Robins, R. (1988) US Patent 4,786,567.

[3] Hagedorn, N. and Thaller, L. Design flexibility of redox flow systems Technical Report TM-82854, DOE/NASA/12726-16 NASA (1982).

[4] Lex, P. and Jonshagen, B. (1999) Power Engineering Journal 13(3), 142 -148. 
[5] Hiroko, H., Negishi, A., Nozaki, K., Sato, K., and Masato, N. (1997) European Patent $51721 \%$.

[6] Hiroko, H., Negishi, A., Nozaki, K., Sato, K., and Nakajima, M. (1994) US 5318865 .

[7] Swette, L. L., LaConti, A. B., and McCatty, S. A. (1994) Journal of Power Sources 47(3), $343-351$.

[8] Jörissen, L. (2006) Journal of Power Sources 155(1), 23 - 32.

[9] Wen, Y., Cheng, J., Xun, Y., Ma, P., and Yang, Y. (2008) Electrochimica Acta 53(20), $6018-6023$.

[10] Wen, Y., Cheng, J., Ma, P., and Yang, Y. (2008) Electrochimica Acta 53(9), $3514-3522$.

[11] Shibata, S. (1978) Electrochimica Acta 23(7), 619 - 623.

[12] Broka, K. and Ekdune, P. (1997) Journal of Applied Electrochemistry 27, 117123.

[13] Zhang, L., Ma, C., and Mukerjee, S. (2003) Electrochimica Acta 48(13), 1845 1859.

[14] Skyllas-Kazacos, M., Kasherman, D., Hong, D., and Kazacos, M. (1991) Journal of Power Sources 35(4), 399 - 404.

[15] Martha, S., Hariprakash, B., Gaffoor, S., Trivedi, D., and Shukla, A. (2006) Journal of Chemical Sciences 118(1), 93-98.

[16] Skyllas-Kazacos, M. (2003) Journal of Power Sources 124(1), 299-302.

[17] Rydh, C. J. and Sandén, B. A. (2005) Energy Conversion and Management 46(11-12), 1957-1979. 
chaper 4

Unitized Vanadium/Air Redox Flow

Battery 


\subsection{Introduction}

Chapter 3 describes a Modular Vanadium/Air Redox Flow Battery (Modular Vanadium/Air-RFB). It is a modular concept since charging and discharging needs to be done with different MEAs. It would be desirable to have a unitized Vanadium/AirRFB in which only one membrane electrode assembly (MEA) is used for charging as well as discharging. Due to that the Modular Vanadium/Air-RFB needs to undergo certain improvements in system design and material choice to increase the efficiency. Furthermore the Modular Vanadium/Air-RFB needs to be unitized to decrease the complexity of the system. Therefore the Unitized Vanadium/Air Redox Flow Battery (Unitized Vanadium/Air-RFB) is described in this chapter (Figure 4.1).

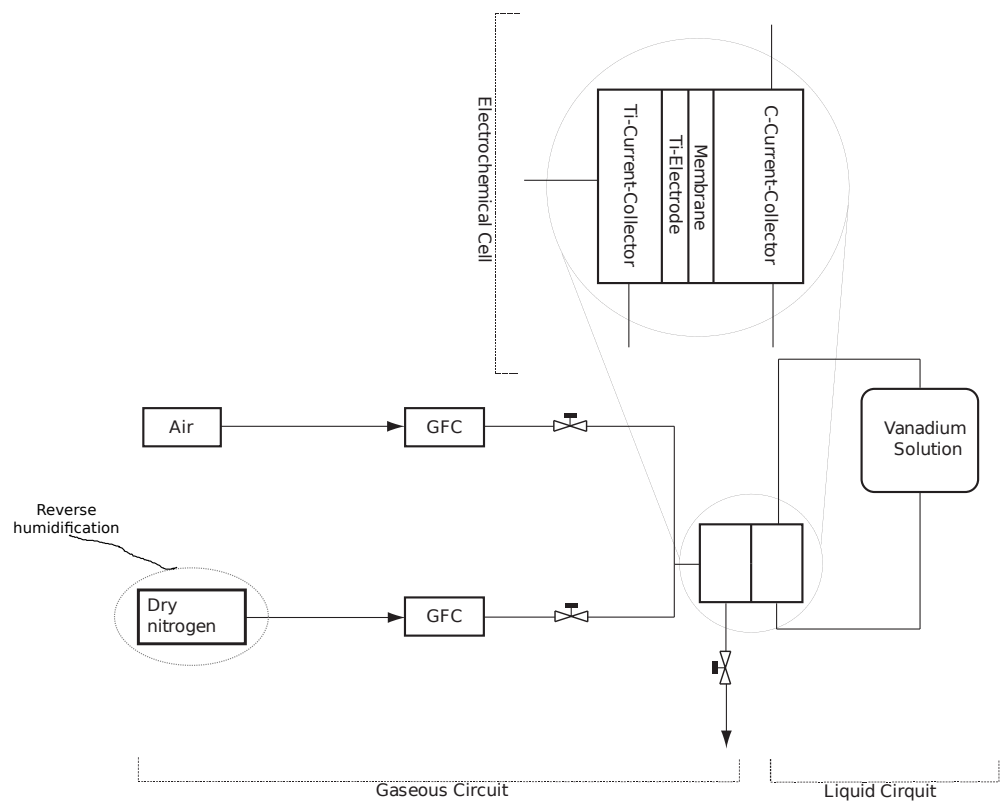

Figure 4.1 Schematic of the Unitized Vanadium/Air-RFB system built at the University of Twente, applying the reverse humidification principal ( $G F C=$ Gas Flow controller).

Following requirements have to be fulfilled: a) restriction of oxygen contamination of the vanadium side and b) suitable electrocatalytical electrodes with high surface area and an efficient catalyst for the bidirectional reactions (water oxidation and oxygen reduction).

Oxygen contamination affects the Vanadium/Air-RFB performance drastically. $\mathrm{V}^{2+}$ which is produced during the charge will be rapidly oxidized by any oxidizing 
agent (oxygen) back to $\mathrm{V}^{3+}$. In order to prevent oxidation of $\mathrm{V}^{2+}$ to $\mathrm{V}^{3+}$ the source of oxygen contamination has to be observed. The oxygen contamination can either happen in-situ, across the membrane from the air side to the vanadium side) or ex-situ. The ex-situ oxygen contamination was eliminated already in the Modular Vanadium/Air-RFB by a nitrogen blanket on the whole system. However, the source for the in-situ oxygen contamination is presented by the water oxidizing reaction for charge and the oxygen reduction reaction used for discharge of the system. During charging water will be oxidized into protons and oxygen gas (Equation 3.1). The produced oxygen will be accumulated directly in the water on the electrode surface. It has been reported [1] that this water can reach oxygen saturation 70 times higher than water at RT and 1 atm. Thus oxygen saturated water will permeate due to osmosis through the polyelectrolyte membrane to the vanadium side, hampering the reduction of $\mathrm{V}^{3+}$ to $\mathrm{V}^{2+}$ required for charging the system. Due to that the Modular Vanadium/Air-RFB was equipped with different MEAs using a very open structured titanium mesh electrode $3.3(100 \mu \mathrm{m}$ thick) for charging. The open structure should prevent the water accumulation inside the electrode pores and its saturation by oxygen. However, this electrode showed low surface area and was therefore unsuitable for the discharge reaction. For discharging a sintered porous titanium felt was used with a high surface area (Figure 3.4) with a thickness of $1 \mathrm{~mm}$ and a porosity of $\sim 45 \%$. Although exhibiting a high surface area, this electrode showed to be unsuitable for the charge reaction since water accumulates from the gas phase inside the electrode structure and become saturated with oxygen leading to a low efficiency during charging. Concluding, an increase of surface area for the charge reaction without suffering from the oxygen contamination during charge would increase the system efficiency and lead to a system with only one electrode.

Here, in this chapter, the design of a new MEA in the Unitized Vanadium/Air-RFB having a thinner electrode with a high surface area is discribed. By the decreased thickness, water can be transported by a dry gas stream along the electrode from the pores restricting the osmosis of oxygen saturated water. Figure 4.2 depicts the SEM pictures of the high surface area A) sintered porous titanium felt for the discharge operation of the Modular Vanadium/Air-RFB and B) sintered porous titanium cloth for charge/discharge operation of the Unitized Vanadium/Air-RFB. Figure 4.2 shows the cross section of the electrodes at the same magnification (200X). It can be seen, that the sintered porous titanium felt consists of bridged grain like structure. In contrast the sintered porous titanium cloth consists of random merged titanium fibers. These properties also influence the mechanical stability regarding to the thickness. 

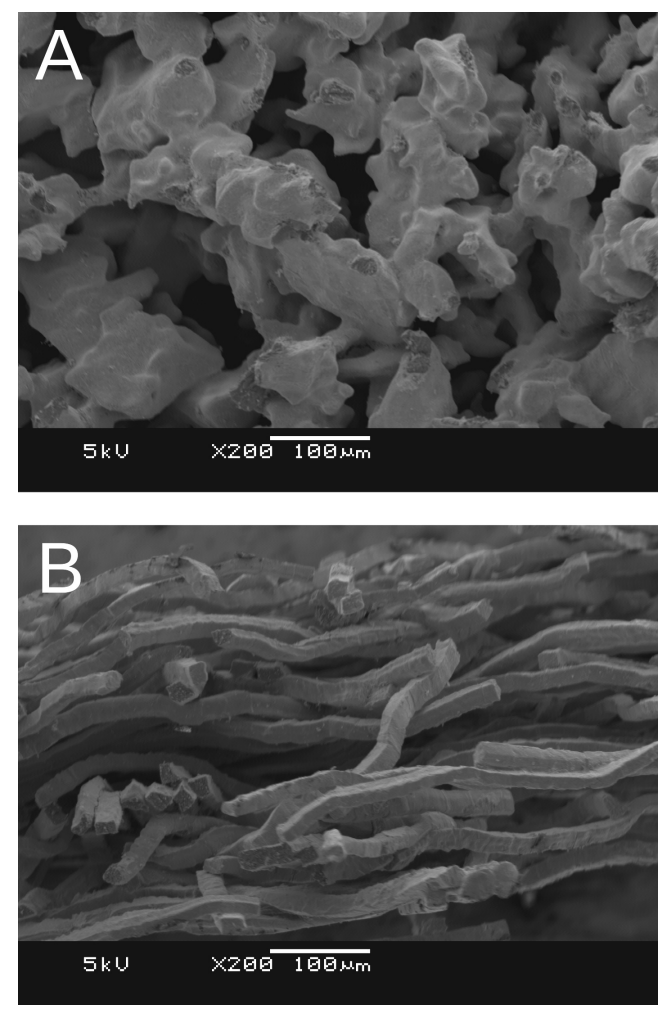

Figure 4.2 SEM pictures of high surface area A) sintered porous titanium felt for the discharge operation of the Modular Vanadium/Air-RFB (minimum stable thickness $=0.7 \mathrm{~mm}$, sintered titanium) and B) sintered porous titanium cloth for charge/discharge operation of the Unitized Vanadium/Air-RFB (minimum stable thickness $=0.25 \mathrm{~mm}$, sintered titanium felt ).

The titanium felt could only be thinned down by electric discharge machining to a minimum thickness of $0.7 \mathrm{~mm}$ without suffering of mechanical instability. The fully flexible titanium cloth on the other hand could be delivered already with a thickness of $0.25 \mathrm{~mm}$ (Bekaert, Japan). This made the titanium cloth a suitable electrode for a MEA applied in the Unitized Vanadium/Air-RFB to decrease the system complexity by using only one MEA and to increase the efficiency by increasing the surface area of the electrode for charging.

To decrease the contamination risk of oxygen saturated water, yet another measure was taken. Therefore, the water supply during charging on the air side was disabled. That means that only dry nitrogen gas was flushed through the half cell during charging. By this, the direction of water permeation was reversed (from the vanadium side 
to the air side).

However, oxygen permeation can also occur during the discharge, where only air is applied at the gaseous circuit to be reduced at the electrode as a counter reaction for the vanadium oxidation on the liquid side. Here oxygen reduction happens at the platinum/iridium catalyst requiring a temperature $>70^{\circ} \mathrm{C}$ in order to be efficient. However, at elevated temperatures however, the oxygen permeability of Nafion will increase [2], leading to a cross-over of oxygen to the vanadium side. To limit the oxygen cross-over, the temperature at the vanadium side was decreased to room temperature. Yet, Nafion is as a polymer material a poor heat conductor. Due to that the vanadium side was cooled down to room temperature to lower the oxygen permeability of the membrane and to stabilize the system. In the following, we present the results obtained by the Unitized Vanadium/Air-RFB system.

\subsection{Experimental}

\subsubsection{Membrane Electrode Assembly (MEA)}

For the MEA, a Nafion-117 membrane was used without any post treatment. The Nafion was cut in a circular shape with a diameter of $60 \mathrm{~mm}$. For hot pressing the $0.25 \mathrm{~mm}$ titanium felt (Bekaert, Japan; $\varnothing=33 \mathrm{~mm}$ ) electrode coated with Pt/Ir was wetted on one side with a Nafion solution to ensure good adhesion between the Nafion membrane and the Ti felt electrode. A $100 \mu \mathrm{m}$ aluminum spacer with inner diameter of $33 \mathrm{~mm}$ was placed on top of the membrane electrode arrangement to prevent that the electrode is pressed entirely inside the membrane during the hot pressing. The hot pressing was performed at $125^{\circ} \mathrm{C}$ under a pressure of $7.01 \mathrm{kN} \mathrm{cm}{ }^{2}$ for 15 minutes. After the hot pressing the aluminum spacer was removed and the MEA was placed into the electrochemical cell for charge discharge cycles.

\subsubsection{Unitized Vanadium/Air-RFB Operation Conditions}

For the Unitized Vanadium/Air-RFB experiments $100 \mathrm{ml}$ of a 1 molar $\mathrm{VOSO}_{4}$ solution was used, except if differently mentioned. The flow rate of the vanadium solution was set to $50 \mathrm{ml} / \mathrm{min}$. In order to improve the stability and the performance of the Vanadium/Air-RFB several measures were taken along the choice of the titanium cloth as electrode material. These are a) the reversed humidification of the MEA b) operation of the system at room temperature for the aqueous vanadium side. 


\subsection{Results and Discussions}

The OCV of the Unitized Vanadium/Air-RFB reached a stable value over 50 hours of 1.2 V (Figure 4.3), in contrast to the the instable OCV of the Modular Vanadium/AirRFB [3]. As in the Modular Vanadium/Air-RFB, the unstable OCV was due to the

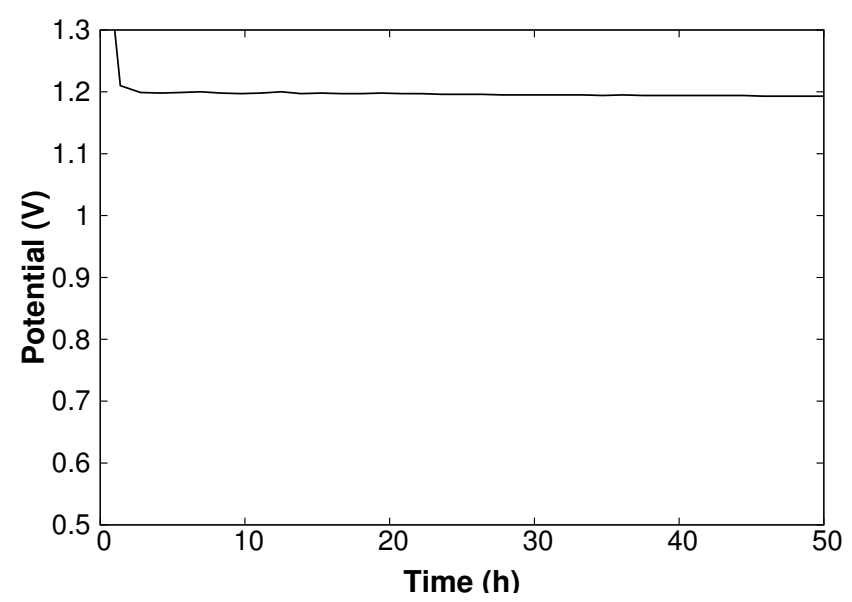

Figure 4.3 Open circuit potential of the Unitized Vanadium/Air-RFB of a charged 1 molar vanadium solution ( $T_{\text {vanadium side }}=R T, T_{\text {air }}$ side $\left.=80^{\circ} \mathrm{C}\right)$.

oxygen contamination (in-situ but also ex-situ [3]). The reverse humidification allowed no oxygen saturated water to pass the membrane from the air side to the vanadium side. This is due to the low humidity on the air side, which forces the water permeation from the vanadium side to the air side. Also the operation of the vanadium side without heating the solution has probably influenced the attempts to decrease the oxygen crossover through the Nafion membrane positively. This enabled a stable OCV.

Figure 4.4 depicts the potential-time discharge cycles at different current densities. 


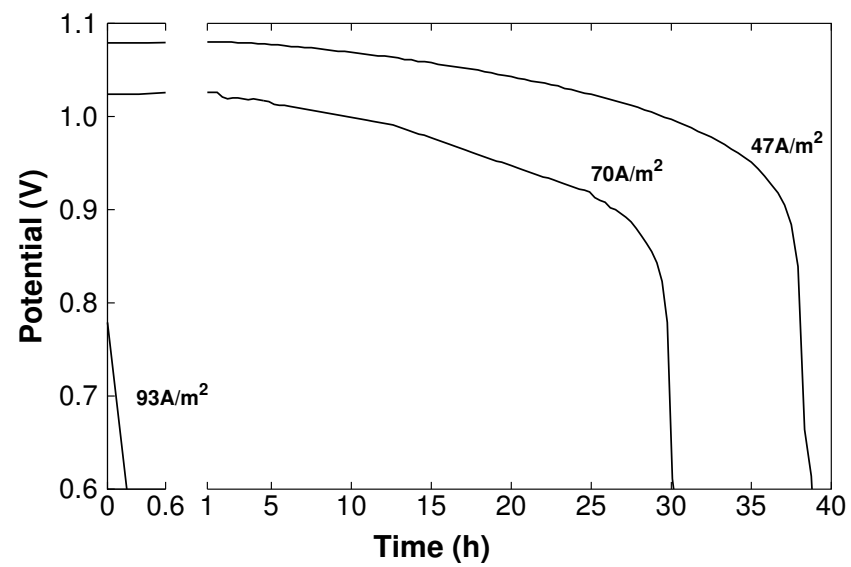

Figure 4.4 Discharge behavior of the Unitized Vanadium/Air-RFB at different current densisties. The value for the discharge current density of $47 \mathrm{~A} / \mathrm{m}^{2}$ has been measured for $70 \mathrm{ml}$ of a 1 molar solution. Theoretical values for the different discharge current densities are: $47 \mathrm{~A} / \mathrm{m}^{2}=\sim 47$ hours, $70 \mathrm{~A} / \mathrm{m}^{2}=\sim 44$ hours, and $93 \mathrm{~A} / \mathrm{m}^{2}=\sim 33$ hours.

Here the best performing discharge behavior was observed under a discharge current density of $47 \mathrm{~A} / \mathrm{m}^{2}$ with a theoretical discharge time of 47 hours (70 ml of 1 molar $\mathrm{VOSO}_{4}$ ). For the discharge current density of $93 \mathrm{~A} / \mathrm{m}^{2}$ (with a theoretical discharge time of 33 hours for $100 \mathrm{ml}$ of 1 molar $\mathrm{VOSO}_{4}$ ), a drastic decline of the potential could be observed. This behavior is probably due to two reasons 1) electrode flooding 2) insufficient catalytic activity towards oxygen reduction. The effect of electrode flooding in the Unitized Vanadium/Air-RFB was not monitored but the system behavior shows the same characteristics as an electrode flooding in the field of Proton Exchange Membrane Fuel Cells (PEMFC). In PEMFCs, water produced by the reduction of oxygen will, accumulate in the porous electrode structure resulting in a voltage brake down as in the case of the Unitized Vanadium/Air-RFB (Figure 4.4). The second reason might be the catalytic activity towards the oxygen reduction reaction (ORR). This can be assumed, since ORR is well known to be sluggish [4].

For the all vanadium redox flow battery typical discharge current densities of up to $400 \mathrm{~A} / \mathrm{m}^{2}$ are reported $[5,6,7]$. For that the values achieved with the Unitized Vanadium/Air-RFB need to be improved in order to compete with commercial storage systems in terms of rate capability. In order to improve the rate capability, three factors have to be enhanced. These are a) the activity of the bifunctional catalyst b) the mass transfer on both sides where in this work the mass flows had been set to the set up specific maxima c) the water management of the air side. Regarding to 
the activity of the catalyst, it has to be pointed out that the activity for the oxygen reduction reaction has to be improved drastically. During discharge of the system, oxygen will be reduced on the air side. However, not only the discharge current density is of great importance, but also the charge current density. Charging at high current densities (fast charging) is important in order to investigate the ability of such a system being used in an application like electrical vehicles. But also for stationary applications used for power plants, where high charge current densities require a stable system. Table 4.1 depicts the optimum charging current density. This has been monitored by the OCV value after charging.

Table 4.1 OCV after charging at different current densities for the calculated theoretical charging time.

\begin{tabular}{cc} 
Charging current density $\left(\mathrm{A} / \mathrm{m}^{2}\right)$ & $\mathrm{OCV}(\mathrm{V})$ \\
\hline \hline 140 & 1.19 \\
163 & 1.17 \\
187 & 1.17 \\
210 & 1.14 \\
233 & 1.10 \\
\hline
\end{tabular}

It has been observed, that the charging current density of the Unitized Vanadium/AirRFB strongly influenced the state of charge of the system and with that the OCV. A high charge current density results in an increased oxygen evolution at the anode. This consequently leads to a high concentration of oxygen at the membrane electrode interface, which increases the oxygen cross over to the vanadium side. Although the reverse humidification has improved the system performance and the ability of using an electrode with an increased surface area, the issue of the oxygen permeation seem to appear at a given current density. Furthermore parasitic side reaction like hydrogen evolution will take place at higher charging current densities which will also decrease the OCV.

In order to test the system on fast charging ability a charging current density of 187 $\mathrm{A} / \mathrm{m}^{2}$ was chosen, which is compared with the Modular Vanadium/Air-RFB $\sim 8$ times higher. In Figure 4.5 the fast charging and slow discharge cycles are depicted. 


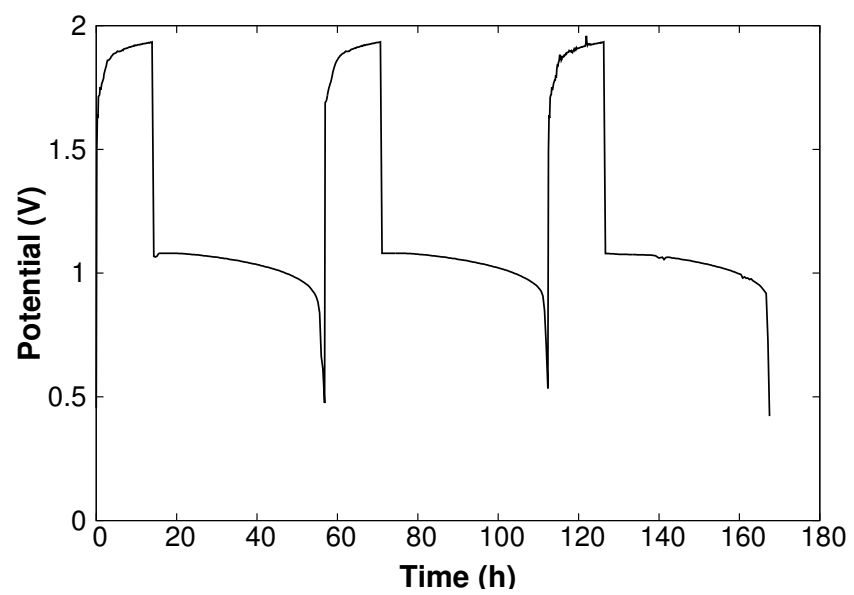

Figure 4.5 Fast charging $\left(187 \mathrm{~A} / \mathrm{m}^{2}\right)$ slow discharging $\left(47 \mathrm{~A} / \mathrm{m}^{2}\right)$ cycles of the Unitized Vanadium/Air-RFB (1 $\mathrm{MVOSO}_{4}$ solution) at room temperature.

As can be seen, the system is able to deal with fast charging, achieving comparable $\eta_{E}$ and $\eta_{E}$ as the Modular Vanadium/Air-RFB which were achieved under lower current densities. For energy storage applications in which charging and discharging current densities are of secondary importance, the Unitized Vanadium/Air-RFB is a promising candidate. The system behavior for such a scenario in which low charge/discharge current densities are applied, is depicted in Figure 4.6. Such an operation mode results in a $\eta_{E}$ of $81 \%, \eta_{V} 81 \%$ and $\eta_{C}$ of $85 \%$. The small inflexion during charging may be due to an uneven heat distribution on the air side, or the presence of $\mathrm{VO}^{2+}$. Attempts to find the cause of this behaviour were not made at this point. 


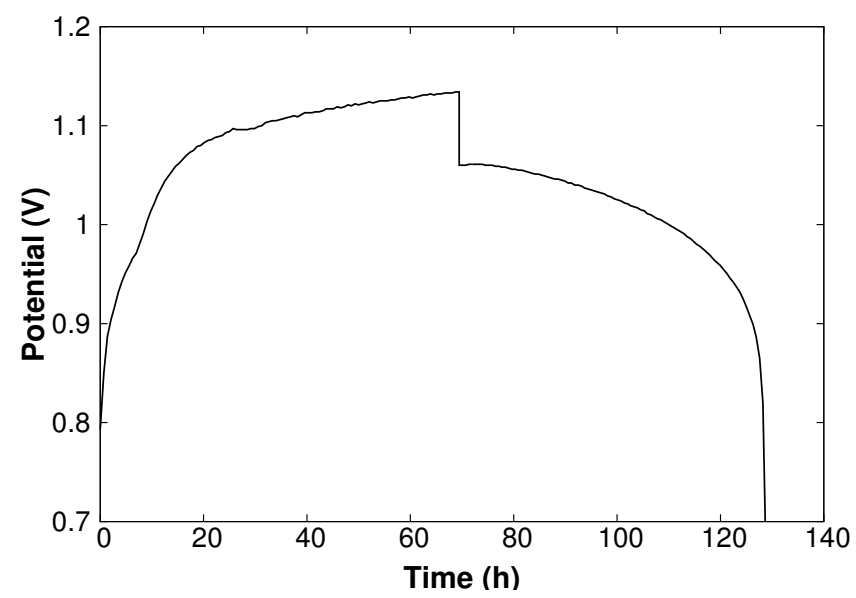

Figure 4.6 Unitized Vanadium/Air-RFB charged and discharged at the same current density (47A/m $\mathrm{m}^{2}$ at room temperature for a $1 \mathrm{MVOSO}_{4}$ solution).

Taking into account the obtained results by the modification of the Modualr Vanadium/Air-RFB system to the Unitized Vanadium/Air-RFB, one can assume that the air side depicts the most challenging compartment of the Unitized Vanadium/AirRFB in terms of a) water management b) catalytic activity towards ORR c) oxygen management. Furthermore the optimization of mass transfer on the vanadium side and the system monitoring in terms of state-of-charge requires as well further work which can be achieved by integration of a reference electrode in the liquid side. However, already now the Unitized Vanadium/Air-RFB presents a potential system which may compete in the future in terms of efficiency and flexibility with many other systems like all vanadium redox flow battery, methanol fuel cells and unitized regenerative fuel cells.

\subsection{Conclusion}

A Unitized Vanadium/Air-RFB was developed by optimization of the operation conditions as well the improvement of the MEA. The new system, entitled as the Unitized Vanadium/Air-RFB reached an $\eta_{E}$ of $81 \%, \eta_{V}$ of $81 \%$ and a $\eta_{C}$ of $85 \%$ for a charge/discharge current density of $47 \mathrm{~A} / \mathrm{m}^{2}$. This enables the system to be, compared with the all vanadium redox flow battery, methanol fuel cells and unitized regenerative fuel cell for mobile applications. Also the charge/discharge behaviour of the system was improved drastically by using $0.25 \mathrm{~mm}$ Ti felt coated with Pt/Ir 
(70:30) and the optimization of the operation conditions, which make the system attractive to applications in which fast charge and discharge is required.

\section{Bibliography}

[1] Shibata, S. (1978) Electrochimica Acta 23, 619-623.

[2] Broka, K. and Ekdunge, P. (1997) Journal of Applied Electrochemistry 27, 117123.

[3] Hosseiny, S. S., Saakes, M., and Wessling, M. (2010) Electrochemistry Communications, DOI:10.1016/j.elecom.2010.11.025.

[4] Koper, M. T. M. (2009) Fuel Cell Catalysis: A Surface Science Approach, John Wiley \& Sons, Inc.

[5] Jia, C., Liu, J., and Yan, C. (2010) Journal of Power Sources 195(13), 4380 4383 .

[6] Qian, P., Zhang, H., Chen, J., Wen, Y., Luo, Q., Liu, Z., You, D., and Yi, B. (2008) Journal of Power Sources 175(1), 613 - 620.

[7] Chieng, S., Kazacos, M., and Skyllas-Kazacos, M. (1992) Journal of Power Sources 39(1), $11-19$. 
${ }_{\text {Chapter }}$

Crosslinked Sulphonated Poly(Ether Ether Ketone) for Redox Flow Battery Applications 


\subsection{Introduction}

Cation exchange membranes such as Nafion and sufonated polyarylethers are frequently used in fuel cell and battery applications. In any of the applications, one desires the have highly conductive and stable membranes.

In this chapter, we look at a new method to prepare sulfonated polyarylethers, that may be applicable for vanadium-based redox flow batteries. The Vanadium Redox Flow Battery (Vanadium-RFB) is an electrochemical energy storage system invented by Maria Skyllas-Kazacos in 1988 [1]. It consists of two electrochemical half cells, separated by an ion exchange membrane (Figure 1.7). Since vanadium can exist in four different oxidation states, the positive half cell employs $\mathrm{VO}^{2+} / \mathrm{VO}_{2}^{+}$where the negative half cell contains $\mathrm{V}^{2+} / \mathrm{V}^{3+}$. When the vanadium battery is charged, the $\mathrm{VO}^{2+}$ ions in the positive half-cell are converted to $\mathrm{VO}_{2}^{+}$ions when electrons are removed from the positive terminal of the battery. Similarly in the negative half-cell, electrons are introduced converting the $\mathrm{V}^{3+}$ ions into $\mathrm{V}^{2+}$. During discharge this process is reversed. Equation 5.1 und 5.2 summarize the electrochemical reactions during charging and discharging.

\section{Charging}

$$
\begin{aligned}
\mathrm{VO}^{2+} & \rightarrow \mathrm{VO}_{2}^{+}+e^{-} \\
V^{3+}+e^{-} & \rightarrow V^{2+}
\end{aligned}
$$

\section{Discharging}

$$
\begin{aligned}
\mathrm{VO}_{2}^{+}+e^{-} & \rightarrow \mathrm{VO}^{2+} \\
V^{2+} & \rightarrow V^{3+}+e^{-}
\end{aligned}
$$

The Vanadium-RFB has been chosen as a special type of redox flow system, since the crossover of the vanadium redox couples through the ion exchange membrane (separator) will not damage the battery system as it would be the case for several other systems like Iron-Chromium, Zinc-Bromine and Zinc-Cerium [2]. However, crossover still remains a critical issue of the ion exchange membrane in the Vanadium-RFB next to other issues such as water crossover, conductivity and chemical stability. Yet, many commercial membranes seem unsuitable for the Vanadium-RFB due to high degradation susceptibility as well as high production costs. Nafion, a perfluorosulfonated polymer is one of the most suitable membranes, being used and investigated extensively in Vanadium-RFBs 1. It shows excellent chemical stability and proton conductivity but suffers from high vanadium crossover since it has very broad and 
well interconnected hydrophilic channels through which vanadium ions can be transported [3]. Also the high costs of ca. $800 \$ / \mathrm{m}^{2}$ would increase the over all costs of such a Vanadium-RFB system. Due to the high price, many researchers have been searching for alternatives for Nafion.

Such an alternative is not only of interest for the Vanadium-RFB but also for many other applications such as for fuel cells [4, 5, 6], Electro Dialysis [7], and Reversed Electro Dialysis (RED) [8]. Especially the membranes applied in a fuel cell and electrodialysis need to withstand harsh conditions. In fuel cells, where $\mathrm{O}_{2}$ is reduced at the membrane electrode interface, intermediate compounds like $\mathrm{OH}^{*}$ radicals and even $\mathrm{H}_{2} \mathrm{O}_{2}$ will be produced continuously. These intermediates are very aggressive and may harm the membrane [9]. Consequently the membrane which can withstand these conditions, may also be suitable for the Vandadium-RFB.

Sulfonated non fluorinated aromatic polymers received strong attention as a suitable alternative to Nafion. To achieve high proton conductivities, one has to increase the sulfonation degree of such polymers up to a point where most of these sulfonated aromatic polymers become very much mechanically and chemically unstable. Low cost polyaryles have shown exceptional chemical stability, especially poly ether ketones like poly ether ether ketone (PEEK). The chemical structure of PEEK is depicted in Figure 5.1.

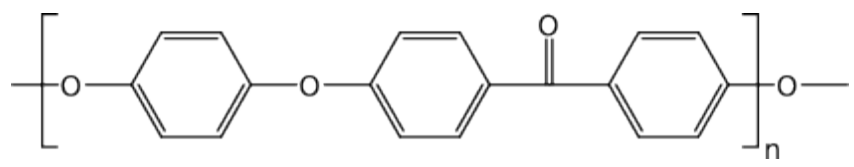

Figure 5.1 The chemical structure of Poly Ether Ether Ketone (PEEK).

PEEK functionalized by electrophilic sulfonation leads to proton conducting sulfonated poly ether ether ketone (SPEEK). The chemical structure of SPEEK is depicted in Figure 5.2. This material can be processed further to a membrane by casting.

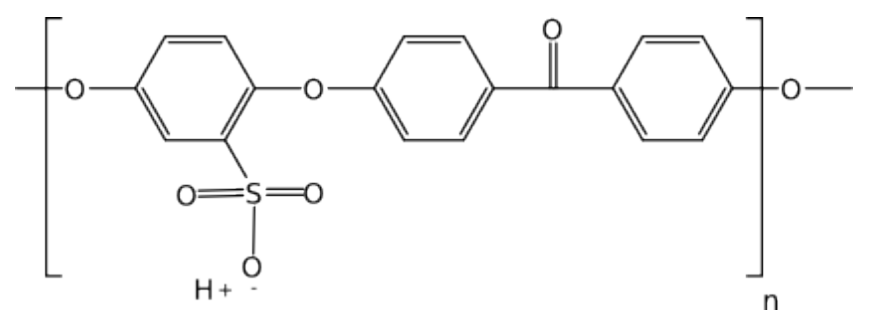

Figure 5.2 The chemical structure of Sulfonated Poly Ether Ether Ketone (SPEEK). 
SPEEK has shown good chemical stability in fuel cell tests [10] and it was also investigated as a potential membrane for Vanadium-RFBs [11, 3].

In Vanadium-RFBs, SPEEK was mainly used to be re-casted on Nafion membranes to decrease the vanadium crossover due to its glassy properties and the undefined and not well interconnected proton conductive channels [11]. However, the micro-structure difference of SPEEK which does not provide the distinct hydrophilic-hydrophobic separation like in the Nafion (Figure 1.15), leads to lower proton conductivities. Yet, the proton conductivity can be increased by increasing the sulfonation through an increase of sulfonation time $[12,13]$ or sulfonation temperature [13]. Hence, it might well be valuable to use an all SPEEK membrane for the Vanadium-RFB application. An increasing sulfonation degree will lead to a poor mechanical stability of the membrane due to high swelling up to total dissolution in water. This would make the membrane not suitable for any separation technique using protic and polar solvents. To overcome this issue, crosslinking of the polymer has shown to be a suitable route to increase mechanical stability of such highly sulfonated polymers [14]. Crosslinking is the association of polymer chains through an ionic or covalent bond and can be performed on three different pathways: a) physical crosslinking (ionically), b) irradiation assisted crosslinking and c) chemically crosslinking. SPEEK crosslinking has been described for all three methods in the scientific literature.

Physical crosslinking makes use of ionic interactions of the proton conducting groups and the crosslinking ions $[15,16]$. Ionic crosslinking can be performed by blending polymeric acids and polymeric bases, leading to an ionic bond by electrostatic or hydrogen bridge interactions. The combination of SPEEK and bases like polybenzimidazoles, polyethyleneamides and polyvinylpyridines have been reported by Kerres et al. [17]. The consumption of the $\mathrm{SO}_{3}^{-}$groups is the base for this method resulting in a low swelling, low cross over but also low proton conductive membrane material. Also the chemical stability of such ionically crosslinked polyelectrolytes has not been investigated deeply in the scientific literature for harsh conditions like in the Vanadium-RFB.

Electrobeam or $\gamma$ irradiation crosslinking presents the second pathway. Yet also this method has certain disadvantages like non uniform properties and the consumption of $\mathrm{SO}_{3}^{-}$groups during crosslinking. Taking into account the above mentioned disadvantages, an interessting approach has been made by Chen et al. [18]. To prevent the decreased proton conductivity due to $\mathrm{SO}_{3}^{-}$consumption during irradiation, the PEEK is pre-irradiated instead of the SPEEK. By this a covalent crosslinking on the backbone of the PEEK can be achieved entitled as c-PEEK. The c-PEEK will be then proceeded further by sulfonation to crosslinked SPEEK. Due to the high swelling of 
the irradiation crosslinked SPEEK membranes these membranes are crosslinked for a second time (thermally induced) in order to decrease the swelling and to increase the mechanical stability. The so called double crosslinked membranes show a proton conductivity of $110 \mathrm{mS} / \mathrm{cm}$ at $100{ }^{\circ} \mathrm{C}$ without degradation for over 200 hours. However, concerning the difficulty during the production procedure and the restriction in casting due to the non solubility of PEEK, irradiation crosslinking presents an interesting approach but need to be improved in terms of complexity, time and cost consumptions.

The third pathway is represented by the chemical crosslinking. Compared to the previous mentioned pathways, this approach offers broader possibilities. Chemical crosslinking of SPEEK has been the focus of many publications [19, 20, 21]. Like in the case of the ionic and irradiation crosslinking the consumption of $\mathrm{SO}_{3}^{-}$groups remains as an issue. To overcome this drawback following ways were proposed in wich the crosslinking shall happen on the backbone and not at the $\mathrm{SO}_{3}^{-}$groups (Figure 5.3):
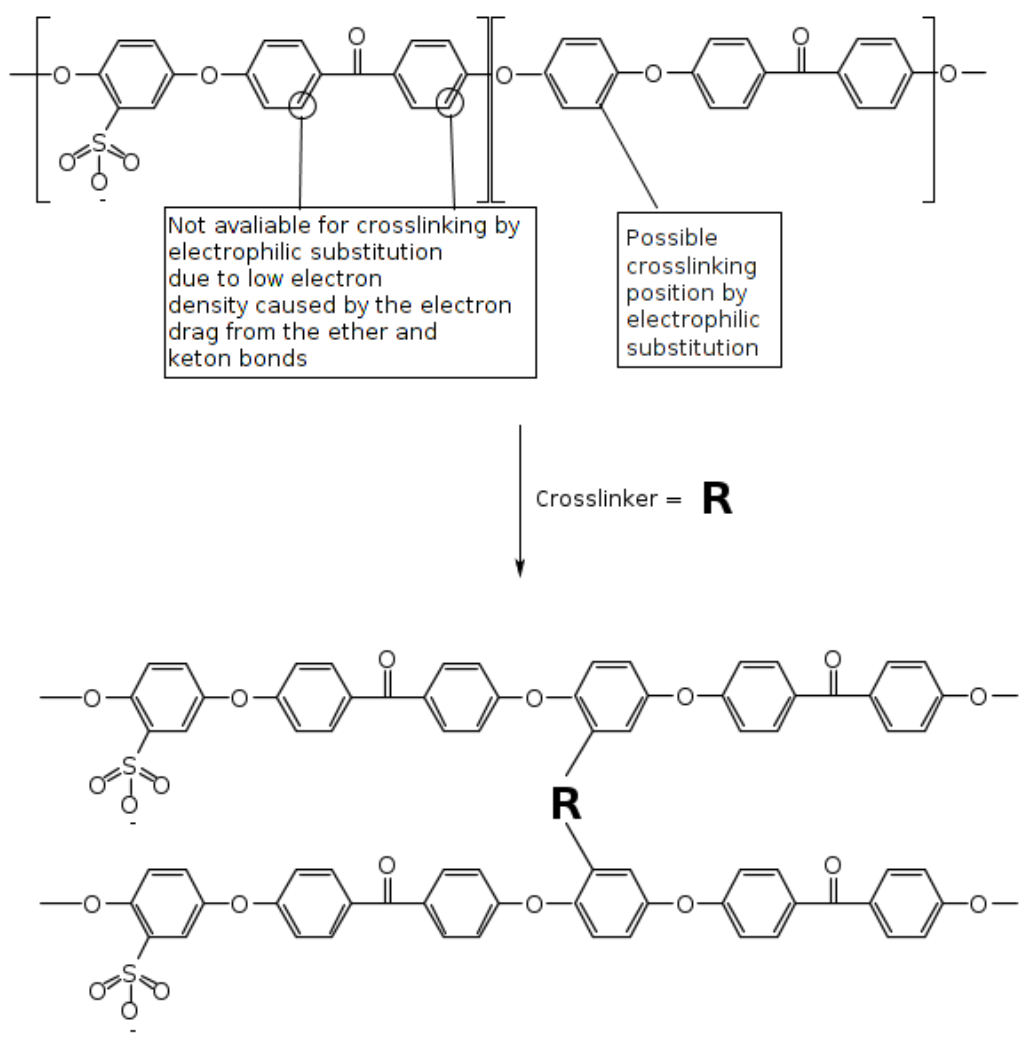

Figure 5.3 Backbone crosslinking of SPEEK with proposed crosslinking position. 
Regarding to the backbone crosslinking Feng et al. [22] proposed a new approach to crosslink the SPEEK directly on the backbone. This approach is done in two steps. First, the ketone present on the polymer backbone is reduced into OH-groups leading to a hydroxyl modified SPEEK. In the second step, the hydroxyl modified SPEEK, more particulary the $\mathrm{OH}$-function, reacts with the epoxy resin via an ring opening to the desired crosslinked SPEEK.

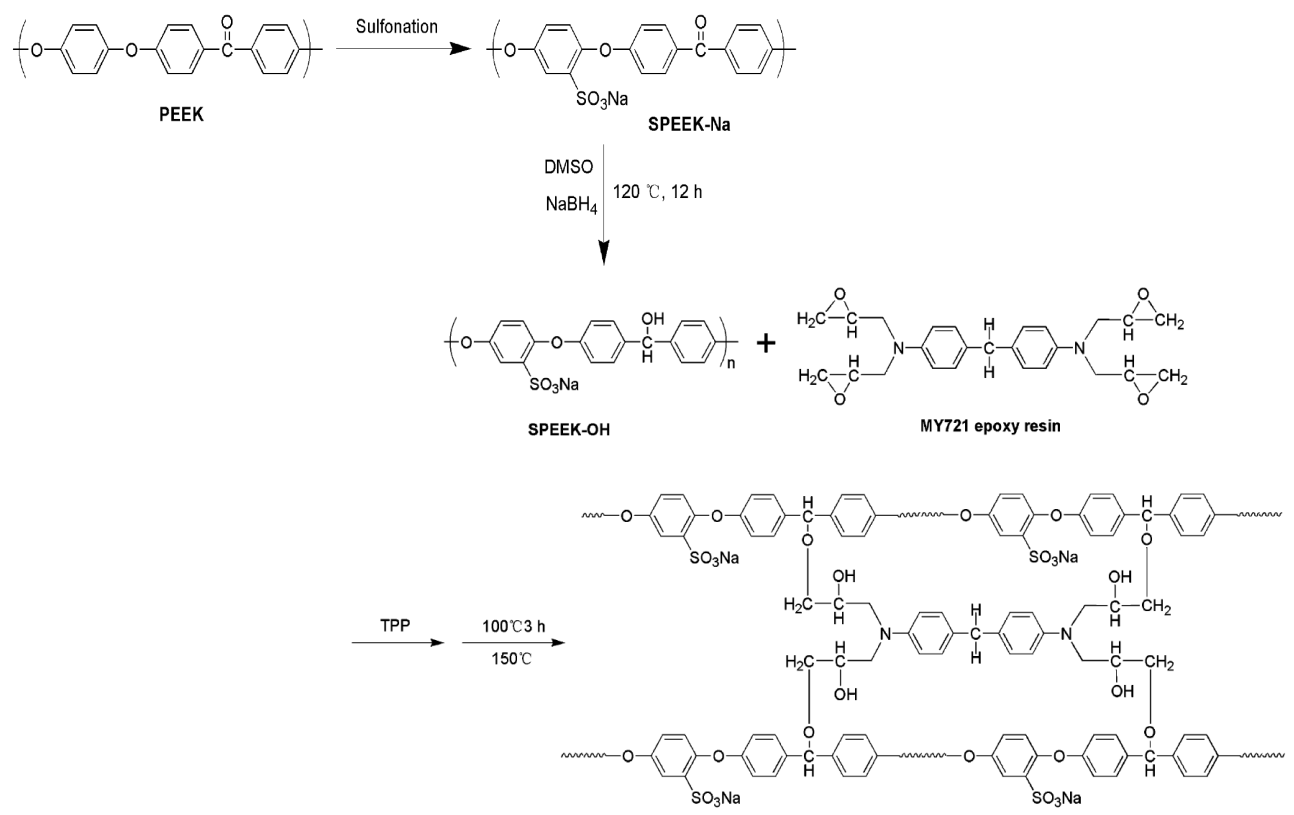

Figure 5.4 Chemical crosslinking proposed by Feng et al. [22].

Membranes prepared via this route achieved a proton conductivity of $96 \mathrm{mS} / \mathrm{cm}\left(30^{\circ} \mathrm{C}\right)$ and a water uptake of $65 \%\left(30^{\circ} \mathrm{C}\right)$. However, the membrane preparation is again time consuming and the complexity of the chemistry is high. Moreover, triphenylphosphine was used, which is as a highly toxic compound [23].

Another chemical crosslinking method reported by [24] uses bishydroxymethyl aryls. In this study the focus has been set on thermal initiated crosslinking of the SPEEK by bishydroxylmethyl aryl compounds. The crosslinking only occurs at the $\mathrm{SO}_{3}^{-}$groups facing the same issue as in the case of many crosslinking methods. Based on bishydroxylmethyl aryls as crosslinker also Linkous et al. [25] reported the crosslinking of SPEEK via Friedel-Craft alkylation route. This route was already discussed earlier by Yao et al. [26] on polystyrene. Linkous et al. reported a crosslinking on the backbone 
of the SPEEK with a higher proton conductivity. Crosslinking was reported to occur at $200^{\circ} \mathrm{C}$ for ten minutes. The resulting membrane exhibits a proton conductivity of $110 \mathrm{mS} / \mathrm{cm}$ at a temperature of $80^{\circ} \mathrm{C}$ and $100 \%$ relative humidity. However, neither swelling nor chemical stability were presented. Furthermore, no chemical analysis of the obtained membranes were reported to prove the crosslinking mechanism.

In analogy to the work of Linkous et al., this chapter present crosslinking of SPEEK by 1,4-benzenedimethanol via Friedel-Crafts alkylation. In particular the chapter focuses on the crosslinking mechanism, the influence of time and temperature of crosslinking on proton conductivity, swelling and vanadium permeation. In contrast to other crosslinking methods, the proposed Friedel-Crafts crosslinking represents a time saving, environmental friendly procedure with only little consumption of $\mathrm{SO}_{3}^{-}$groups. Furthermore, the membranes show high potentials for Vanadium-RFB application since the vanadium cross over through the membrane could be reduced by a factor of 100 compared with the Nafion membrane.

\subsection{Experimental}

\subsubsection{Membrane Preparation}

The preparation of highly sulfonated SPEEK was prepared following the procedure described elsewhere [13]. A 10\%-15\% weight solution of SPEEK in ethanol was prepared and filtered through a $20 \mu \mathrm{m}$ filter to remove insoluble particles. For the crosslinking 1,4-benzenedimethanol was added to the solution with a molar ratio between 2:1, 3:1 and 4:1 (mol repeat unit : mol benzenedimethanol). $\mathrm{ZnCl}_{2}$ is added as a catalyst $(1 \% \mathrm{w} / \mathrm{w})$ with respect to the dry weight of the SPEEK. Membranes were casted from this solution on a glass plate with a $0.47 \mathrm{~mm}$ casting knife and dried overnight under nitrogen. After drying, the membranes were heat treated in an oven with a temperatures of $150^{\circ} \mathrm{C}$ or $200^{\circ} \mathrm{C}$ with a duration between 10 minutes and 2 hour. After curing, the membranes were taken of the glass plate and washed in boiling Milli-Q water to rinse the $\mathrm{ZnCl}_{2}$ out of the membrane.

\subsubsection{Proton Conductivity}

Proton conductivity measurements were carried out with membranes soaked in 3 molar $\mathrm{H}_{2} \mathrm{SO}_{4}$ using $\mathrm{AC}$ impedance spectroscopy at the oscillation amplitude of 100 $\mathrm{mV}$ in the frequency range of $100 \mathrm{~Hz}$ to $10^{5} \mathrm{~Hz}$. The resistance of the membranes 
was calculated by fitting the impedance response to the equivalent circuit model depicted in Figure 2.7 from [27]. The conductivity was calculated by Equation 5.3, where $\sigma$ is the proton conductivity of the membrane in $\mathrm{mS} / \mathrm{cm}, l$ is the thickness of the membrane in $\mathrm{cm}$ and $\mathrm{R}$ is the resistance of the membrane in $\Omega$ (For further information see Chapter 2.

$$
\sigma=\frac{1}{l * R}
$$

\subsubsection{Ion Exchange Capacity (IEC)}

The ion exchange capacity (IEC) was determined through titration. The membranes in $\mathrm{H}^{+}$form were immersed in $1 \mathrm{M} \mathrm{NaCl}$ solution for $24 \mathrm{~h}$ to transform the membrane into the sodium form. The $\mathrm{NaCl}$ solution was then back titrated with $0.1 \mathrm{M} \mathrm{NaOH}$. The IEC was calculated by the Equation 5.4, where $I E C$ is the ion exchange capacity in $\mathrm{meq} / \mathrm{g}$ (or $\mathrm{mmol} / \mathrm{g}$ ).

$$
I E C=\frac{\text { volume added } \mathrm{NaOH}(\mathrm{ml})}{\text { dry weight membrane }(\mathrm{g})} * \mathrm{NaOH} \text { concentration }\left(\frac{\mathrm{mmol}}{\mathrm{g}}\right)
$$

\subsubsection{Water Uptake}

To determine the water uptake the dry weight $\mathrm{m}_{d r y}$ and the wet weight $\mathrm{m}_{\text {wet }}$ of the membrane is measured. The swelling was calculated according to Equation 5.5.

$$
\operatorname{Swelling}(\%)=100 * \frac{m_{w e t}-m_{d r y}}{m_{d r y}}
$$

\subsubsection{Permeability of Vanadium Ions}

The vanadium permeation was measured using a diffusion cell described elsewhere [28] and depicted in Figure 5.5. The diffusion cell consisted of two half cells with each $75 \mathrm{~mL}$ volume. The solutions were stirred continuously at a stirring speed of 300 rpm. Samples from the $\mathrm{MgSO}_{4}$ half cell of the diffusion cell were taken for UV/VIS Spectroscopy analysis to investigate the vanadium permeability. The permeability was calculated by Equation 5.6 [29]. 


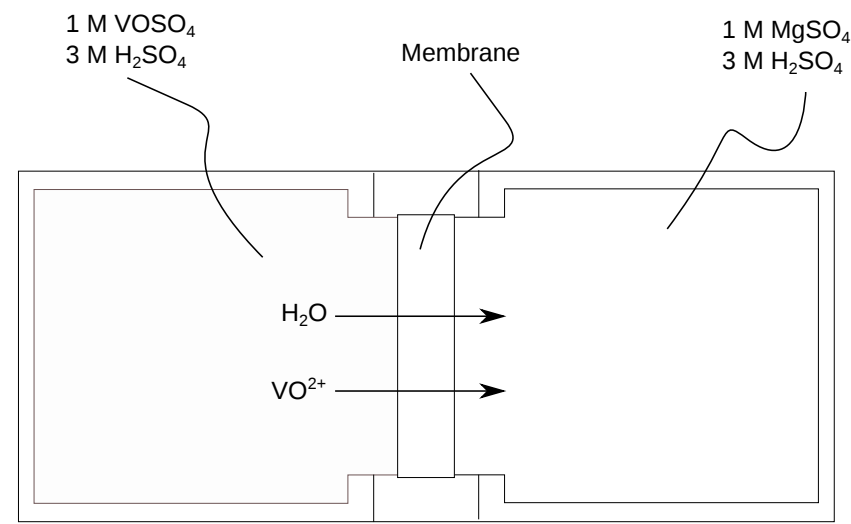

Figure 5.5 Schematics of a diffusion cell for vanadium permeation evaluation, indicating the $\mathrm{VO}^{2+}$ transport and the water transport due to the hydration shell of the $\mathrm{VO}^{2+}$.

$$
-\ln \left(1-\frac{C_{t}}{C_{0}}\right)=\frac{P * a}{l * v} * t
$$

Where $C_{t}$ is the vanadium concentration in the $\mathrm{MgSO}_{4}$ reservoir in mol/l, $C_{0}$ the initial concentration of the vanadium in the vanadium reservoir in mol/l, $P$ the permeablity in $\mathrm{cm}^{2} / \mathrm{s}, a$ the area of the membrane exposed to the solution in $\mathrm{cm}^{2}, l$ the thickness of the membrane in $\mathrm{cm}$ and $v$ the volume of the volume of the solution in both sides in $\mathrm{ml}$.

\subsubsection{Fourier Transform Infra-red Spectroscopy}

Fourier Transform Infrared Spectroscopy (FT-IR) measurements were done with the Frontier FT-IR from Perkin Elmer in order to determine the position of the crosslinking.

\subsection{Results}

\subsubsection{Crosslinking SPEEK}

Visual observation of the membrane before and after crosslinking at 150 and $200^{\circ} \mathrm{C}$ were done (Figure 5.6). From the picture it can be noticed, that cSPEEK appears in a 
different color than the non crosslinked membrane. Crosslinked membranes exhibit a brown color, while the uncrosslinked membrane appears transparent. Moreover it was observed, that depending on the crosslinking conditions the color varies from brown to black. This irreversible thermochromism may be an indication of a conformation change of the backbone, resulting from the crosslinking [30].

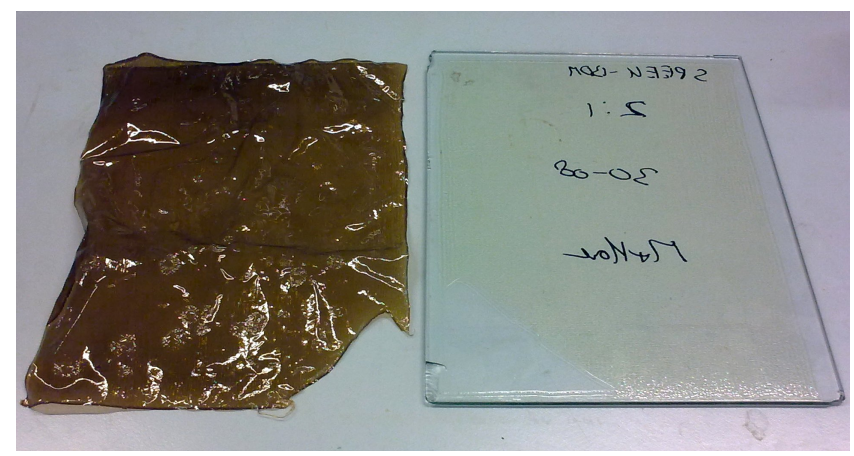

Figure 5.6 Crosslinked SPEEK membrane (left) and non crosslinked SPEEK membrane casted on a glass plate (right).

The FT-IR spectra of crosslinked and non crosslinked SPEEK are depicted in Figure 5.7. Crosslinking reaction was done under two different temperatures, $150^{\circ} \mathrm{C}$ and $200^{\circ} \mathrm{C}$, as described in the experimental. In Figure 5.7, no new peak appeared in the spectra of the membrane which was crosslinked at $200^{\circ} \mathrm{C}$ compared to the non crosslinked SPEEK. However, in the case of the membrane crosslinked at $150^{\circ} \mathrm{C}$, three new peaks appeared. These are summarized in Table 5.1, as the characteristic peaks for $\mathrm{SO}_{3}^{-}$and $\mathrm{S}=\mathrm{O}$ of SPEEK.

Table 5.1 Characteristic FT-IR peaks [31, 32, 33].

\begin{tabular}{|c|c|}
\hline Wavelength $\left(\mathrm{cm}^{-1}\right)$ & Bond \\
\hline $1370,1356,1178$ & $\mathrm{RSO}_{3} \mathrm{R}^{\prime}$ (sulfonate ester) \\
\hline 1025 & $\mathrm{SO}_{3}^{-}$ \\
\hline 1018 & $\mathrm{SO}$ \\
\hline
\end{tabular}




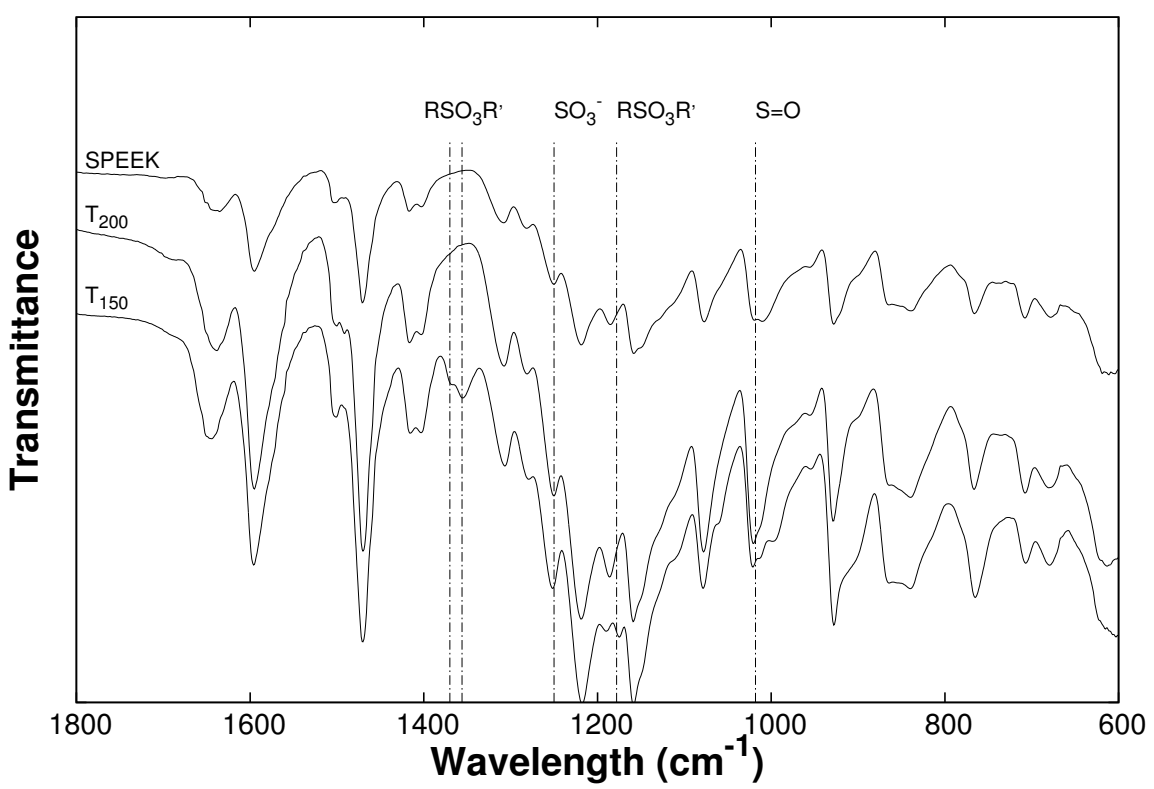

Figure 5.7 FT-IR of non crosslinked and crosslinked SPEEK with the molar ratio SPEEK:crosslinker 3:1 ( $T_{150}=c S P E E K$ prepared at $150^{\circ} \mathrm{C}, T_{200}=c S P E E K$ prepared at $\left.200^{\circ} \mathrm{C}\right)$. All crosslinked membranes were crossslinked for 60 minutes under the given temperatures.

Figure 5.7 shows that sulfonate ester $\left(\mathrm{RSO}_{3} \mathrm{R}\right.$ ') bands appear in the cSPEEK membranes cured at $150^{\circ} \mathrm{C}$ but not at $200^{\circ} \mathrm{C}$. $\mathrm{RSO}_{3} \mathrm{R}$ ' linkages are the result of a crosslinking reaction between the 1,4-benzenedimethanol and the sulfonic acid groups of the SPEEK, which had been reported to occur at even lower temperatures $\left(135^{\circ} \mathrm{C}\right)$ without catalyst but a comparable crosslinker [24]. The disappearance of the sulfonate ester bonds at elevated temperatures might be due to the thermal instability of the sulfonate ester linkages, probably also affected by the catalyst, which had been described elsewhere [31, 33].

\subsubsection{Swelling and Proton Conductivity}

Table 5.2 depicts the swelling of different membranes in water and in $3 \mathrm{M}$ sulfuric acid as a function of crosslinking time, temperature and composition of the membrane. Uncrosslinked samples cannot be used since they can dissolve in water, hence they cannot be used as a reference. 
Table 5.2 Swelling and proton conductivity of different cSPEEK membranes with different SPEEK:crosslinker ratios (2:1, 3:1 and 4:1), for which the error of the conductivity data was reproducible in the range of $0.01 \%$. Nafion reached in our experiments at room temperature a proton conductivity up to $80.1 \mathrm{mS} / \mathrm{cm}$ where a swelling up to $26 w \mathrm{w} \%$ was reported elsewhere [34]. All swelling experiments were done at room temperature.

\begin{tabular}{|c|c|c|c|c|c|c|c|c|}
\hline & \multicolumn{4}{|c|}{$150^{\circ} \mathrm{C}$} & \multicolumn{4}{|c|}{$200^{\circ} \mathrm{C}$} \\
\hline & \multicolumn{2}{|c|}{ Swelling(\%) } & \multicolumn{2}{|c|}{$\begin{array}{l}\text { Proton Conductiv- } \\
\text { ity }(\mathrm{mS} / \mathrm{cm})\end{array}$} & \multicolumn{2}{|c|}{ Swelling(\%) } & \multicolumn{2}{|c|}{$\begin{array}{l}\text { Proton Conductiv- } \\
\text { ity }(\mathrm{mS} / \mathrm{cm})\end{array}$} \\
\hline & 5 min. & $60 \mathrm{~min}$. & $5 \mathrm{~min}$. & $60 \mathrm{~min}$. & $5 \mathrm{~min}$. & $60 \mathrm{~min}$. & $5 \mathrm{~min}$. & 60 min. \\
\hline cSPEEK 2:1 & $24 \pm 7$ & $23 \pm 3$ & 30.8 & 26.8 & $27 \pm 10$ & $32 \pm 2$ & 10.9 & 30.2 \\
\hline cSPEEK 3:1 & $42 \pm 14$ & $15 \pm 1$ & 36 & 8.4 & $35 \pm 5$ & $50 \pm 8$ & 13.3 & 36.3 \\
\hline cSPEEK 4:1 & $56 \pm 4$ & $22 \pm 3$ & 61.8 & 9 & $45 \pm 6$ & $32 \pm 1$ & 25.9 & 38.1 \\
\hline
\end{tabular}

From Table 5.2, it can be concluded that proton conductivity and swelling are strongly influenced by the concentration of the crosslinker, the treatment temperature and time. However, simple trends cannot be identified easily. The swelling values for membranes crosslinked at $200^{\circ} \mathrm{C}$ for 60 minutes showed an increase in average compared to the swelling behavior of the same membranes treated at $150^{\circ} \mathrm{C}$ for the same time. This is possibly to the fact that the $\mathrm{SO}_{3}^{-}$groups were not affected negatively by the crosslinking reaction after 60 minutes at $200^{\circ} \mathrm{C}$ but at $150^{\circ} \mathrm{C}$. Indeed at $150^{\circ} \mathrm{C}$ and 60 minutes, the crosslinking took place at the $\mathrm{SO}_{3}^{-}$groups, leading to a sulfonate ester as previously indicated by the FTIR spectroscopy. This decreased the hydrophilic properties of the membrane, leading to a decrease of swelling of the membrane. This fact is also reflected in Table 5.2, where the conductivity is compared with the swelling. At $200^{\circ} \mathrm{C}$, not only the swelling increased but also the proton conductivity. This is probably due to the thermal instability of the sulfonate ester, which can turn back to its original form, i.e. $\mathrm{SO}_{3}^{-}$. At this point it has to be pointed out, that the swelling behaviour of the SPEEK membranes crosslinked for 60 minutes at $200^{\circ} \mathrm{C}$ does not agree with the conductivity data for this series. This litte deviation is most probably due to experimental errors. However, in order to choose a suitable membrane for the Vanadium-RFB swelling and conductivity need to be adjusted carefully. A highly conductive membrane may show as well high swelling and by this the risk of high vanadium crossover is given. Due to that, cSPEEK60 2:1 and cSPEEK60 3:1 would possibly represent suitable candidates for the Vanadium-RFB application. 

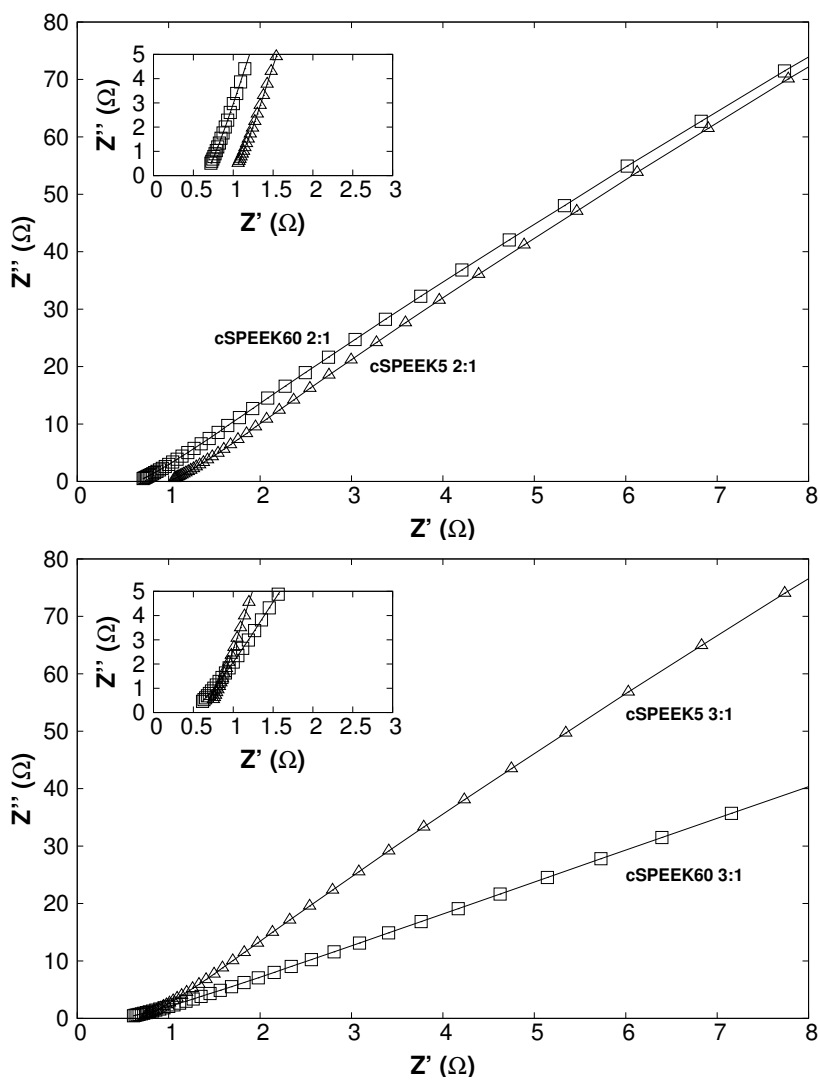

Figure 5.8 Electrochemical impedance spectra of crosslinked SPEEK series cured at $T=200^{\circ} \mathrm{C}$ (sample code : cSPEEK60 2:1 = crosslinked SPEEK with a crosslinking time of 60 minutes and a SPEEK : crosslinking ratio of 2:1). 

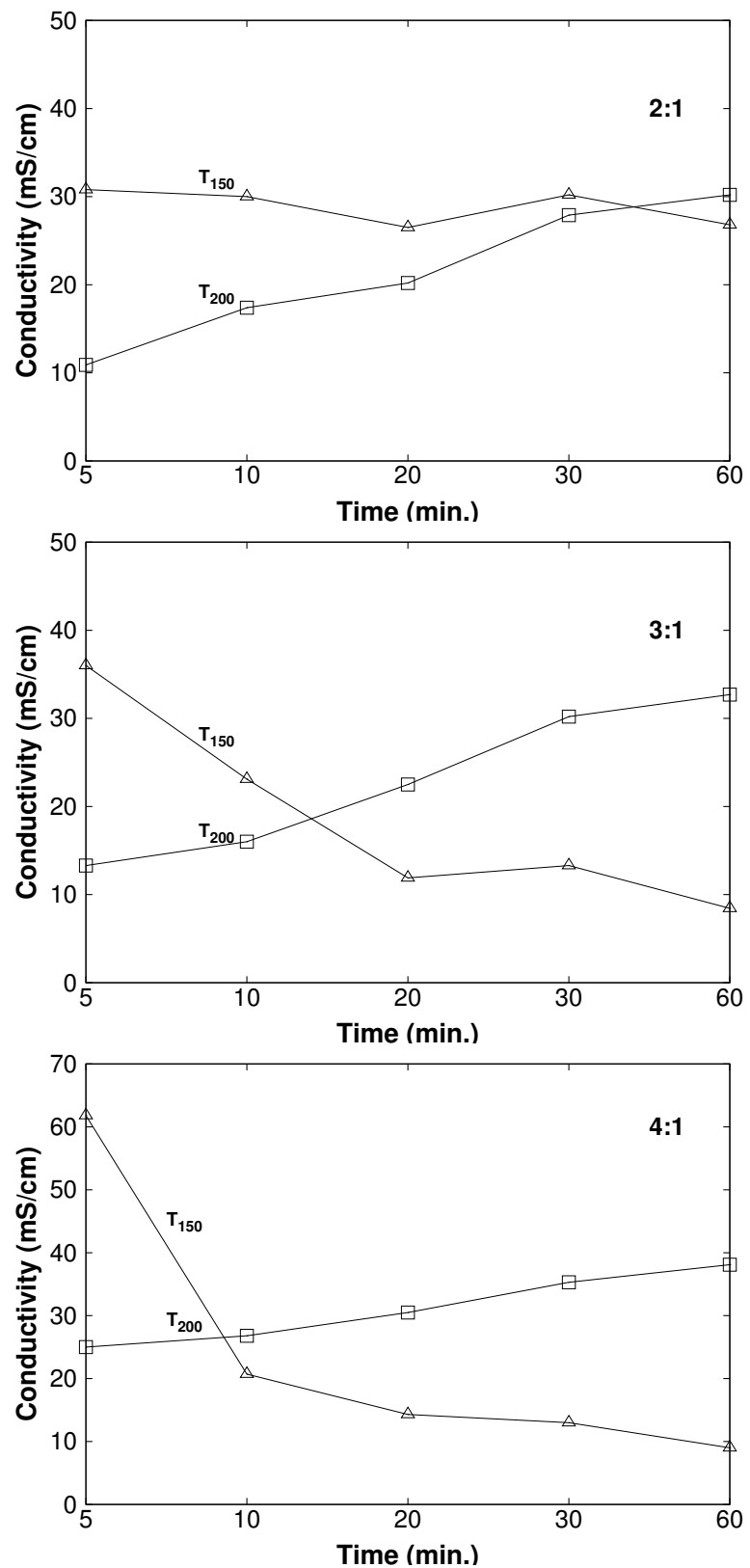

Figure 5.9 Conductivity of crosslinked SPEEK as a function of crosslinking time with different $S P E E K$ :crosslinker ratios indicated in the upper right corner of the graphs $\left(T_{150}=\right.$ $c S P E E K$ prepared at $150^{\circ} \mathrm{C}, T_{200}=c S P E E K$ prepared at $\left.200^{\circ} \mathrm{C}\right)$. 
Figure 5.8 depicts the electrochemical impedance spectra of the at $200^{\circ} \mathrm{C}$ cured cSPEEK membranes for the 3:2 and 2:1 (SPEEK:crosslinker) series where Figure 5.9 depicts the calculated conductivity behavior from the impedance data as function of the crosslinking time and temperature. It can be seen, that at $150^{\circ} \mathrm{C}$ the conductivity decreases with the time. For the crosslinking at $200^{\circ} \mathrm{C}$ this behavior is inverted. This is related to the crosslinking position of the crosslinker, which can change spontaneously from the $\mathrm{SO}_{3}^{-}$group to the backbone of the PEEK repeat unit (Figure 5.11). To prove this theory a SPEEK membrane was crosslinked in two steps. 1) SPEEK was crosslinked at $150^{\circ} \mathrm{C}$ for 60 minutes 2) The same membrane was further treated at $200^{\circ} \mathrm{C}$ for another 60 minutes. The proton conductivity was measured via samples in between of the two steps. The results regarding to the proton conductivity of the membranes are depicted in Figure 5.10.

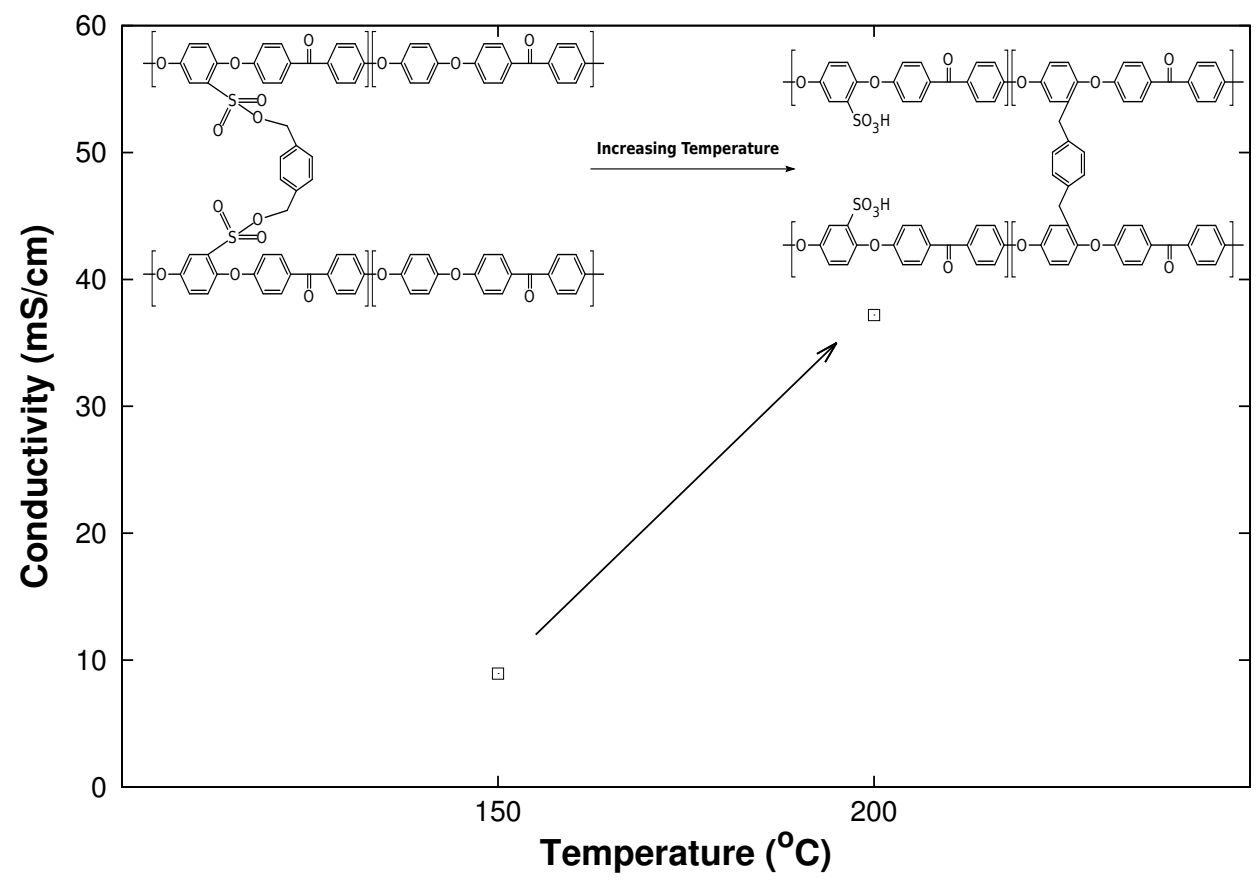

Figure 5.10 Dependency of crosslinking temperature and proton conductivity on one SPEEK membrane sample for a cSPEEK membrane with a SPEEK:crosslinker ratio of 3:1.

As illustrated in the Figure 5.10 the ionic conductivity increases after the second step, i.e. after exposition at $200^{\circ} \mathrm{Cfor} 60$ minutes. The resulting conductivities support the previous hypothesis of the sulfonate ester appearance at lower crosslinking tempera- 
ture and the change of the crosslinking position of the 1,4 benzendimethanol at higher temperatures and longer crosslinking duration.

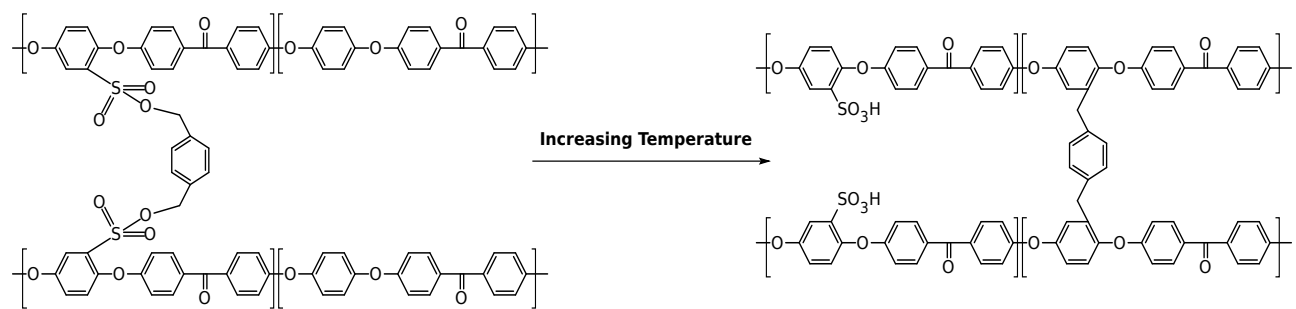

Figure 5.11 Crosslinking positions of the 1,4 Benzyl-di-methanol.

The hypothesis of the heat conducted shifting of the crosslinking group also correlates with the ion exchange capacity (IEC) data. Indeed, IEC is directly related to the number of the $\mathrm{SO}_{3}^{-}$groups of the membrane. Its value mirrors the free amount of uncrosslinked $\mathrm{SO}_{3}^{-}$groups. It was found, that the IEC of the membrane after 60 minutes at $200^{\circ} \mathrm{C}$ was close to the initial value i.e. IEC for the non crosslinked SPEEK (Table 5.3). Therefore, the IEC supports the hypothesis of the crosslinker shifting after a heat treatment.

\subsubsection{Vanadium Permeability}

The vanadium permeability of the synthesized and commercial membranes were studied. This was done in a diffusion cell which consists of two half cells separated by the membrane under investigation. Figure 5.12 depicts the increase of vanadium concentration in the $\mathrm{MgSO}_{4}$ compartments over time, where Table 5.3 depicts the permeability of $\mathrm{VO}^{2+}$ through these membranes. It can be seen, that the vanadium permeability decreased with decreasing the amount of SPEEK (i.e. increasing the crosslinking). However, the vanadium permeability remains still higher than through a Nafion 117 membrane. This may be a result of the highly sulfonated SPEEK which has a high water uptake. To overcome this issue, the ratios of crosslinked $\mathrm{SO}_{3}^{-}$groups to the non crosslinked $\mathrm{SO}_{3}^{-}$groups had to be adjusted. This was done by decreasing the crosslinking time at $200^{\circ} \mathrm{C}$ from 60 to 30 minutes. By this, the synthesized membrane (cSPEEK30 2:1) exhibited in a vanadium permeability 100 times lower than Nafion 117 (Table 5.3). However, the FTIR spectroscopy of the cSPEEK30 2:1 has not shown a significant increase of the sulfonate ester bonds. This might be due to the low resolution a FTIR can offer on such intermediate crosslinked material. Due 
to that, other analysis methods like Solid State-NMR could be of great help to understand the extend of crosslinking.

The reason for the low vanadium cross over in the case of the crosslinked SPEEK lies in its glassy properties and rigid backbone. Furthermore the dead end hydrophilic channels of SPEEK also decrease the vanadium permeability, since these are not as well interconnected as in the case of Nafion.

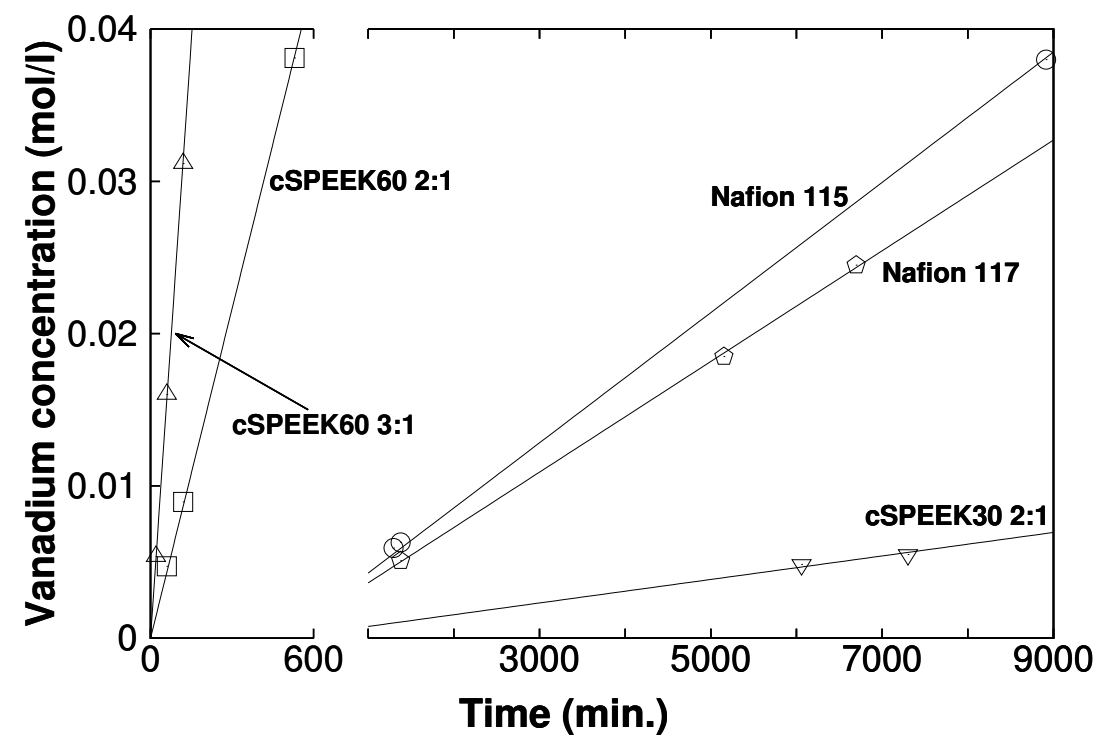

Figure 5.12 VO ${ }^{2+}$ crossover through cSPEEK membranes cured at $200^{\circ} \mathrm{C}$ and Nafion membranes sample code : cSPEEK60 2:1 = crosslinked SPEEK with a crosslinking time of 60 minutes and a SPEEK: corsslinking ratio of 2:1).

Table 5.3 Ion exchange capacity ( $\mathrm{meq} / \mathrm{g})$ and vanadium permeability $\left(\mathrm{cm}^{2} \mathrm{~s}^{-1}\right)$ of observed membranes (sample code : cSPEEK60 2:1 = crosslinked SPEEK with a crosslinking time of 60 minutes and a SPEEK:corsslinking ratio of 2:1).

\begin{tabular}{|c|c|c|c|c|c|}
\hline \multirow[b]{2}{*}{ Membranes } & \multicolumn{3}{|c|}{ IEC } & \multicolumn{2}{|c|}{ Permeability } \\
\hline & Non crosslinked & $150^{\circ} \mathrm{C}$ & $200^{\circ} \mathrm{C}$ & Non crosslinked & $200^{\circ} \mathrm{C}$ \\
\hline cSPEEK60 3:1 & & 1.60 & 2.05 & & $6.7 * 10^{-6}$ \\
\hline cSPEEK60 2:1 & & 1.43 & 1.97 & & $4.8^{*} 10^{-6}$ \\
\hline cSPEEK30 2:1 & & 1.12 & 1.34 & & $5.7 * 10^{-8}$ \\
\hline Nafion 117 & $1.9[34]$ & & & $1.9 * 10^{-6}$ & \\
\hline SPEEK & 2.24 & & & $\sim$ & \\
\hline
\end{tabular}




\subsection{Conclusion}

A new route for crosslinking SPEEK was described to prepare an efficient proton conductive membranes for redox flow battery applications, especially vanadium redox flow batteries. The crosslinking reaction is obtained by Friedel Crafts alkylation [25] without the use of toxic compounds, expensive materials or methods in a one step reaction. For this reaction, two crosslinking pathways were proposed and proved by FTIR, IEC and proton conductivity measurements. These are the crosslinking of the 1,4-benzendimethanol on $\mathrm{SO}_{3}^{-}$groups at temperatures $\leq 150^{\circ} \mathrm{C}$ and the crosslinking of the 1,4-benzendimethanol on the backbone of the SPEEK unit at a temperature of $200^{\circ} \mathrm{C}$. By applying a crosslinking temperature of $200^{\circ} \mathrm{C}$, the proton conducting groups $\left(\mathrm{SO}_{3}^{-}\right)$can be preserved. However, since the highly proton conductive SPEEK shows a high vanadium permeability, the ratio of crosslinked and non crosslinked $\mathrm{SO}_{3}^{-}$groups was balanced in order to decrease the vanadium crossover. This adjustment was done by varying the crosslinking time. The final membrane exhibits a proton conductivity of $27.9 \mathrm{mS} / \mathrm{cm}$ and a 100 times lower vanadium permeability than Nafion 117 . Furthermore the use of this material in an UVA-RFB (4) needs as well to investigated. The challenges to be faced are in particular the preparation of a membrane electrode assembly.

\section{Bibliography}

[1] Skyllas-Kazacos, M., Rychick, M., and Robins, R. (1988) US Patent $478656 \%$.

[2] deLeon C., P., Frias-Ferrer, A., Gonzalez-Garcia, J., Szantoc, D. A., and Walsh, F. C. (2006) Journal of Power Sources 160(1), 716-732.

[3] Jia, C., Liu, J., and Yan, C. (2010) Journal of Power Sources 195, 4380-4383.

[4] Peighambardoust, S., Rowshanzamir, S., and Amjadi, M. (2010) International Journal of Hydrogen Energy 35(17), 9349 - 9384.

[5] Silva, V. S., Mendes, A., Madeira, L. M., and Nunes, S. P. (2006) Journal of Membrane Science 276(1-2), 126 - 134.

[6] Park, H. B., Lee, C. H., Sohn, J. Y., Lee, Y. M., Freeman, B. D., and Kim, H. J. (2006) Journal of Membrane Science 285(1-2), 432 - 443.

[7] Kariduraganavar, M. Y., Nagarale, R. K., Kittur, A. A., and Kulkarni, S. (2006) Desalination 197(1-3), 225 - 246. 
[8] Dlugolecki, P., A.Gambier, Nijmeijer, K., and Wessling, M. (2009) Environmental Science and Technology 43, 6888-6894.

[9] Hubner, G. and Roduner, E. (1999) Journal of Material Chemistry 9, 409.

[10] Kreuer, K. D. (2001) Journal of Membrane Science 185(1), 29 - 39.

[11] Luo, Q., Zhang, H., Chen, J., You, D., Sun, C., and Zhang, Y. (2008) Journal of Membrane Science 325(2), 553-558.

[12] Daoust, D., Devaux, J., and Godard, P. (2001) Polymer International 50(8), 932-936.

[13] Shibuyal, N. and Porter, R. S. (1992) Macromolecules 25, 6495-6499.

[14] Zeng, J., Jiang, C., Wang, Y., Chen, J., Zhu, S., Zhao, B., and Wang, R. (2008) Electrochemistry Communications 10(3), 372 - 375.

[15] Luua, D. X. and Kim, D. (2010) Solid State Ionics DOI:10.1016/j.ssi.2010.05.007.

[16] Xuea, Y., Fub, R., Wub, C., and Leeb, J. Y. (2010) Journal of Membrane Science 350, 148-153.

[17] Kerres, J., Ullrich, A., Meier, F., and Häring, T. (1999) Solid State Ionics 125, $243-249$.

[18] Chen, J., Maekawaa, Y., Asanoa, M., and Yoshidaa, M. (2007) Polymer 48, 6002-6009.

[19] Vona, M. L. D., Sgreccia, E., Licoccia, S., Alberti, G., Torte, L., and Knauth, P. (2009) Journal of Physical Chemistry 113, 75057512.

[20] Yea, Y.-S., Yena, Y.-C., Chenga, C.-C., Chenb, W.-Y., Tsaib, L.-T., and Changa, F.-C. (2009) Polymer 50, 3196-3203.

[21] Deb, P. C., Rajput, L. D., Hande, V. R., Sasane, S., and Kumar, A. (2007) Polymers for Advanced Technologies 18, 419426.

[22] Fenga, S., Shanga, Y., Wanga, Y., Liua, G., Xiea, X., Donga, W., Xua, J., and Mathurb, V. K. (2010) Journal of Membrane Science 352, 14-21.

[23] MSDS , http://www.msdssearch.com/dblinksn.htm.

[24] Hande, V. R., Rao, S., Rath, S. K., Thakur, A., and Patri, M. (2008) Journal of Membrane Science 322(1), 67 - 73. 
[25] Linkous, C. A., Rhoden, S. L., Linkous, W. G., Pearman, B. P., and Mohajeri, N. (2008) ECS Transactions 16, 705-710.

[26] Yao, H., Zhu, J., McKinney, M. A., and Wilkie, C. A. (2000) Journal of Vinyl and Additive Technology 6, 205210.

[27] Compan, V., Riande, E., Fernandez-Carretero, F., Berezina, N., and Sytcheva, A.-R. (2008) Journal of Membrane Science 318, 255263.

[28] Mohammadi, T. and Skyllas-Kazacos, M. (1995) Journal of Membrane Science 107(1-2), $35-45$.

[29] Luo, X., Lu, Z., Xi, J., Wu, Z., Zhu, W., Chen, L., and Qiu, X. (2005) The Journal of Physical Chemistry B 109(43), 20310-20314.

[30] A. Murray, K., B. Holmes, A., C. Moratti, S., and Rumbles, G. (1999) J. Mater. Chem. 9(9), 2109-2116.

[31] Masamitsu, S., Satoshi, M., Haruyuki, O., and Masahiro, T. (2002) Chemistry of Materials 14(1), 334-340.

[32] Deb, P. C., Rajput, L. D., Hande, V. R., Sasane, S., and Kumar, A. (2007) Polym. Adv. Technol. 18(6), 419-426.

[33] Okamura, H., Takatori, Y., Tsunooka, M., and Shirai, M. (2002) Polymer 43(11), $3155-3162$.

[34] Xi, J., Wu, Z., Qiu, X., and Chen, L. (2007) Journal of Power Sources 166, 531536. 


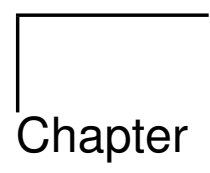

Appendix to Chapter 5 
In Chapter 5 crosslinked sulfonated poly ether ether ketone membranes were likely produced by Friedel- Craft alkylation, in which the resulting polymer and the membranes showed good properties with respect to vanadium cross over and proton conductivity. However, the proposed crosslinking mechanism has been discussed only to a certain extend in Chapter 5. The crosslinking mechanism has been deduced from the increase of conductivity, ion exchange capacity but also by infrared spectroscopy and water uptake. All these methods focus on the concentration and the existence of sulfonic acid groups. The crosslinked polymer structure is envisioned as depicted in Figure 6.1.

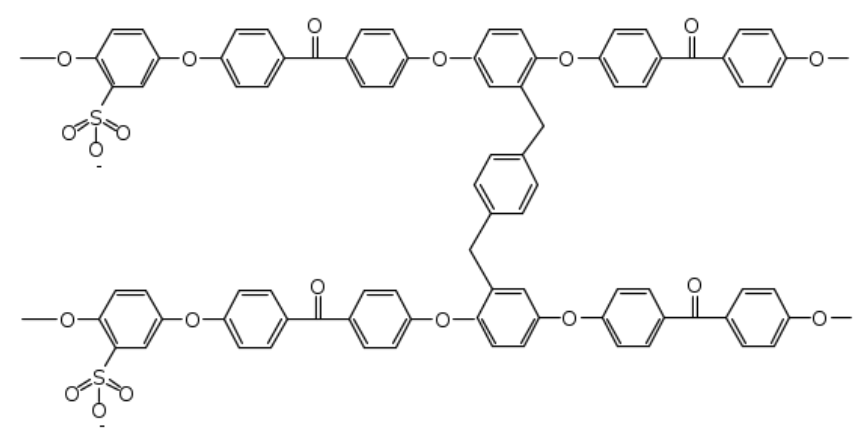

Figure 6.1 The proposed chemical structure of crosslinked Sulfonated Poly Ether Ether Ketone (SPEEK) vial Friedels Craft alcylation.

The proposed position of the crosslinker has been chosen to be on the neighbored segment of the sulfonated segment: the sulfonated segment will not allow any further electrophilic substitution due to the electron drawing $\mathrm{SO}_{3}^{-}$group. To investigate the position of the crosslinker, Proton Nuclear Magnetic Resonance (H-NMR) studies were conducted. However, as already described in Chapter 5, the crosslinked membranes showed no solubility in water and $\mathrm{H}_{2} \mathrm{SO}_{4}$ and as it will be also indicated later in this appendix, also no solubility was observed for common solvents.

Due to that H-NMR measurements were performed of the membranes in a swollen state. For that the crosslinked polymer was soaked in 6d-DMSO. To overcome issues of low resolution, the measuremnts were performed with the magic angle spinning (MAS) technique, where the sample was spined under an angle of $\sim 54.74^{\circ}$. Figures 6.2 and 6.3 depict the down field H-NMR-MAS spectra of non crosslinked SPEEK (SD $85 \%)$ and crosslinked SPEEK membranes (3:1 SPEEK:Crosslinker cured at $200^{\circ} \mathrm{C}$ for 60 minutes). It is clear that the non crosslinked SPEEK delivers a spectra with 


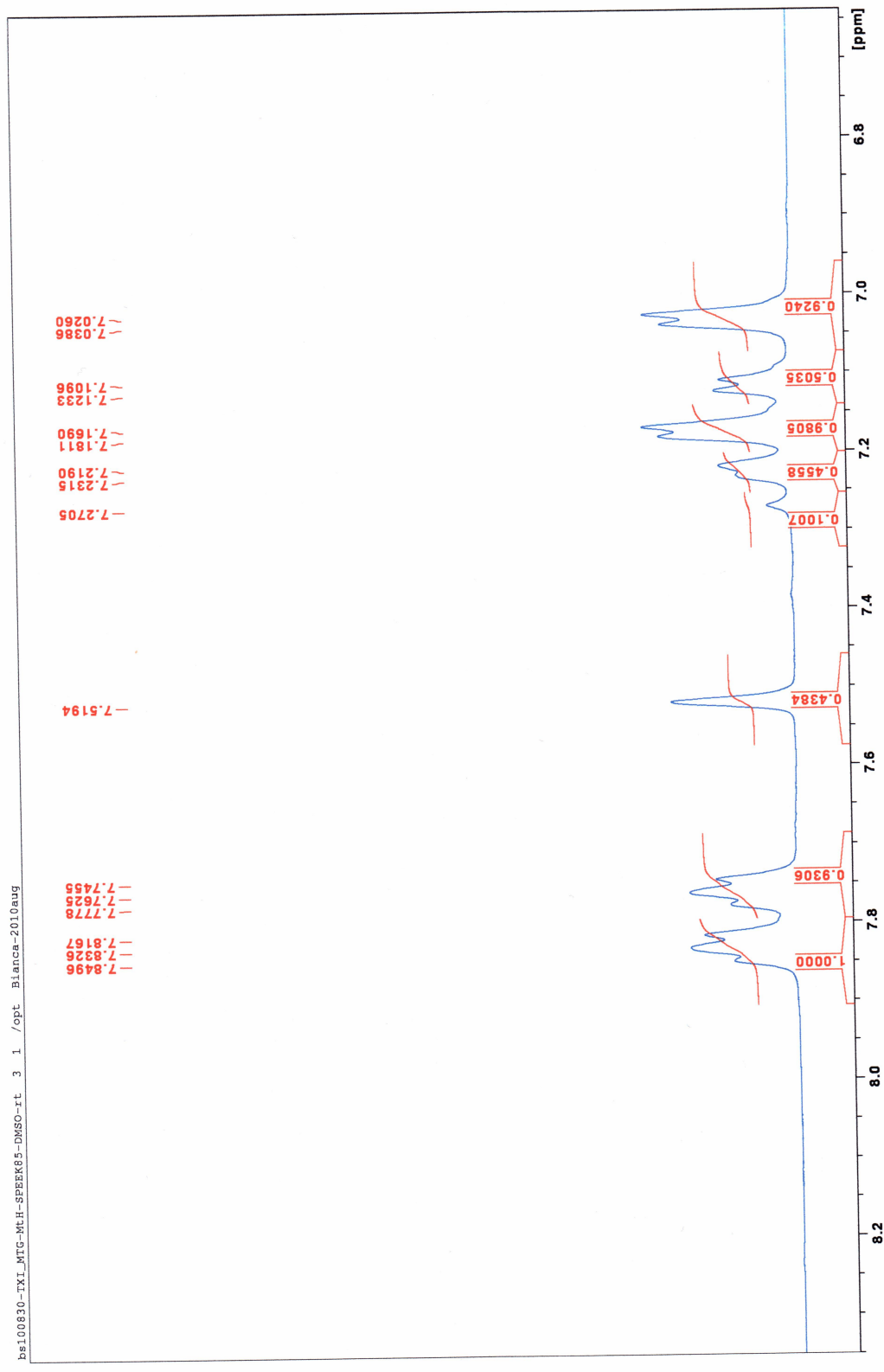

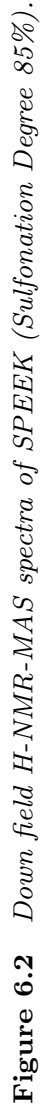




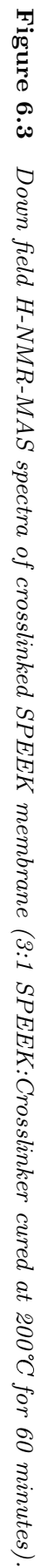

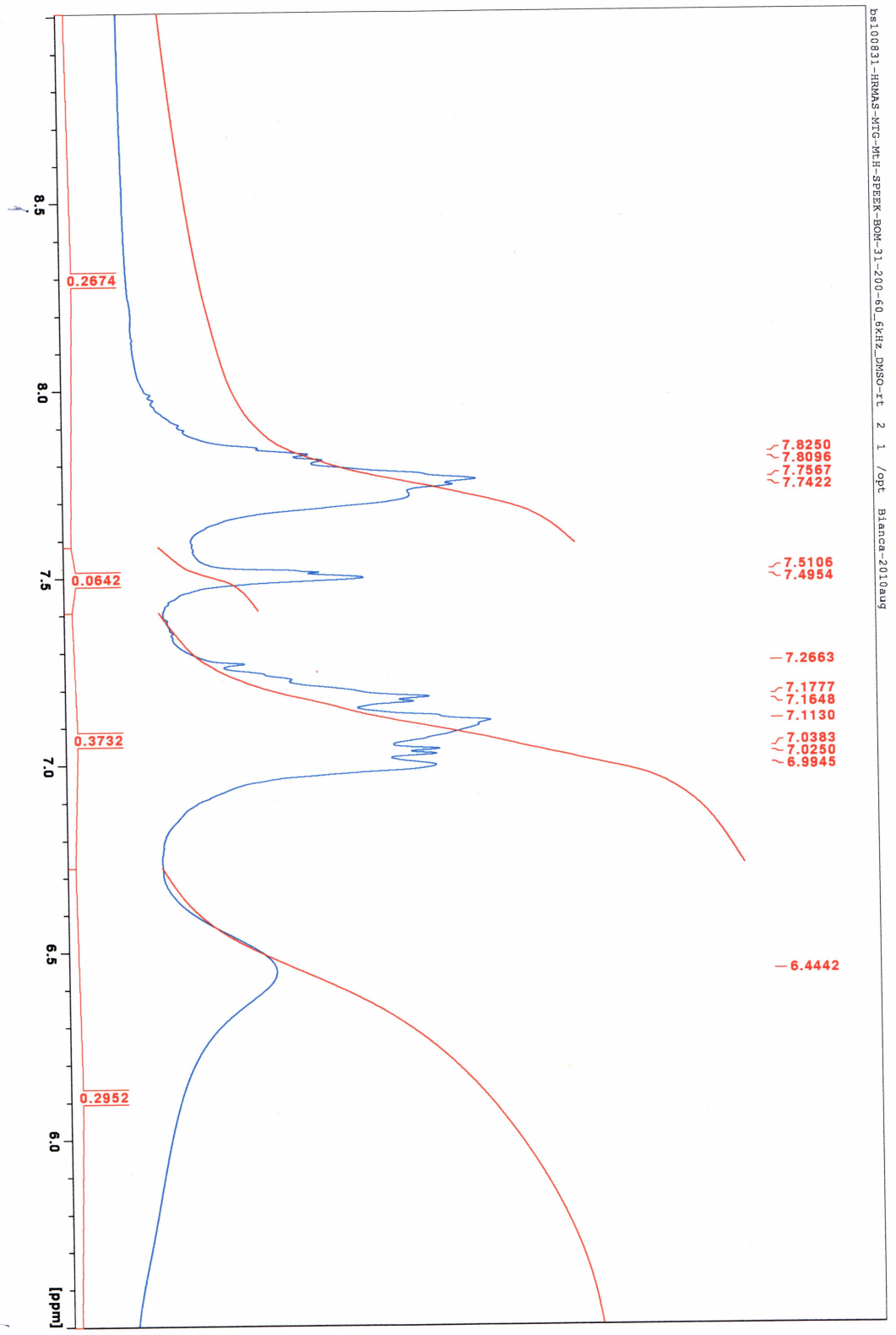


a good resolution where the crosslinked SPEEK results in a spectra with broad and overlapping peaks. Due to this an optimization needs to be done in order to increase the swelling state to narrow down the peaks and enable a characterization. With the view on the crosslinking of SPEEK at elevated temperatures $\left(\mathrm{T}=200^{\circ} \mathrm{C}\right)$ via the Friedel- Craft alkylation for curing times $=60$ minutes as described in Chapter 5 also effects the swelling behavior, as it decreases the water uptake but remaining conductive.

The lower water uptake coupled initiated the investigation on stability of crosslinked SPEEK membranes in solvents for non aqueous membrane applications like solvent resistant filtration [1], and non aqueous energy storage systems like redox flow batteries [2] or alcohol fuel cells [3]. For that the swelling in different common aqueous and non aqueous solvents have been tested. The results are summarized in Table 6.1 .

Table 6.1 Swelling results of crosslinked SPEEK membrane cured at $200^{\circ} \mathrm{Cin}$ aqueous and non aqueous solvents (sample code : cSPEEK60 2:1 = crosslinked SPEEK with a crosslinking time of 60 minutes and a SPEEK:corsslinking ratio of 2:1).

\begin{tabular}{ccc}
\hline Solvents & Swelling cSPEEK60 2:1 (\%) & Swelling cSPEEK60 3:1 (\%) \\
\hline $\mathrm{H}_{2} \mathrm{SO}_{4}$ & $20.8 \pm 9$ & $40.6 \pm 3$ \\
$\mathrm{NaOH}$ & $68.4 \pm 5$ & $134.7 \pm 6$ \\
Ethanol & $59.7 \pm 10$ & $86.3 \pm 14$ \\
Methanol & $44.0 \pm 15$ & $78.6 \pm 11$ \\
Cyclohexane & $9.2 \pm 8$ & $26.4 \pm 6$ \\
Toluene & $17.2 \pm 2$ & $13.4 \pm 1$ \\
$\mathrm{NMP}$ & $17.7 \pm 0.5$ & $41.4 \pm 1$ \\
\hline
\end{tabular}

As can be seen from Table 6.1 crosslinked SPEEK shows low swelling for Toluene, Cyclohexane and NMP but also methanol and ethanol swelling will enable the membrae for the alcohol fuel cell application. Furthermore the stability of the membrane in high $\mathrm{pH}$ environment has been tested since the swelling, especially for the cSPEEK60 $2: 1$, has proven to be reasonable for membrane applications.

The thermal stability by thermal gravimetric analysis (TGA) to examine the applicability as proton exchange membrane in high temperature applications like high temperature fuel cells, which operate in a temperature range $160{ }^{\circ} \mathrm{C} 180{ }^{\circ} \mathrm{C}[5]$. Figure 6.4 depicts the TGA of the non crosslinked SPEEK and the cSPEEK membranes. The TGA of both materials shows three main weight reduction steps. 


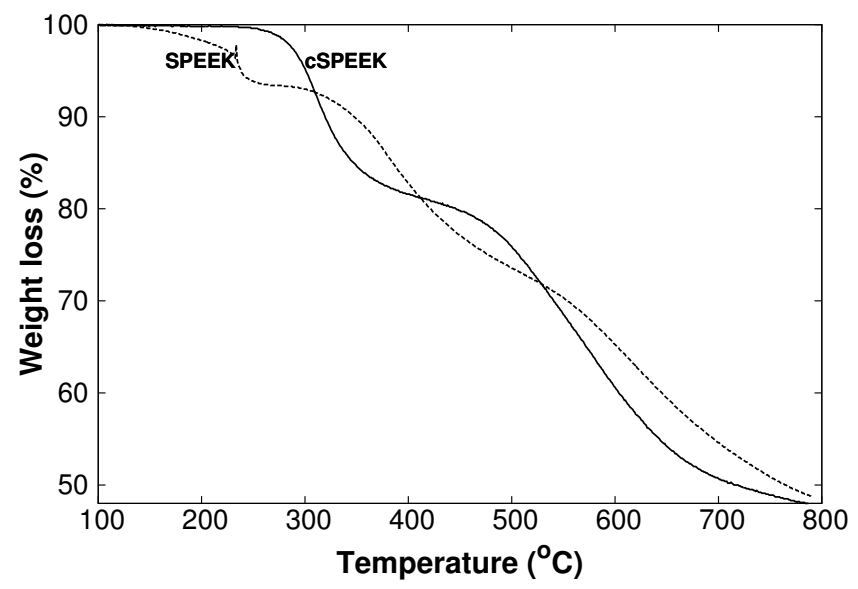

Figure 6.4 TGA spectra of non crosslinked SPEEK and crosslinked SPEEK.

The first step is due to the bound water [6]. This is only noted for the SPEEK membrane. The second weight loss can be attributed to the desulfonation reaction in which the sulfonic groups will split off [6]. It can be seen, that for the cSPEEK the degradation of the sulfonic acid groups started earlier. This is probably due to the electron donating structure of the crosslinker, by which the sulfonate group may be destabilized at elevated temperatures. Also the third weight loss, is due to the backbone degradation. The cSPEEK shows a lower temperature of degradation. Concluding from the TGA, the cSPEEK will probably not be a potential candidate high temperature application, due to the introduction of more electron withdrawing groups, which may stabilize the system leading to a more stable material. Consequently the crosslinking of SPEEK described in Chapter 5, leads to a material with high potential for many membrane applications due to good chemical stability.

\section{Bibliography}

[1] Malaisamy, R., Talla-Nwafo, A., and Jones, K. L. (2011) Separation and Purification Technology $77(3), 367-374$.

[2] Liu, Q., Sleightholme, A. E. S., Shinkle, A. A., Li, Y., and Thompson, L. T. (2009) Electrochemistry Communications 11(12), 2312 - 2315.

[3] Wongyao, N., Therdthianwong, A., and Therdthianwong, S. (2011) Energy Conversion and Management 52(7), 2676 - 2681. 
[4] Schlesinger, R., Götzinger, G., Sixta, H., Friedl, A., and Harasek, M. (2006) Desalination 192(1-3), $303-314$.

[5] Zhang, J., Xie, Z., Zhang, J., Tang, Y., Song, C., Navessin, T., Shi, Z., Song, D., Wang, H., Wilkinson, D. P., Liu, Z.-S., and Holdcroft, S. (2006) Journal of Power Sources 160(2), $872-891$.

[6] Hande, V. R., Rath, S. K., Rao, S., and Patri, M. (2011) Journal of Membrane Science 372(1-2), $40-48$. 


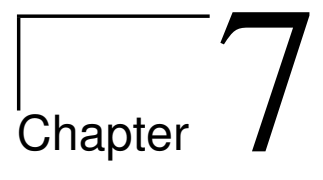

Bifunctional Oxygen/Air

Electrodes 


\subsection{Introduction}

Bifunctional oxygen electrodes (BOAE) make use of electro-catalysts performing the oxygen reduction reaction as well as the oxygen evolution reaction (Equation 7.1, 7.2).

Oxygen reduction reaction (ORR)

$$
\mathrm{O}_{2}+4 \mathrm{H}^{+}+4 e^{-} \rightarrow 2 \mathrm{H}_{2} \mathrm{O}
$$

\section{Oxygen evolution reaction (OER)}

$$
\mathrm{H}_{2} \mathrm{O} \rightarrow \mathrm{O}_{2}+4 \mathrm{H}^{+}+4 e^{-}
$$

One typical application in which bi-functional catalysts play a key role is the unitized regenerative fuel cell, where a hydrogen fuel cell has been combined and unitized with a water electrolyzer. The reactions which are combined in the URFC are depicted by Equations 7.3, 7.4 .

Electrolyzer

$$
\begin{aligned}
2 \mathrm{H}_{2} \mathrm{O} & \rightarrow 4 \mathrm{H}^{+}+\mathrm{O}_{2}+4 e^{-} & & \text {(Anode) } \\
4 \mathrm{H}^{+}+4 e^{-} & \rightarrow 2 \mathrm{H}_{2} & & \text { (Cathode) }
\end{aligned}
$$

Fuel cell:

$$
\begin{aligned}
2 \mathrm{H}_{2} & \rightarrow 4 \mathrm{H}^{+}+4 e^{-} & & \text {(Anode) } \\
4 \mathrm{H}^{+}+\mathrm{O}_{2}+4 e^{-} & \rightarrow 2 \mathrm{H}_{2} \mathrm{O} & & \text { (Cathode) }
\end{aligned}
$$

Recently a second developed application where bi-functional catalyst is essential, is the Vanadium/Air Redox Flow Battery(Vanadium/Air-RFB) [1] which is a combination of a fuel cell and a regenerative redox flow battery(Chapter 3). Also in this case, the combination of two systems requires also a combined catalyst to achieve a functioning unit. The reactions during the operation of the Vanadium/Air-RFB are depicted in Equation 7.5and 7.6.

Charge:

$$
\begin{aligned}
2 \mathrm{H}_{2} \mathrm{O} & \rightarrow 4 \mathrm{H}^{+}+\mathrm{O}_{2}+4 e^{-} \\
V^{3+}+e^{-} & \rightarrow V^{2+}
\end{aligned}
$$


Discharge:

$$
\begin{aligned}
4 \mathrm{H}^{+}+\mathrm{O}_{2}+4 e^{-} & \rightarrow 2 \mathrm{H}_{2} \mathrm{O} \\
V^{2+} & \rightarrow V^{3+}+e^{-}
\end{aligned}
$$

In both systems, the necessity of a proper functioning bifunctional oxygen air electrocatalyst is essential. The catalytic activity will determine the economics of the system. Nowadays commercial bifunctional oxygen air catalyst, operating in acidic conditions, are composed of two metals (metal oxides) Pt and Ir, where Pt is responsible for the ORR and Ir for the OER.

A decrease in platinum content and an increase of the catalytic activity towards the ORR and OER reaction would lead to a greater attractiveness for the Vanadium/AirRFB and URFC as energy storage systems. In the following section, we will summarize the attempts reported to decrease the platinum content and to increase the catalytic activity by the application of non noble metals and conclude why vanadium as a non noble metal is a promising candidate to achieve these goals.

\subsubsection{Electrocatalysts for Oxygen Reduction Reaction}

Platinum is one of the most active and stable metal for the oxygen reduction reaction (ORR) [2]. The oxygen reduction reaction is expressed in Equation 7.1. This reaction is used for many applications, among them the PEMFC, where the reduction of oxygen occurs on the cathode and the oxidation of e.g. hydrogen [3], methanol [4] and ethanol [5].

However, these application suffer from a) high price of the platinum b) sluggish reaction mechanism of the ORR on $\mathrm{Pt}[6]$. In order to decrease the costs but also to increase the catalytic activity of the catalyst for the ORR, many attempts were made to achieve these goals. One route is the incorporation of other transition metals (metal oxides) to enhance the catalytic activity of Pt and to decrease the Pt content. Here transition metals like $\mathrm{Co}[7,8,9,10]$, Ni [11, 8], $\mathrm{Cu}[12]$, Fe [13] and V [14, 15] have been studied extensively and proved to increase the catalytic activity compared to pure Pt towards ORR. Among these transition metals the doping with vanadium has not only increased the catalytic activity of platinum but also of iridium towards ORR $[16,17]$ leading to a platinum free ORR catalyst making the vanadium, as a transition metal, a potential candidate for the oxygen reduction reaction. 


\subsubsection{Electrocatalysts for Oxygen Evolution Reaction}

The OER is also a widely and important occurring reaction, for instance, in the water electrolysis [18] or electrowinning [19]. The OER is depicted in Equation 7.3). As electrocatalyst for the OER, many platinum group metals were analyzed with respect to their activities towards OER. Miles et al. [20] has reported the OER activity of the following metals in this order:

$\mathrm{Ir} \approx \mathrm{Ru}>\mathrm{Pd}>\mathrm{Rh}>\mathrm{Pt}>\mathrm{Au}>\mathrm{Nb}$. Ir is the most active catalyst for the OER. Binary electrocatalyst like $\mathrm{Ru} / \mathrm{Pt}$ [21], Ir/Ta [22], Ir/Pt [22] and $\mathrm{Ir} / \mathrm{Ru}[23,22]$ and ternary eletrocatalyst like $\mathrm{Ru} / \mathrm{Pt} / \mathrm{Pd}$ and $\mathrm{Ru} / \mathrm{Pt} / \mathrm{Ir}$ [21] were investigated as well to increase the catalytic activity. Yet, all these compositions consisted of platinum group metals and no research has been done to decrease the amount of these metals in order to decrease the costs for commercialization of these electrodes. To our best knowledge, the incorporation of non noble (non platinum group) metals has not been investigated so far for the increase of catalytic activity of electrocatalytic oxygen evolution reaction.

Haber et al. [24] observed that vanadium doped rutile as an electrocatalyst for hydrogen oxidation reaction (HOR). However, they missed in the interpretation of their data that the vanadium doping improves the OER activity. We take this as an indication, that vanadium might also be a potential metal to increase the OER activity of the existing electrocatalysts.

\subsection{Catalyst Support}

A suitable support material for the OER catalyst is as important as the right catalyst composition in order to develop a good performing OER electrode. This is due to two reasons a) a harsh environment will be created during the oxygen evolution reaction and b) a so called cracked mud morphology of the catalyst layer of the OER electrodes allowing access of the electrolyte to the support. 


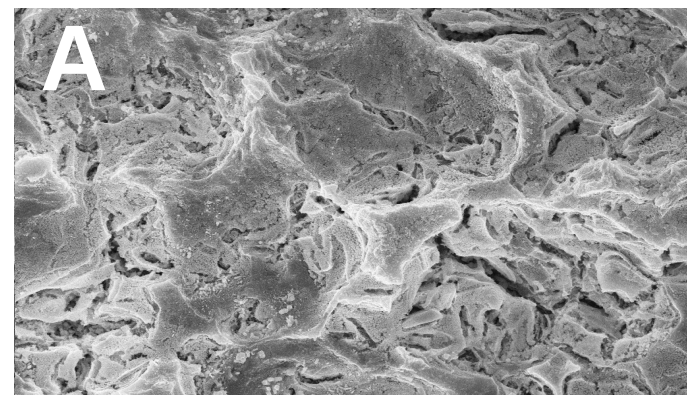

B

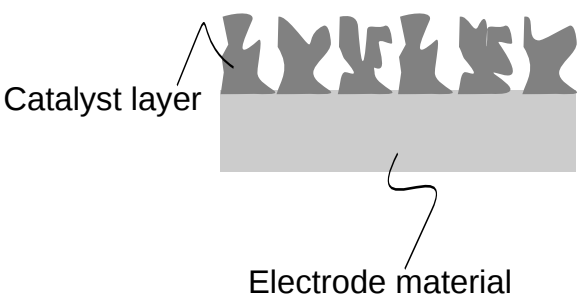

Figure 7.1 Cracked mud structure of a Pt/Ir catalyst coated on a titanium plate A) top view(SEM picture of a cracked mud structured catalyst coating) B) schematic of the side view of a cracked mud structured catalyst coating.

The OER by itself will create an aggressive environment: this is due to the in situ generated oxygen during the reaction. This oxygen shows a high oxidative potential (activated oxygen) which is due to an activation of the oxygen which can occur via two different mechanisms [25].

The first mechanism (Equation 7.8) starts with the splitting of water and describes the activated oxygen as an adsorbed hydroxyl-radical on the catalyst surface $\left(\mathrm{MO}_{\mathrm{X}}\right)$.

$$
\mathrm{MO}_{\mathrm{X}}+\mathrm{H}_{2} \mathrm{O} \rightarrow \mathrm{MO}_{\mathrm{X}}(\bullet \mathrm{OH})+\mathrm{H}^{+}+e^{-}
$$

The second mechanism(Equation 7.8) describes the integration of the oxygen inside the metal oxide lattice forming a so called higher metal oxide $\left(\mathrm{MO}_{\mathrm{x}+1}\right)$. The hydroxyl radical reacts with the already present oxygen inside the metal lattice and releases the proton and electron.

$$
M O_{X}(\bullet O H) \rightarrow M O_{X+1}+H^{+}+e^{-}
$$

The physiosorbed activated oxygen as hydroxyl-radical and the chemisorbed active oxygen as higher metal oxide will produce dioxygen in the absence of any oxidizable material according to the following equation:

$$
\begin{aligned}
M O_{X}(\bullet O H) & \rightarrow \frac{1}{2} O_{2}+M O_{X}+H^{+}+e^{-} \\
M O_{X+1} & \rightarrow \frac{1}{2} O_{2}+M O_{X}
\end{aligned}
$$

A cracked mud structure as shown in Figure 7.1, shows a common morphology for thermally produced catalyst coating [26]. The activated oxygen can attack the support material at the interphase and lead to severe corrosion of the electrode material. 
Furthermore the cracks in the catalyst layer enable the surrounding electrolyte to penetrate to the electrode material and also cause, depending on the nature of the surrounding electrolyte, damage on the electrode material. All damages on the electrode material will lead to a) either increase of electrical resistivity of the electrode material due to oxide formation or b) exfoliation of the catalytic layer. In the first case, the energy consumption increases, in the second case deactivation of the electrode will occur. Due to that, the electrode material needs to be resistant against corrosion and the catalytic layer formation has to be efficient in order to reduce cracks in the catalytic layer. With respect to the catalytic layer formation, vanadium (vanadium oxide) has shown in previous studies of Centi et al., to have a high surface coverage behavior when applied on $\mathrm{TiO}_{2}$. This was explained by the acidity of the $\mathrm{V}_{2} \mathrm{O}_{5}$ and the basicity of $\mathrm{TiO}_{2}$ [27]. Hence vanadium (vanadium oxide) seems as well to be a potent partner to overcome the issues of the cracked mud structure and enhance the life time stability of the OER electrode.

\subsection{Bifunctional Oxygen / Air Electrode (BOAE)}

The development of bifunctional electrocatalyst being able to perform both ORR and OER efficiently led in the past to the following binary and ternary electrocatalysts: $\mathrm{Pt} / \mathrm{Ir}, \mathrm{Pt} / \mathrm{Ru} / \mathrm{Ir}[28]$ and $\mathrm{Pt} / \mathrm{IrO}_{2} / \mathrm{RuO}_{2}$. The bifunctionality is obtained by simply blending the most efficient electrocatalyst for a) ORR, which is Pt black (platinum powder) and b) OER, Ir, $\mathrm{IrO}_{2}$ and $\mathrm{IrO}_{2} / \mathrm{RuO}_{2}$ together [29]. Furthermore the support of the catalyst seem to play an important role in the catalytic behavior like in the case of $\mathrm{Pt} / \mathrm{Ir} / \mathrm{TiC}$ [29] where $\mathrm{Pt}$ and Ir were deposited on $\mathrm{TiC}$ support by a plasma reduction process. Although this catalyst has shown an increase of catalytic activity, the production procedure is rather complex. Also the reduced use of platinum group metals was not achieved, since the $\mathrm{TiC}$ was only used as support material. Another case of support dependent activity has been reported by Chen et al. [30] where three types of supports were examined: 1) Ebonex (which is a mixture of $\mathrm{Ti}_{4} \mathrm{O}_{7}$ and other phases ), 2) phasepure microcrystalline $\mathrm{Ti}_{4} \mathrm{O}_{7}$ and 3) $\mathrm{Ti}_{0.9} \mathrm{Nb}_{0.1} \mathrm{O}_{2}$ and were found more stable in a broader range of catalyst combination. To the best of our knowledge, no other non-noble transition metals was ever used a) to decrease the content of platinum group metals b) to enhance the catalytic activity and c) to improve the life time and resistance as a third component in a BOAE.

Above mentioned background indicated that vanadium may be a valuable third com- 
ponent in a ternary catalyst with $\mathrm{Pt}$ and Ir. This chapter describes experimental evidence through cyclic voltammetry and accelerated life time testing. Structure analysis of the new ternary catalyst is carried out by X-ray diffraction (XRD), scanning electron microscopy (SEM), and energy dispersive X-ray spectroscopy (EDX).

\subsection{Experimental}

\subsubsection{Chemicals and Materials}

Pt/Ir (70/30 wt\%; $\left.8.05 \mathrm{~g} / \mathrm{m}^{2} \mathrm{Pt}\right)$ and Pt/Ir/V (63/27/10 wt\%; $\left.7.47 \mathrm{~g} / \mathrm{m}^{2} \mathrm{Pt}\right)$ catalyst coated on titanium were supplied by Magneto Special Anodes B.V. Schiedam, The Netherlands. $\mathrm{VOSO}_{4}(97 \%)$ was purchased from Sigma Aldrich. As reference electrode an $\mathrm{Ag} / \mathrm{AgCl}$ electrode was used. The CVs were recorded with a Titraplate PST050 and the accelerated lifetime tests were performed in a dedicated set up at Magneto consisting of an $\mathrm{Ag} / \mathrm{AgCl}$ reference electrode and an auxiliary electrode made from platinum mesh. The investigated BOAEs were functioning as working electrodes.

\subsubsection{Electrode Preparation}

Initial screening experiments of the influence of vanadium on the catalyst activity were performed using commercial Pt/Ir on titanium electrodes of Magnet. The electrodes were immersed inside a $3 \mathrm{M}$ sulfuric acid solution containing $0.25 \mathrm{M}$ of $\mathrm{VOSO}_{4}$. The solution was heated up under reflux to $80^{\circ} \mathrm{C}$ for 2 hours followed by the removal of the electrode and transferring it to an oven at $550^{\circ} \mathrm{C}$. After 1 hour of heat treatment the electrode was removed from the oven and allowed to reach room temperature under the fume hood. This procedure was adopted Magneto special Anodes B.V. where $\mathrm{VOSO}_{4}$ was integrated inside the catalyst ink solution and applied to the titanium plates in order to produce $\mathrm{Pt} / \mathrm{Ir} / \mathrm{V}$ coated titanium electrodes. The data presented below were obtained with the $\mathrm{Pt} / \mathrm{Ir} /$ and $\mathrm{Pt} / \mathrm{Ir} / \mathrm{V}$ catalysts coated on titanium plate produced by the company Magneto Special Anodes B.V..

\subsubsection{Cyclic Voltammetry}

Cyclic voltammograms (CV) were recorded in a potential range of $400 \mathrm{mV}$ to $1600 \mathrm{mV}$ (vs. $\mathrm{Ag} / \mathrm{AgCl}$ ) with a scanning rate of $5 \mathrm{mV} / \mathrm{s}$ in a $25 \% \mathrm{H}_{2} \mathrm{SO}_{4}$ electrolyte at $25.0^{\circ} \mathrm{C}$. 
The electrolyte solution was purged with air for 30 minutes before every CV measurements in order to ensure oxygen saturation. CVs for the electrochemical surface area analysis by carbon monoxide stripping were recorded in the potential range of $-200 \mathrm{mV}$ to $1000 \mathrm{mV}$ (vs. $\mathrm{Ag} / \mathrm{AgCl}$ ) at a scan rate of $20 \mathrm{mV} / \mathrm{s}$ in a $0.5 \mathrm{M} \mathrm{H}_{2} \mathrm{SO}_{4}$.

\subsubsection{X-Ray Diffraction}

Powder Diffraction patterns have been obtained by employing x-ray diffraction experiments using the Copper K-alpha emission lines filtered by nickel to suppress the K-beta line. A Philips XPert 4-angle diffractometer was used with a multi-channel detector for faster data acquisition in Bragg-Brentano geometry.

\subsubsection{Accelerated Lifetime Tests}

Accelerated lifetime tests of the $\mathrm{Pt} / \mathrm{Ir}$ and $\mathrm{Pt} / \mathrm{Ir} / \mathrm{V}$ electrodes $\left(65 \mathrm{~mm}^{2}\right)$ were done in $25 \% \mathrm{H}_{2} \mathrm{SO}_{4}$ solution at a current density of $2.5 \mathrm{kA} / \mathrm{m}^{2}$ at $50^{\circ} \mathrm{C}$. The reversal of the polarity was done every 5 minutes. These conditions are standard conditions for the company Magneto B.V. which has tested the electrodes. The reversal of the current was applied to increase the stress on the electrodes.

\subsubsection{High Resolution Scanning Electron Microscopy and Energy- Dispersive X-Ray Spectroscopy}

High resolution scanning electron microscopy (HR-SEM) images were obtained using a HR-SEM - Zeiss 1550 microscope at $20 \mathrm{kV}$ accelerating voltage. Energy-dispersive X-ray spectroscopy (EDX) observations were obtained with a Thermo Noran Vantage EDX system at $20 \mathrm{kV}$ accelerating voltage. 


\subsection{Results and Discussion}

The catalytic activity of the developed vanadium doped Pt/Ir coated Ti electrode was observed towards OER and ORR by the cyclic voltammetry. Figure 7.2 (A) shows the forward scan $(1.2 \mathrm{~V}-1.6 \mathrm{~V}$ vs. $\mathrm{Ag} / \mathrm{AgCl})$ for oxygen evolution reaction (OER) and $(\mathrm{B})$ the backward scan $(0.6 \mathrm{~V}-0.4 \mathrm{~V}$ vs. $\mathrm{Ag} / \mathrm{AgCl})$ for oxygen reduction reaction (ORR).
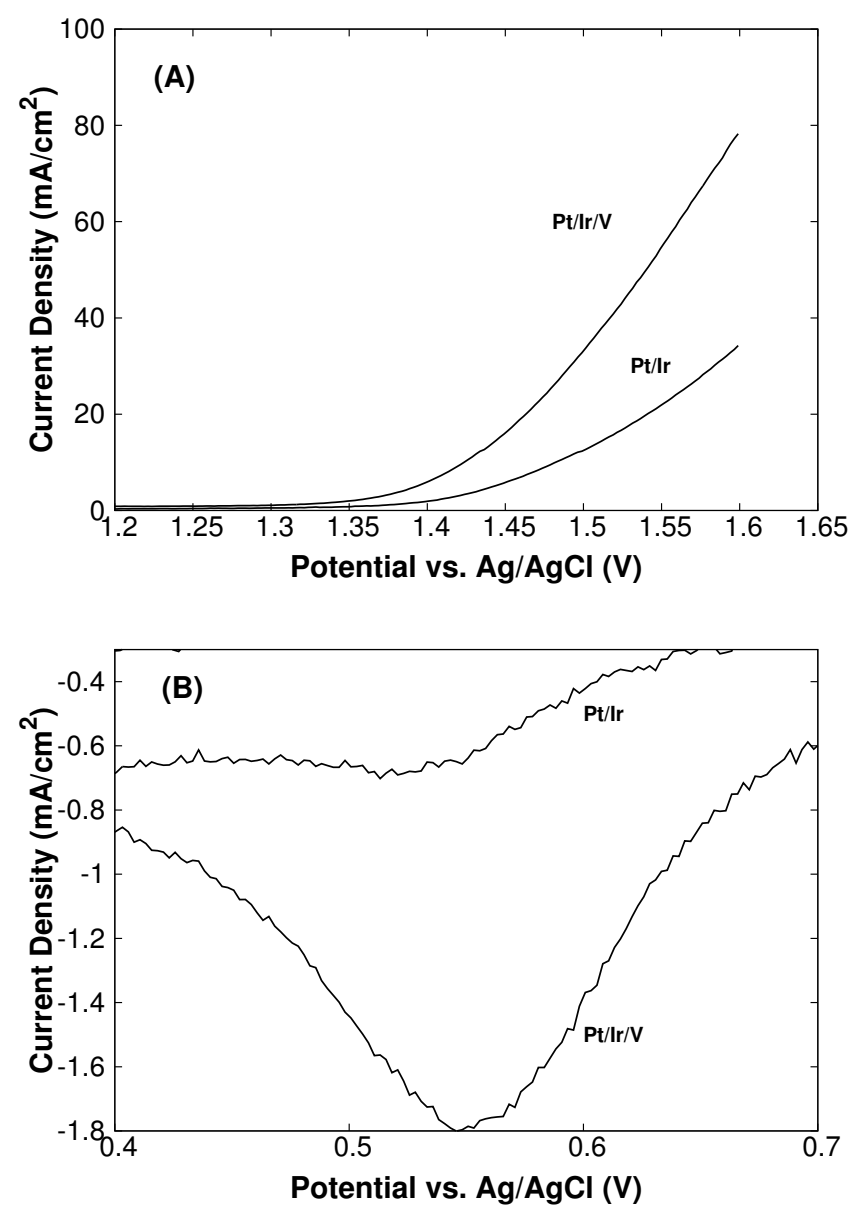

Figure 7.2 $C V$ of Pt/Ir (70/30 wt\%) and Pt/Ir/V (63/27/10 wt\%) catalyst coated on Ti in 25\% $\mathrm{H}_{2} \mathrm{SO}_{4}$ at room temperature recorded at a scan rate of $5 \mathrm{mV} / \mathrm{sec}$ where A) shows the $O E R$ and $B)$ the ORR.

CVs show that the catalytic activity of the $\mathrm{Pt} / \mathrm{Ir} / \mathrm{V}$ is higher for the ORR and the 
OER than the commercial bifunctional electrodes (Pt/Ir). Such drastic increase of the catalytic activity might be due to an increase of ECSA, which could be confirmed by the surface area calculations from the CO stripping voltammetry data, where Pt/Ir was determined to have an electrochemical surface area of $2.75 \mathrm{~m}^{2} / \mathrm{g}$ and for $\mathrm{Pt} / \mathrm{Ir} / \mathrm{V}$ $29.33 \mathrm{~m}^{2} / \mathrm{g}$. This might be due to two reasons a) the addition of vanadium improved significantly the dispersion of the metallic components leading to an increase of catalytic sides and so to an increased catalytic activity or b) the addition of vanadium leads to a nano crystalline morphology resulting in a higher surface area.

Here XRD data may also indicate the presence of nano crystals (Figure 7.3). The XRD patterns in Figure 7.3 are made from the titanium coated electrodes, due to that also titanium reflexes are visible in the XRD pattern. The titanium specific reflections are therefore marked red in the figure and will not be taken into account for the further observations. The coatings are $\mathrm{Pt}, \mathrm{Ir}, \mathrm{Pt} / \mathrm{Ir}$ and $\mathrm{Pt} / \mathrm{Ir} / \mathrm{V}$. The dotted lines in Figure 7.3 indicate Pt reflections. As the XRD indicates, Ir coated Ti electrodes do not show any reflections. This is probably due to nano crystalline morphology or an amorphous morphology. However it can be seen, that the dotted line marked reflections occurring in the case of pure platinum also occur in the case of $\mathrm{Pt} / \mathrm{Ir}$ and in a very broad and weak form also in $\mathrm{Pt} / \mathrm{Ir} / \mathrm{V}$. In XRD, strong reflections as in the case of $\mathrm{Pt}$ and $\mathrm{Pt} / \mathrm{Ir}$, indicate a crystalline phase where weak reflections as in the case of $\mathrm{Pt} / \mathrm{Ir} / \mathrm{V}$ indicate either a) nano crystallinity $(5-10 \mathrm{~nm}$ ) or b) no crystallinity (amorphous morphology). 


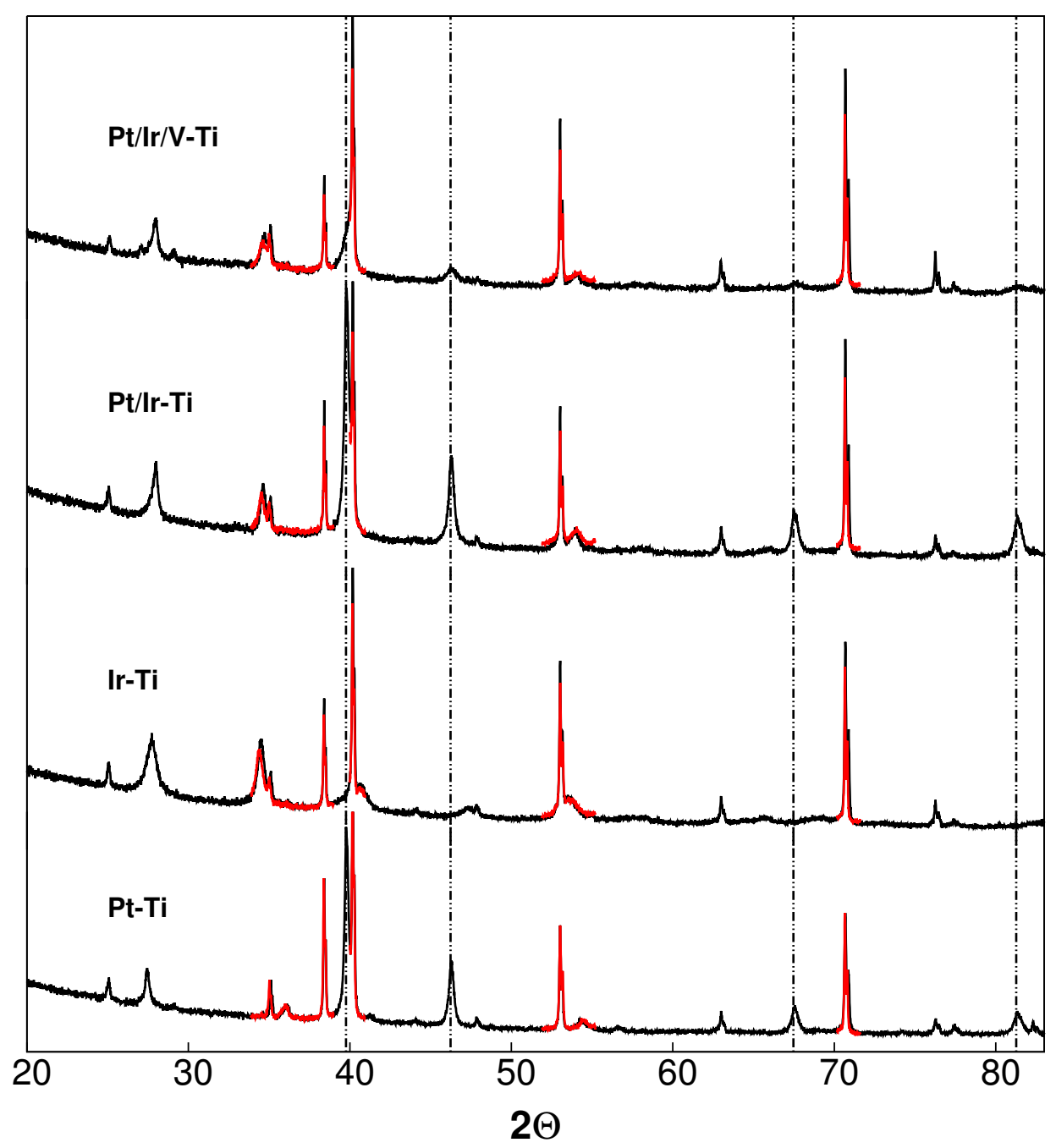

Figure 7.3 XRD patterns of catalyst coated on titanium, catalysts are Pt, Ir, Pt/Ir (70/30 wt\%) and $\mathrm{Pt} / \mathrm{Ir} / \mathrm{V}(63 / 27 / 10 \mathrm{wt} \%)$, dotted lines indicate the reflections due to Pt.

Scanning electron microscopy can reveal overall and fine structure of the electrode catalytic surface. Figures 7.4 and 7.5 show the standard Pt/Ir-Ti electrode at two different resolutions. The figures reveal the well known cracked mud morphology. The vanadium modified $\mathrm{Pt} / \mathrm{Ir} / \mathrm{V}$-Ti electrode shows a grainy morphology, however the cracked like defects are now filled and smoothened. Whether or not this new surface has a larger surface area cannot be concluded from the SEM pictures. 

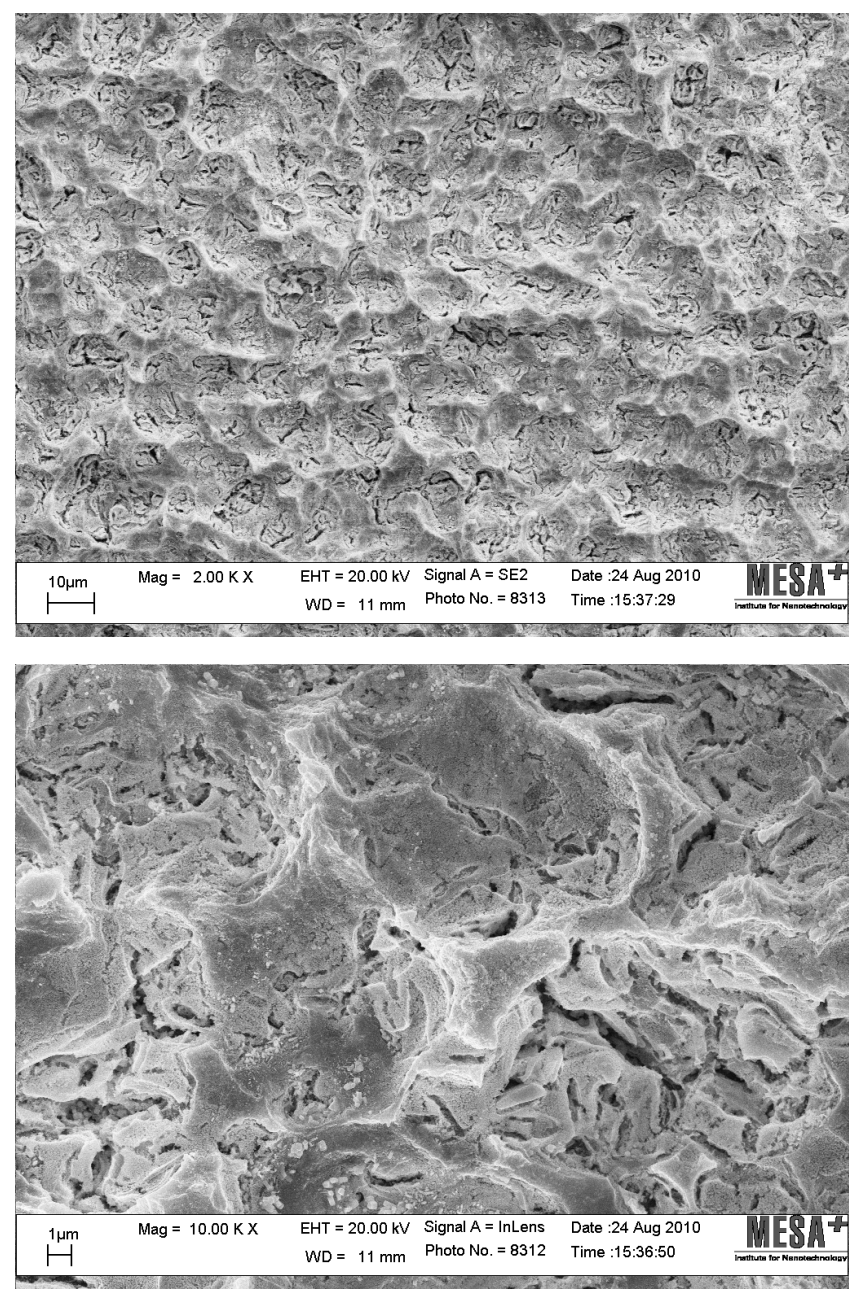

Figure 7.4 High resolution SEM of the Pt/Ir (70/30 wt\%) catalyst on a Ti substrate. A grain like morphology with crack like defects are visible. 

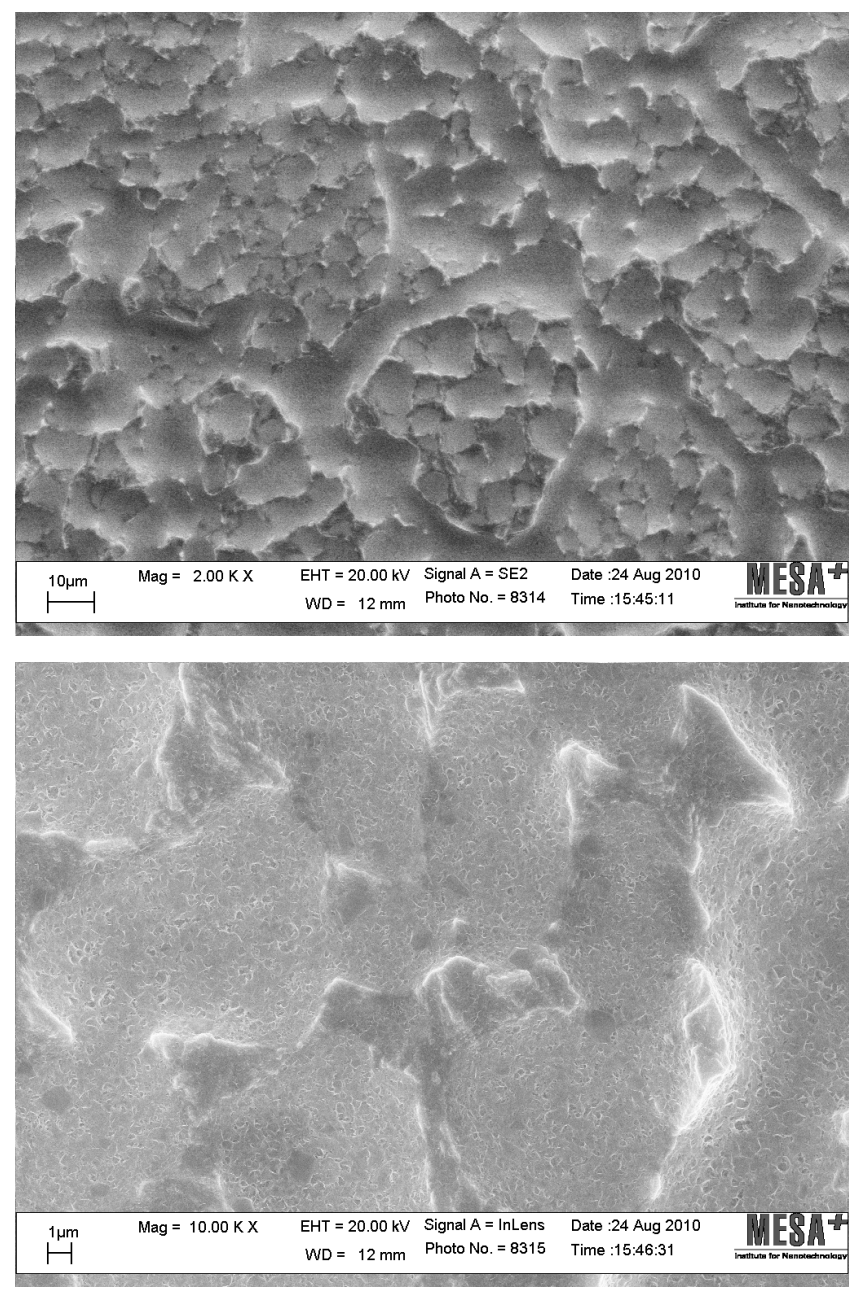

Figure 7.5 High resolution SEM of the Pt/Ir/V (63/27/10 wt\%) catalyst on a Ti substrate. Crack like defects are not visible. Grain like domains appear to be bridged by an intergrain phase.

The surface coverage of the vanadium doped Pt/Ir has also a positive effect on the electrochemical stability of the electrode as can be seen by the accelerated lifetime test where the electrode was tested towards the OER. The OER has been chosen to test the life time stability due to the aggressive nature of the reaction intermediates which are produced during the oxygen evolution reaction. 


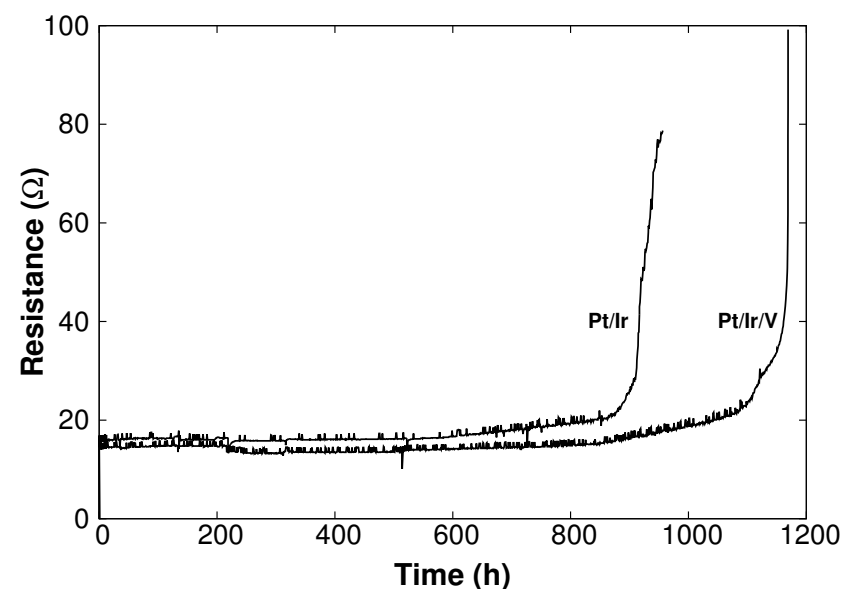

Figure 7.6 Accelerated life time test of Pt/Ir (70/30 wt\%) and Pt/Ir/V (63/27/10 wt\%) catalyst coated on Ti in $25 \% \mathrm{H}_{2} \mathrm{SO}_{4}$ recorded at $2.5 \mathrm{kA} / \mathrm{m}^{2}$ current density at $50^{\circ} \mathrm{C}$.

The vanadium doping increases the life time of the electrode up to $17 \%$ under the harsh testing conditions. The extended life time also proofs the positive influence of the surface coverage in the case of the vanadium doped titanium electrode by the catalyst. Indeed, the major reason of electrode deactivation is due to the failure of the titanium support material. The homogeneous coverage of the electrode by the catalyst layer may be due to the coverage properties of vanadium oxide as described elsewhere [27] where it was observed, that vanadium oxide shows a smooth and homogeneous surface coverage when sputtered on an indium tinoxide coated glass. This hypothesis may be supported by the EDX observations (Figure 7.7, 7.8) of the vanadium doped Pt/Ir. It shows that with the appearance of vanadium also oxygen is incorporated, which may indicate, that the catalyst layer consists of $\mathrm{Pt} / \mathrm{Ir} / \mathrm{V}_{2} \mathrm{O}_{5}$. 


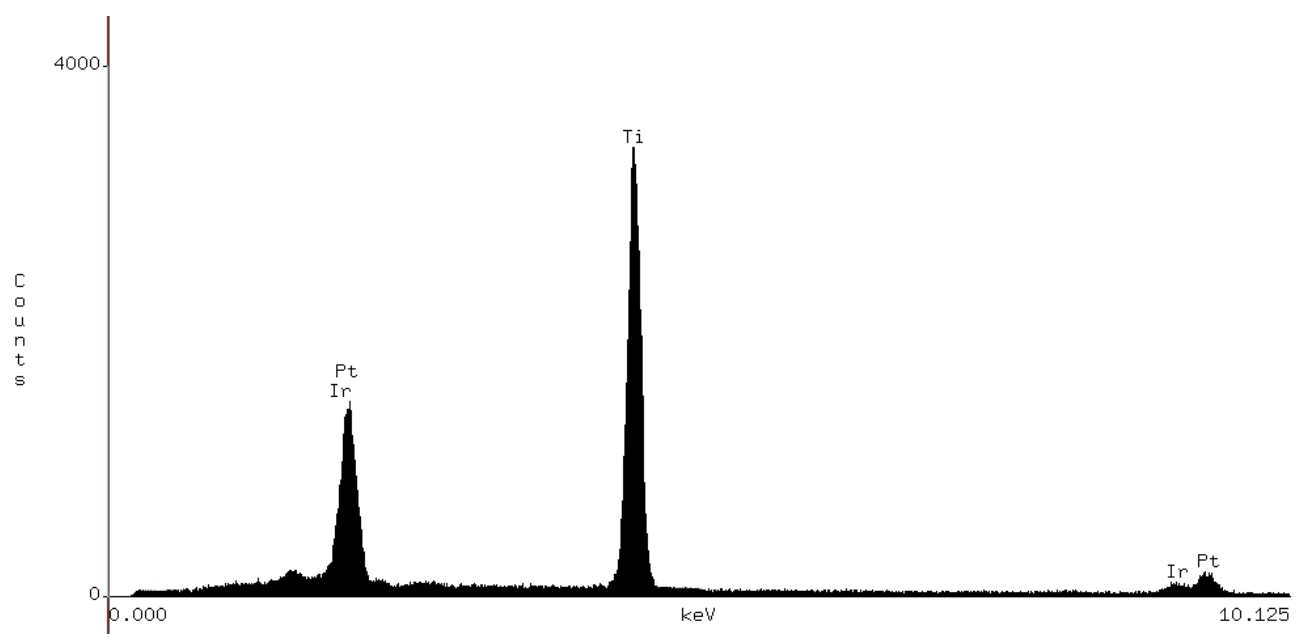

Figure 7.7 EDX of the Pt/Ir (70/30 wt\%) catalyst on Ti substrate.

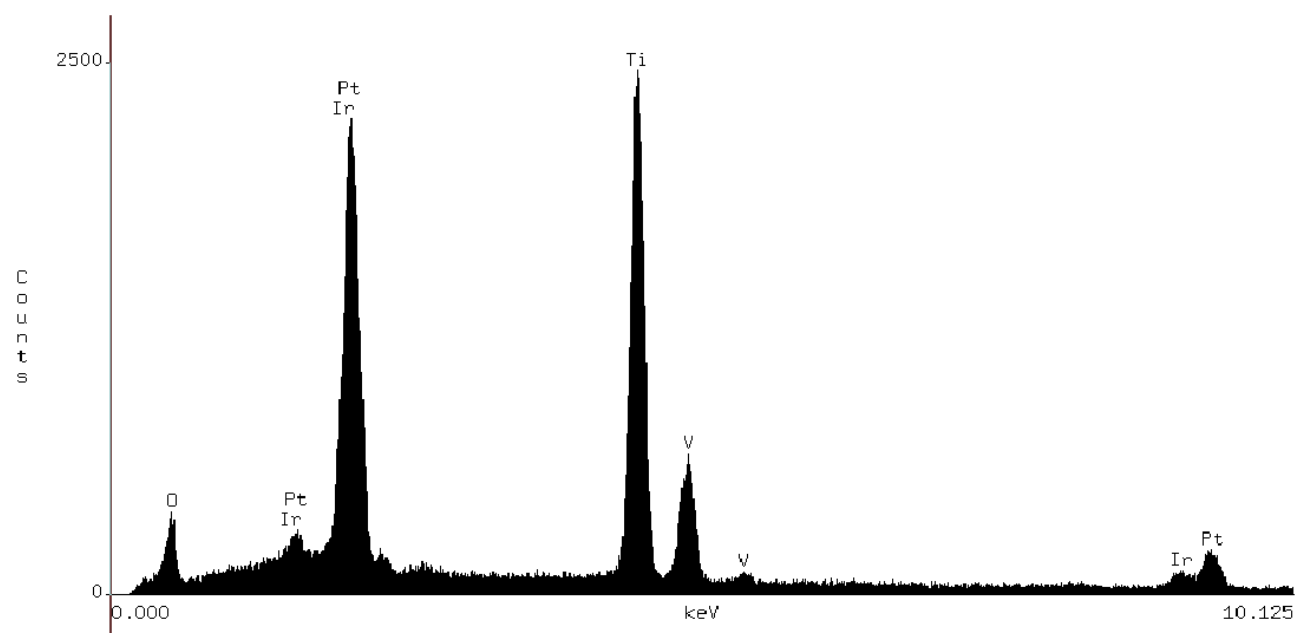

Figure 7.8 EDX of the Pt/Ir/V (63/27/10 wt\%) catalyst on Ti substrate.

However, the coverage of the catalyst layer on the titanium support may also not be complete in the case of the vanadium doped $\mathrm{Pt} / \mathrm{Ir}$ since also this catalyst shows a certain life time. Due to that, further observations in the coverage efficiency of the catalyst is of great importance in order to understand the coverage behavior of the vanadium doped catalyst. By the deep understanding of the coverage behavior, the catalyst composition might be tuned in such a way, that complete coverage could take place. By this, not only the life time could be increased further but also more 
economical electrode support materials other than titanium could be used. Vanadium turns out to be a powerful third ingredient for the catalyst composition in order to develop low platinum, high efficient and long service time bifunctional oxygen air electrodes.

\subsection{Conclusion}

$\mathrm{Pt} / \mathrm{Ir} / \mathrm{V}$ catalyst show increased OER and ORR catalytic activities compared to the commercial available bifunctional $\mathrm{Pt} / \mathrm{Ir}$ catalysts. Also the lifetime has been increased about $17 \%$ by the doping with vanadium which is probably due to the improved crack less catalytic layer formation. By this, also the possibility of applying the catalyst on other substrates, other than $\mathrm{Ti}$ will be given, since the durability of the substrate against corrosion is one of the major issues for the electrocatalytic active electrodes. Applying a cheaper substrate coupled with the reduction of noble metals in the catalyst and an increase of the catalytic activity towards ORR and OER. However, during our investigation, we also observed an increase of catalytic activity for other reactions which are of great importance for other electrical energy conversion and storage procedures like the methanol and hydrogen fuel cells and metal/air batteries. These investigations will be shortly discussed in the appendix and need to be closer observed in the future. For now, the increased catalytic activity by vanadium doping in the ternary catalyst complex can only be explained by the $\sim 20$ fold increase of electrochemical surface area which has been observed within this work, where further investigation on material properties need to be followed to understand the effect of vanadium doping.

\section{Bibliography}

[1] Hosseiny, S. S., Saakes, M., and Wessling, M. (2010) Electrochemistry Communications DOI:10.1016/j.elecom.2010.11.025.

[2] Zhang, J. (2008) PEM Fuel Cell Electrocatalysts and Catalyst Layers, SpringerVerlag London.

[3] Moore, J. (2009) Fuel Cells Bulletin 2009(8), 12 - 14.

[4] Zainoodin, A., Kamarudin, S., and Daud, W. (2010) International Journal of Hydrogen Energy 35(10), 4606 - 4621. 
[5] Song, S. and Tsiakaras, P. (2006) Applied Catalysis B: Environmental 63(3-4), $187-193$.

[6] Koper, M. T. M. (2009) Fuel Cell Catalysis: A Surface Science Approach, John Wiley \& Sons, Inc.

[7] Gasteiger, H. A., Kocha, S. S., Sompalli, B., and Wagner, F. T. (2005) Applied Catalysis B: Environmental 56(1-2), 9 - 35.

[8] Paulus, U. A., Wokaun, A., Scherer, G. G., Schmidt, T. J., Stamenkovic, V., Markovic, N. M., and Ross, P. N. (2002) Electrochimica Acta 47(22-23), 3787 3798.

[9] Mayrhofer, K., Juhart, V., Hartl, K., Hanzlik, M., and Arenz, M. (2009) Angewandte Chemie International Edition 48(19), 3529-3531.

[10] Koh, S., Leisch, J., Toney, M. F., and Strasser, P. (2007) The Journal of Physical Chemistry C 111(9), 3744-3752.

[11] Stamenkovic, V. R., Fowler, B., Mun, B. S., Wang, G., Ross, P. N., Lucas, C. A., and Markovic, N. M. (2007) Science 315(5811), 493-497.

[12] Koh, S. and Strasser, P. (2007) Journal of the American Chemical Society 129(42), 12624-12625.

[13] Mitsuru, W., S., H., M., S., Hiroyuki, U., and Masahiro, W. (2008) The Journal of Physical Chemistry C 112(7), 2750-2755.

[14] Antolini, E. (2007) Applied Catalysis B: Environmental 74(3-4), $324-336$.

[15] Santos, L. G. R. A., Freitas, K. S., and Ticianelli, E. A. (2009) Electrochimica Acta 54(22), 5246-5251.

[16] Qiao, J., Li, B., Yang, D., and Ma, J. (2009) Applied Catalysis B: Environmental 91(1-2), $198-203$.

[17] Qiao, J., Lin, R., Li, B., Ma, J., and Liu, J. (2010) Electrochimica Acta 55(28), $8490-8497$.

[18] Matsumoto, Y. and Sato, E. (1986) Materials Chemistry and Physics 14(5), 397 -426 .

[19] Cardarelli, F. (2008) Materials Handbook, Springer London. 
[20] Miles, M. H., Klaus, E. A., Gunn, B. P., Locker, J. R., Serafin, W. E., and Srinivasan, S. (1978) Electrochimica Acta 23(6), 521 - 526.

[21] Neyerlin, K. C., Bugosh, G., Forgie, R., Liu, Z., and Strasser, P. (2009) Journal of The Electrochemical Society 156(3), B363-B369.

[22] Blasi, A. D., Urso, C. D., Baglio, V., Antonucci, V., Arico, A., Ornelas, R., Matteucci, F., Orozco, G., Beltran, D., Meas, Y., and Arriaga, L. (2009) Journal of Applied Electrochemistry 39, 191-196.

[23] Fuentes, R. E., Farell, J., and Weidner, J. W. (2011) Electrochemical and SolidState Letters 14(3), E5-E7.

[24] Haber, J. and Nowak, P. (2002) Topics in Catalysis 20, 75-83.

[25] Comninellis, C. (1994) Electrochimica Acta 39(11-12), 1857 - 1862.

[26] Chandler, G. K., Genders, J. D., and Pletcher, D. (1997) Platinum Metals Review 41, 54-63.

[27] Centi, G., Pinelli, D., and Trifiro, F. (1991) Materials Chemistry and Physics 29(1-4), $271-285$.

[28] Chen, G., D., D. A., Sarangapani, S., and Mallouk, T. E. (2001) Catalysis Today 67(4), $341-355$.

[29] Sui, S., Ma, L., and Zhai, Y. (2011) Journal of Power Sources DOI: 10.1016/j.jpowsour.2011.02.058.

[30] Chen, G., Bare, S. R., and Mallouk, T. E. (2002) Journal of The Electrochemical Society 149(8), A1092-A1099. 
$\Gamma_{\text {Chapter }}$

$\mathrm{Pt} / \mathrm{Ir} / \mathrm{V}-$

A Multifunctional Electrocatalyst? 


\subsection{Introduction}

A new ternary electro catalyst $(\mathrm{Pt} / \mathrm{Ir} / \mathrm{V})$ was described in Chapter 7 as a bifunctional oxygen air catalyst with enhanced catalytic properties towards OER and ORR compared to the commercial Pt/Ir. The incorporation of a non-noble transition metal into the $\mathrm{Pt} / \mathrm{Ir}$ catalyst was triggered by the aim to decrease the platinum group metal content of the existing bifunctional oxygen air catalyst and to increase the catalytic properties towards the OER and ORR. The choice of using vanadium was based on a literature study, in which vanadium noble metal alloys showed catalytic activity for OER and ORR (Section 7.1). A simple blending strategy was used to increase catalytic activity and to decrease the noble metal content, where $\mathrm{Pt} / \mathrm{Ir}$ was doped with vanadium and further processed by heat treatment to the $\mathrm{Pt} / \mathrm{Ir} / \mathrm{V}$.

Surprisingly, during the electrochemical characterization further beneficial properties of the new $\mathrm{Pt} / \mathrm{Ir} / \mathrm{V}$ catalyst were discovered and investigated to a certain extend. These include an increased activity for hydrogen evolution reaction (HER) and carbon monoxide oxidation reaction. In the following the investigated characteristics of the $\mathrm{Pt} / \mathrm{Ir} / \mathrm{V}$ will be discussed in more details.

\subsection{Hydrogen Evolution Reaction (HER)}

In recent years the focus on renewable energy sources have been significantly increased due anticipated shortage disadvantages of fossil fuels as energy carriers (Chapter 1). In particular a strong interest has been developed in replacing the fossil fuels with renewable resources like solar, wind and biomass. However, the development of new technologies being able to replace the fossil fuels as energy source will strongly depend on the success of transforming electrons into chemical species. This may have a strong impact in the case of a redox flow battery or a chemical conversion function in order to produce for instance hydrogen. Here as an energy carrier and as the most abundant element hydrogen became the focus of many researcher as an alternative energy source which can be produced by the combination of protons and electrons. Equation 8.1 depicts the hydrogen evolution reaction (HER).

$$
2 \mathrm{H}^{+}+2 e^{-} \rightarrow \mathrm{H}_{2}
$$

While the reaction seems a simple one electron transfer reaction, it appeared that only certain catalyst can promote this reaction to produce hydrogen efficiently. One of the most active catalyst for the HER in acidic conditions is platinum. Although showing 
the highest activity for HER [1], the price of platinum is one major disadvantage of this material, since platinum as a noble metal is among the least abundant elements in the Earths crust [2] with a estimated world resource of 47,500 tonnes only [3]. Due to that low platinum containing catalysts are highly appreciated for the HER purpose.

Strategies of decreasing the content of platinum and with that the costs of HER catalysts for acidic media were reported by $[4,5,6]$. However, these catalyst have either a lower HER activity as pure platinum or the preparation of the catalyst is too complex. An interesting study on hydrogen evolution has been made by Bélanger et al. [7] where vanadium has been mentioned to be active in the HER. To the best of our knowledge, this reference is the first one which examined vanadium in acidic media on HER. Bélanger observed that HER was promoted on vanadium electrodes in acidic media. Due to that we have extended the observation range of the $\mathrm{Pt} / \mathrm{Ir} / \mathrm{V}$ catalyst of Chapter 7 by $\mathrm{CV}$ to investigate the influence of the vanadium doping on the HER behavior. Pt/Ir/V electrodes were prepared as described in Chapter 7 and CVs were recorded as described in a range of $0 \mathrm{~V}$ to $-1 \mathrm{~V}$ vs. an $\mathrm{Ag} / \mathrm{AgCl}$ reference electrode with a scan rate of $5 \mathrm{mV} / \mathrm{s}$. Figure 8.1 depicts the recorded CVs for the above mentioned potential range.

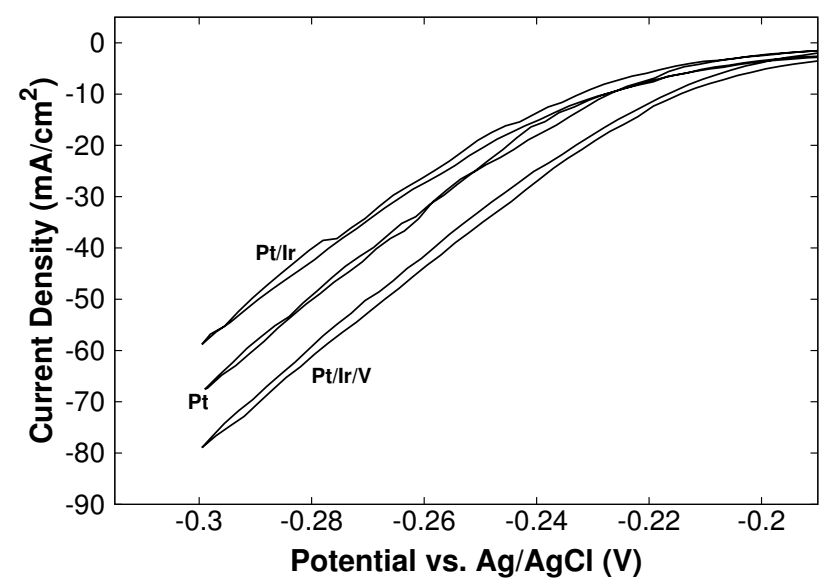

Figure 8.1 Hydrogen evolution CV of Pt; Pt/Ir (70/30 wt\%) and Pt/Ir/V (63/27/10 wt\%) catalyst coated on $\mathrm{Ti}$ in $25 \% \mathrm{H}_{2} \mathrm{SO}_{4}$ at room temperature recorded at a scan rate of $5 \mathrm{mV} / \mathrm{sec}$.

Figure 8.1 shows that the addition of Iridium to Platinum decreases the HER activity. Addition of Vanadium to the Pt/Ir increases the HER activity significantly. Yet, we have not explored the influence of Pt and V only, nor do we know whether $10 \mathrm{wt} \% \mathrm{~V}$ 
doping is the optimum with respect to the various electrochemical reactions. To fully comprehend the multi-functional electro-catalytic behavior of the vanadium doped Pt-Ir, further investigations are required:

- EDX measurement of the vanadium doped Pt/Ir has shown that the incorporation of oxygen appears simultaneously with the vanadium doping. Vanadium may be present inside the $\mathrm{Pt} / \mathrm{Ir} / \mathrm{V}$ catalyst as $\mathrm{V}_{2} \mathrm{O}_{5}$.

Vanadium oxide was found to function as a regenerative agent for HER on nickel in alkaline media, where the HER could not be further enhanced as on a pure $\mathrm{Ni}[8]$. However, this this is not of relevance in our case since 1) vanadium has undergone a thermal treatment with other metals 2) the observation of HER were done in acidic media. Assuming that the vanadium in the formulation is present as an oxide, the catalytic activity of the pure oxide has to be observed in the future since transition metal oxides like $\mathrm{IrO}_{2}$ and $\mathrm{RuO}_{2}$ were discovered as active HER electrocatalyst [9], where the stability of these oxides was attributed to the conducting properties of the oxides.

- As discussed in Chapter 7 the resulting $\mathrm{Pt} / \mathrm{Ir} / \mathrm{V}$ catalyst may be present in form of nano crystals in the range of 5-10 nm. Such small crystals will increase the surface area of the formulation leading to an increase in active sides. Due to that, further investigations in the morphology analysis have to follow in order to understand the doping.

- The electronical structure of Pt and Ir are rather different as compared to V . Due to that the concept of the strong metal support interaction (SMSI) has to be included as well for the future, where the electronical structure of the metals (when deposited on each other) can generate a synergistic effect [9], which might be beneficial for the HER.

Applying further analytic methods like X-ray absorption spectroscopy to observe the electronical configuration of the catalyst formulation, atomic force microscopy to observe surface properties and rotating disk electrode measurements to understand the kinetics will maybe lead to a deep understanding of the effect of the vanadium doping with which new routes to low or even platinum free catalyst composition for efficient hydrogen production and a cleaner future might be open. 


\subsection{Carbon Monoxide Tolerance}

One of the important areas of fuel cell application is the study of the electrocatalysis of hydrogen oxidation reaction (HOR) [10], methanol oxidation reaction (MOR) [11] and ORR. A very potent electrocatalyst for HOR and MOR is platinum. However, Pt shows two major disadvantages 1 ) high price (as already described in 8.2) and 2) low CO tolerance $[10,11]$. It has to be pointed out, that the efficiency of Pt strongly depends on the $\mathrm{CO}$ content. CO adsorption on platinum (also showing a higher adsorption energy of 1.49-1.8eV [12] than hydrogen adsorption with 0.7-0.83 eV) blocks per adsorbed $\mathrm{CO}$ due to several effects more than one active sides for hydrogen adsorption [13]. This will decrease drastically the efficiency of platinum towards HOR as well MOR. Therefore the development of CO tolerant electrocatalyst is of great importance.

In the course of our work, CO stripping has been used to observe the electrochemical surface area (ECSA) of the developed $\mathrm{Pt} / \mathrm{Ir} / \mathrm{V}$ catalyst. However, during the experiments a increased activity towards $\mathrm{CO}$ oxidation of the $\mathrm{Pt} / \mathrm{Ir} / \mathrm{V}$ catalyst was observed, compared with pure Pt or Pt/Ir (Figure 8.2, 8.3, 8.4). In order to visualize the different areas of interest in the CVs (CO oxidation, hydrogen adsorption and hydrogen desorption) CVs are presented here as measured and as color modified plots.

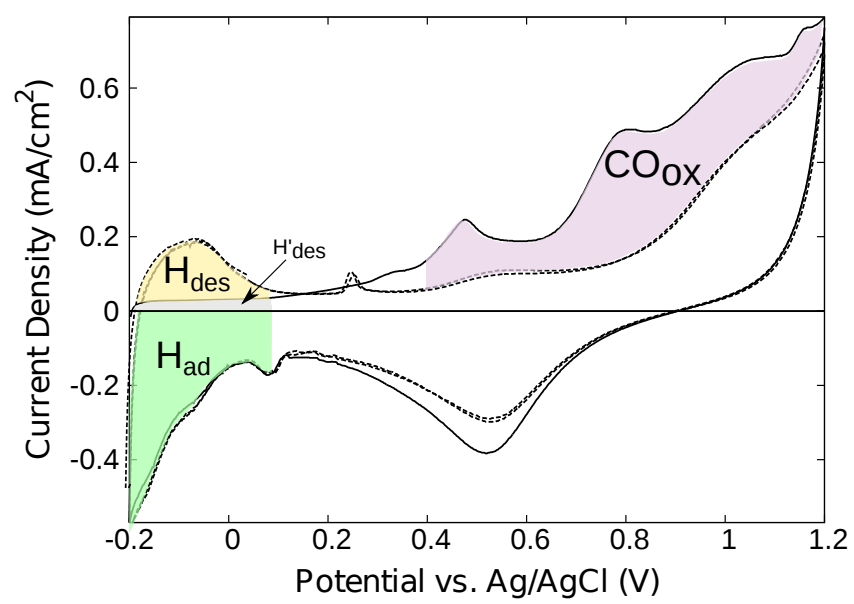

Figure 8.2 Color modified CO stripping voltammogram of Pt coated on Ti in $0.5 \mathrm{M} \mathrm{H}_{2} \mathrm{SO}_{4}$ with a scan rate of $20 \mathrm{mV} / \mathrm{s}$ (solid line indicates the first scan, dashed line indicates the second and third scan). $C O_{o x}=C O$ oxidation, $H_{a d}=$ hydrogen adsorption, $H_{d e s}$ = hydrogen desorption after $\mathrm{CO}$ oxidation, $H^{\prime}{ }_{\text {des }}=$ hydrogen desorption before $\mathrm{CO}$ oxidation. 


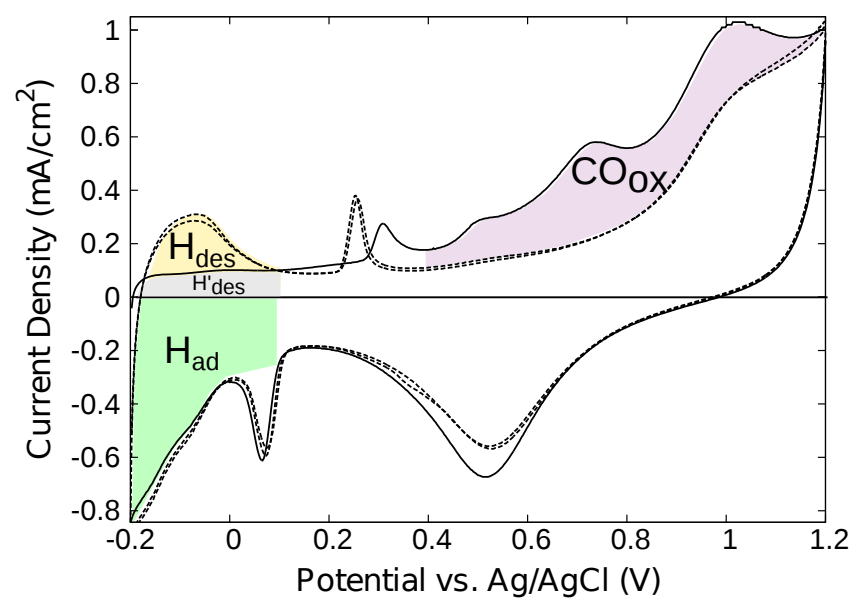

Figure 8.3 Color modified CO stripping voltammogram of Pt/Ir (70/30 wt\%) coated on Ti in 0.5 $\mathrm{M} \mathrm{H}_{2} \mathrm{SO}_{4}$ with a scan rate of $20 \mathrm{mV} / \mathrm{s}$ (solid line indicates the first scan, dashed line indicates the second and third scan). $C O_{o x}=C O$ oxidation, $H_{a d}=$ hydrogen adsorption, $H_{\text {des }}=$ hydrogen desorption after $C O$ oxidation, $H^{\prime}{ }_{\text {des }}=$ hydrogen desorption before CO oxidation.

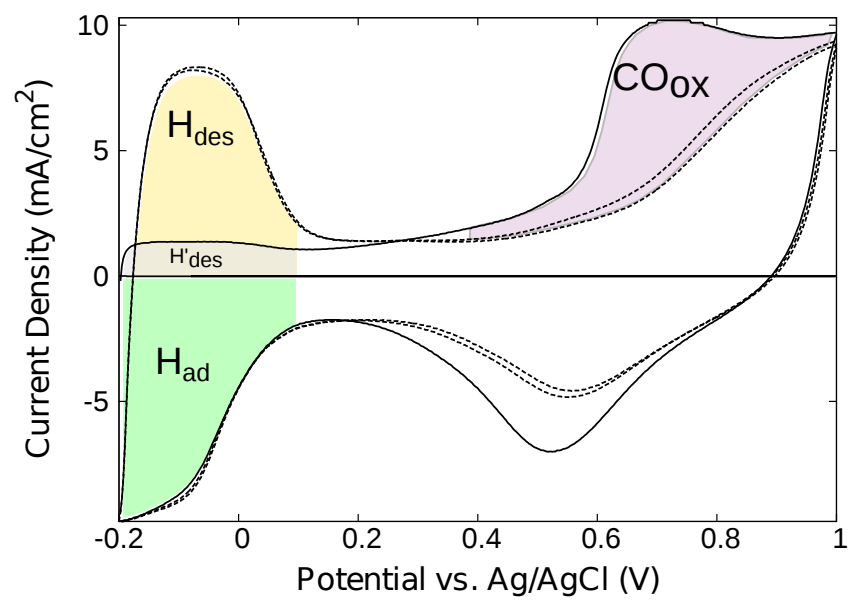

Figure 8.4 Color modified CO stripping voltammogram of Pt/Ir/V (63/27/10 wt\%) coated on Ti in $0.5 \mathrm{M} \mathrm{H}_{2} \mathrm{SO}_{4}$ with a scan rate of $20 \mathrm{mV} / \mathrm{s}$ (solid line indicates the first scan, dashed line indicates the second and third scan). $C O_{o x}=C O$ oxidation, $H_{a d}=$ hydrogen adsorption, $H_{\text {des }}=$ hydrogen desorption after $C O$ oxidation, $H_{\text {des }}^{\prime}=$ hydrogen desorption before $C O$ oxidation.

As can be seen, the catalytic activity towards $\mathrm{CO}$ oxidation, hydrogen adsorption and hydrogen desorption increased drastically in the case of the vanadium doped $\mathrm{Pt} / \mathrm{Ir} / \mathrm{V}$ 
catalyst.

The increase in $\mathrm{CO}$ oxidation might be due to the oxiphilic nature of the vanadium [14] since the $\mathrm{CO}$ tolerance of one of the most promissing $\mathrm{CO}$ tolerant catalyst $(\mathrm{Pt} / \mathrm{Ru})$ $[15,16,17]$ is as well attributed to the oxiphilic nature of the $\mathrm{Ru}$. In this case vanadium might have the same function as the Ru. Such an activation in CO oxidation might also indicate an increase in methanol oxidation reaction (MOR), since the CO is one of the intermediates produced during the MOR [18]. However, only a few recent studies reported the application of a vanadium as alloying material for the preparation of methanol electrocatalyst [19, 20, 21, 22]. Justin et al. [19] explained the increase in methanol oxidation activity with the by scavenging the adsorbed $\mathrm{CO}$ by vanadium oxides from the Pt particles. Here, further experiments have to follow in order to compare the MOR and the $\mathrm{CO}$ oxidation on $\mathrm{Pt} / \mathrm{V}$ and $\mathrm{Ir} / \mathrm{V}$, to understand the role of vanadium inside the formulation. Furthermore the observed behavior in the CVs shows a rather smooth run in the case of the $\mathrm{Pt} / \mathrm{Ir} / \mathrm{V}$ catalyst compared with the $\mathrm{Pt}$ or Pt/Ir. This behavior however could not be explained until now. It might be that the electron transfer rates increased as a result of increased catalytic activity, that no intermediate steps are required to run a reaction e.g. CO oxidation. Yet, theories about the catalytic behavior need to be observed more closely in the future.

As a second effect it can be seen from Figure 8.4, that the activity towards hydrogen adsorption and desorption reactions increased, as well as, the reversibility of these. However, although the results of hydrogen adsorption and desorption seem interesting, this reaction has to be repeated under controlled hydrogen saturated solution in order to interpret correctly the catalytic behavior towards these reactions.

\subsection{Conclusion}

With the view on the observed catalytic activities, and to our best knowledge we can say, that such a catalyst was not yet reported before catalyzing efficiently four different reactions by only one formulation and being more economic than existing catalyst for the same reactions at the same time. Here, further analysis and deep understanding of the catalyst may help future work on catalytic systems to optimize catalysts and to apply the gained knowledge of the multifunctioning $\mathrm{Pt} / \mathrm{Ir} / \mathrm{V}$ catalyst to other catalytic systems. Furthermore the understanding of the catalytic system 
can help to make a further step forward in direction of a cleaner energy source by producing and using hydrogen more efficiently.

\section{Bibliography}

[1] Lai, L.-B., Chen, D.-H., and Huang, T.-C. (2001) J. Mater. Chem. 11(5), 14911494.

[2] Cobelo-Garcia, A., Neira, P., Mil-Homens, M., and Caetano, M. (2011) Marine Pollution Bulletin 62(3), 646 - 650 .

[3] Borgwardt, R. H. (2001) Transportation Research Part D: Transport and Environment 6(3), 199 - 207.

[4] Wu, M., Shen, P. K., Wei, Z., Song, S., and Nie, M. (2007) Journal of Power Sources 166(2), $310-316$.

[5] Raoof, J.B., O. R. E. S. N. S. (2010) International Journal of Hydrogen Energy 35(9), 3937-3944.

[6] Kiani, A. and Hatami, S. (2010) International Journal of Hydrogen Energy 35(11), $5202-5209$.

[7] Belanger, A. and Vijh, A. K. (1974) Journal of The Electrochemical Society 121(2), 225-230.

[8] Abouatallah, R. M., Kirk, D. W., Thorpe, S. J., and Graydon, J. W. (2001) Electrochimica Acta 47(4), 613 - 621.

[9] P. Barbaro and C. Bianchini, (ed.) (2009) Catalysis for Sustainable Energy Production, WILEY-VCH Verlag GmbH \& Co. KGaA, Weinheim.

[10] Zhang, J. (2008) PEM Fuel Cell Electrocatalysts and Catalyst Layers, SpringerVerlag London.

[11] Wasmus, S. and Küver, A. (1999) Journal of Electroanalytical Chemistry 461(12), $14-31$.

[12] Koper, M. T. M., Shubina, T. E., and vanSanten, R. A. (2002) The Journal of Physical Chemistry B 106(3), 686-692. 
[13] Chen, L., Chen, B., Zhou, C., Wu, J., Forrey, R. C., and Cheng, H. (2008) The Journal of Physical Chemistry C 112(36), 13937-13942.

[14] Veith, M., Mathur, S., and Mathur, C. (1998) Polyhedron 17(5-6), 1005 - 1034.

[15] Antolini, E. (2003) Materials Chemistry and Physics 78(3), 563 - 573.

[16] Spendelow, J., Babu, P., and Wieckowski, A. (2005) Current Opinion in Solid State and Materials Science $\mathbf{9 ( 1 - 2 ) ,} 37$ - 48.

[17] Geng, D., Matsuki, D., Wang, J., Kawaguchi, T., Sugimoto, W., and Takasu, Y. (2009) Journal of The Electrochemical Society 156(3), B397-B402.

[18] Iwasita, T. (2002) Electrochimica Acta 47(22-23), 3663 - 3674.

[19] Justin, P., R. G. (2009) Catalysis Today 141(1-2), 138-143.

[20] Maiyalagan, T. and Khan, F. N. (2009) Catalysis Communications 10(5), 433 436.

[21] Zhang, L., Zhang, J., Wilkinson, D. P., and Wang, H. (2006) Journal of Power Sources 156(2), $171-182$.

[22] Folkesson, B., L. R. Z. J. (1989) Journal of Electroanalytical Chemistry 267(1-2), 149-161. 
$\Gamma_{\text {Chapter }}$

Summary and Outlook 


\subsection{Summary}

During last decades, the interest in electrical energy storage has grown substantially. Industry and research but also communities have been triggered by the growing demand of energy, the finite sources of fossil fuels and the increasing pollution caused by fossil fuels to develop and improve storage of electrical energy from renewable power sources.

Electrical storage systems can be categorized in three major sections a) mechanical b) capacitative (no redox couples envolved) and c) electrochemical systems (Table 9.1 )

Table 9.1 Energy Storage Systems.

\begin{tabular}{ccc} 
Mechanical & Capacitative & Electrochemical \\
Pumped Hydro & Super Capacitors & Batteries \\
Compressed Air & Redox Flow Batteries \\
Fly Wheels & Fuel Cells \\
\hline
\end{tabular}

where only the electrochemical section can be implemented to both mobile and stationary application with large energy storage capabilities. However, the existing systems show several major drawbacks, which have to be solved. Some of these drawbacks are the efficiency of the energy that can be stored, the weight of the system (regarding mobile applications) and the costs.

In this work a new approach has been taken to develop a suitable energy storage system with highly improved components for large energy storage applications but also for mobile purpose.

Chapter 1 describes in general the energy situation and gives an overview of the most recent developed systems in consideration of the designated use. Subsequently the chapter focuses on polyelectrolyte membrane based electrochemical storage media with the main focus on polyelectrolyte membranes for the use in vanadium redox flow batteries.

Chapter 2 describes some electrochemical analysis methods applied in the scope of 
this work in order to analyze the existing systems and the materials developed within in this work.

Chapter 3 describes the first generation of the vanadium air redox flow battery entitled as Modular Vanadium/Air Redox Flow Battery (Modular Vanadium/Air-RFB). The Modular Vanadium/Air-RFB is a hybrid system combining two energy storage technologies, namely the fuel cells and the redox flow battery systems. The development of such a system has been triggered by mainly two points a) decrease of the weight with respect to the existing redox flow battery systems with two liquid storage media containers and b) decrease of the costs regarding to the existing fuel cells by minimizing the catalyst usage to half of the required amount. The chapter describes in detail the system properties, and the preparation of the membrane electrode assembly. It describes the shortcomings of the system and the pathways to overcome the observed shortcomings. Finally the Modular Vanadium/Air-RFB performance will be presented under different conditions.

Chapter 4 focuses on the improvement of the Modular Vanadium/Air-RFB in order to increase the suitability of the system for mobile applications as well as to overcome the shortcomings of the system decribed in Chapter 3. For this, the focus of the chapter is the improvement of the MEA as well as optimization of the operating conditions leading to the second generation storage system entitled as Unitized Vanadium/Air Redox Flow Battery (Unitized Vanadium/Air-RFB). Finally, the performance of the so called Unitized Vanadium/Air-RFB will be demonstrated.

Chapter 5 focuses on polyelectrolyte membrane development for energy storage but also for energy conversion devices. Polyelectrolyte membrane based storage and conversion devices put great demands on the properties of the applied polyelectrolytes, which can be met by material modification or development of new material. The chapter will give a short overview of some interesting material modification methods and will show a new approach to produce crosslinked SPEEK by a new crosslinking route and the control of the membrane properties by the crosslinking conditions in order to present a of a new material as an stable alternative to the expensive and widely used Nafion.

Chapter 7 focuses in view of energy consumption for many industrial applications and hybrid systems like the Vanadium/Air-RFB and the Unitized Regenerative Fuel 
Cell on the catalyst requirements in the above mentioned applications. Here a novel quad-functional catalyst with improved activity towards ORR, OER, HER and CO oxidation is developed, presented and analyzed in terms of the activity, long term stability under harsh conditions and the coating properties.

Chapter 8 focused on further findings which were observed on the developed $\mathrm{Pt} / \mathrm{Ir} / \mathrm{V}$ catalyst in order to present the obtained data towards the observed reactions and to emphasis the application of the $\mathrm{Pt} / \mathrm{Ir} / \mathrm{V}$ in a broad range of processes as multifunctioning catalyst but also to encourage further investigations of these type of catalyst to achieve a deep understanding of the material in order to develope links to improve other catalytic systems. 


\subsection{Outlook}

The work of this thesis was focused on the developed, investigation and improvement of a new energy storage system and its components (catalyst and polyelectrolyte membrane). The developmened energy storage system (Vanadium Air Redox Flow Battery, Vanadium/Air-RFB) represents an interesting system in which the combination of fuel cell and redox flow battery technology has been unitized successfully.

What are the fields of unsolved problems and challenges? 


\section{Diminishing Oxygen Crossover}

Oxygen cross over was a major challenge in the Vanadium/Air-RFB development and it still remains as one of the major challenges. It was decreased significantly in our work (this thesis) by the development of the Unitized Vanadium/Air-RFB. The reasons for oxygen transport are mainly:

- oxygen permeation as gas through the polyelectrolyte membrane to the vanadium side (oxygen from the gaseous side during charge and discharge)

- oxygen permeation as dissolved gas in water through the polyelectrolyte membrane due to osmosis (oxygen resulting from oxidation of water during charge)

\section{Gaseous Oxygen Permeation}

Gaseous oxygen permeation through the polyelectrolyte membrane is a challenge which has to be tackled on the whole range by modification of polyelectrolyte material or even the synthesis of new materials since this is an material issue. To tackle this issue, the reason for oxygen permeation needs to be understood. This has been already investigated in the scientific literature since oxygen permeation is also an issue in the fuel cell technology. Mohamed et al. [1] reported, that according to the free volume model gas permeation can only occur by molecular diffusion through inter-chain open space or free volume.

In order to decrease free volume in polyelectrolytes a layer by layer method has been applied from Yang et al. [2] where polyethylenimine and polyacrylic acid were deposited on a substrate layer by layer in order to decrease the free volume and by this the gas permeation. In the case of the Vanadium/Air-RFB this might show a great potential to decrease the oxygen permeation of any polyelectrolyte.

\section{Dissolved Oxygen Permeation}

This issue mainly attributes to the electrode design. A thick electrode will have sufficient free volume (in this case the pores of the porous electrode) for water accumulation. This issue could already be reduced for the charge reaction due to the applied principle of the reverse humidification (Chapter 4). However, during discharge water is produced at the air side, resulting in water which might accumulate by insufficient transport mechanism inside the electrode pores. With that the water presents a potential matrix for oxygen, which can be dissolved and transported through the membrane by osmosis to the vanadium side leading to a self discharge 
of the Vanadium/Air-RFB. Having this in mind, a new electrode design in which the water can not accumulate but instead is dragged out with a dry air stream will lead to a better battery performance. Here, a thin electrode design or even an electrode less design of the MEA would further decrease the oxygen permeation to the vanadium side. An electrode less design in which the catalyst is directly applied to the membrane surface has already been discussed in the literature [3, 4]. Using the sputtering method a very thin film of the desired catalyst can be directly applied on the membrane. By this not only the free volume of the electrode for water accumulation will decrease but also:

- the expensive electrode made of titanium will be ruled out, making the MEA preparation more economic (here more economic materials like iron, copper, nickel could be used)

- the membrane will not suffer from mechanical treatments (hot pressing), since no electrode will be needed

- the catalyst loading could be decreased to the minimum by exact controlling of the sputtering conditions

\section{Catalytic Activity}

on one side the vanadium oxidation and reduction was already studied on different carbon materials in the view of the all vanadium redox flow battery by many researchers $[5,6,7,8]$. It has been shown that by the modification of the surface groups of the applied carbon materials towards oxygen containing groups can lead to an improvement of the redox reaction kinetics of all the vanadium redox reactions in all four oxidation states. Reflecting this to the Vanadium/Air-RFB this could lead to lower overpotentials for the charge/discharge reactions, meaning that the battery performance could be improved in terms of efficiency.

On the other side, the electrode coated with a bifunctional air electrode operating in acidic condition appears not to be a major research topic analyzing the scientific literature. Here the catalyst of choice has always been $\mathrm{Pt} / \mathrm{Ir}$ or $\mathrm{Pt} / \mathrm{IrO}_{2}$. Chen et al. [9] developed a new tertiary catalyst for this propose, made of $\mathrm{Pt}_{4.5} \mathrm{Ru}_{4} \mathrm{Ir}_{0.5}$. The doping of the known Pt/Ir catalyst with $\mathrm{Ru}$ increased the catalytic activity in both directions ORR and OER. However, the sensitive composition and the use of Ru as a rare transition metal of the platinum group would make such a catalyst not suitable to every process and application since some applications like the Vanadium/Air-RFB need to be produced at a lower price to compete with other systems. Here, the new 
catalyst developed in this work $(\mathrm{Pt} / \mathrm{Ir} / \mathrm{V})$ represents a good alternative to increase the reaction kinetics of the ORR and OER and being more economic, due to the reduced $\mathrm{Pt}$ by $7 \mathrm{wt} \%$ and Ir content by $3 \mathrm{wt} \%$.

\section{Increasing the Battery Energy Efficiency}

Increasing the battery efficiency can also be achieved on a different pathway than described before. This can be achieved by reducing the theoretical potential of $1.49 \mathrm{~V}$ for the charging cycle. To achieve this, redox couples (or the fuel, namely water) for charging need to be changed in such a way, that vanadium can be charged at a lower potential where at the same time a counter reaction with a lower redox potential will take place in the other compartment. An interesting approach can be found in the scientific literature presented by Ilicic et al. [10].

The described direct methanol redox fuel cell (for more details see Chapter 4) uses methanol as fuel, which has a redox potential of $0.06 \mathrm{~V}$ vs. SHE. To decrease the complexity of the system the methanol was applied directly to the storage media $\left(\mathrm{Fe}^{2+} / \mathrm{Fe}^{3+}\right)$ in order to permeate through the polyelectrolyte membrane and being oxidized in the other compartment to deliver electrons and protons.

Applying this to the Vanadium/Air-RFB, a theoretical charging potential of $0.32 \mathrm{~V}$ could be achieved, and at discharge by applying oxygen the cell potential would lay at a theoretical value of $1.49 \mathrm{~V}$. By this, not only more energy could be gained as introduced but also the use of an expensive titanium electrode would not be necessary, since no active oxygen would be produced during charging and no electrode corrosion would occur. Furthermore, the bifunctional catalyst would be ruled out since methanol oxidation and oxygen reduction can be catalyzed sufficiently by only platinum.

\section{Bibliography}

[1] Mohamed, H. F., Kobayashi, Y., Kuroda, C. S., Takimoto, N., and Ohira, A. (2010) Journal of Membrane Science 360, 8489.

[2] Yang, Y.-H., Haile, M., Park, Y. T., Malek, F. A., and Grunlan, J. C. (2010) Macromolecules DOI:10.1021/ma1026127.

[3] Cha, S. Y. and Lee, W. M. (1999) Journal of The Electrochemical Society 146(11), 4055-4060. 
[4] O'Hayre, R., Lee, S.-J., Cha, S.-W., and Prinz, F. B. (2002) Journal of Power Sources 109(2), $483-493$.

[5] Sun, B. and Skyllas-Kazakos, M. (1991) Electrochimica Acta 36(3-4), 513 - 517.

[6] Kaneko, H., N., K., Wada, Y., Aoki, T., Negishi, A., and Kamimoto, M. (1991) Electrochimica Acta 36(7), 1191 - 1196.

[7] Zhong, S., Padeste, C., Kazacos, M., and Skyllas-Kazacos, M. (1993) Journal of Power Sources 45(1), 29 - 41.

[8] Han, P., Wang, H., Liu, Z., Chen, X., Ma, W., Yao, J., Zhu, Y., and Cui, G. (2011) Carbon 49(2), $693-700$.

[9] Chen, G., Delafuente, D. A., Sarangapani, S., and Mallouk, T. E. (2001) Catalysis Today 67(4), $341-355$.

[10] Ilicic, A. (2010) PhD Thesis. 


\section{List of Symbols}

$\eta_{C} \quad$ Coulomb efficiency

$\eta_{E} \quad$ Energy efficiency

$\eta_{V} \quad$ Voltage efficiency

$\sigma \quad$ Proton conductivity

$\mathrm{mS} / \mathrm{cm}$

a Area

$\mathrm{cm}^{2}$

$C$ Concentration

$\mathrm{mol} / \mathrm{l}$

E Potential

$\mathrm{V}$

$F \quad$ Faraday constant

$\mathrm{C} / \mathrm{mol}$

I Current

$\mathrm{mA}$

$l \quad$ Thickness

$\mathrm{cm}$

$M \quad$ Molar mass

$\mathrm{g} / \mathrm{mol}$

$P \quad$ Permeability coefficient

$\mathrm{cm}^{2} / \mathrm{s}$

$Q \quad$ Capacity

$\mathrm{Ah}$

$R \quad$ Electrical resistance $\quad \Omega$

$v \quad$ Volumen $\quad \mathrm{ml}$

$Z \quad$ Impedance $\Omega$ 


\section{List of Tables}

1.1 Customary primary battery systems $\ldots \ldots \ldots \ldots \ldots$

1.2 Customary secondary battery systems . . . . . . . . . . . 10

1.3 Secondary batteries as large scale energy storage systems $\ldots \ldots \ldots$

1.4 Redox Flow Battery Systems _. . . . . . . . . . . . . . 13

1.5 Cation exchange membranes for Vanadium-RFB application . . . . . . 33

1.6 Anion exchange membranes for Vanadium-RFB application . . . . . . 35

1.7 Amphotheric ion exchange membranes for Vanadium-RFB application 37

4.1 OCV after charging at different current densities $\ldots \ldots \ldots \ldots$

$5.1 \quad$ FT-IR analysis of membranes . . . . . . . . . . . . . . 90

5.2 Swelling and proton conductivity of different cSPEEK membranes . . 92

5.3 Ion exchange capacity and vanadium permeability $\ldots \ldots \ldots . . .97$

6.1 Swelling of crosslinked SPEEK _ . . . . . . . . . . . . . 105

9.1 Energy Storage Systems. . . . . . . . . . . . . . . . . . . . 138

9.2 Energieopslagsystemen. . . . . . . . . . . . . . . . . 155 


\section{List of Figures}

1.1 Scientific publications on "renewable electrical energy" . . . . . . . . 2

1.2 Schematic of a Volta Pile . . . . . . . . . . . . . . . . . . . 3

1.3 EESC systems . . . . . . . . . . . . . . . . . 4

1.4 General schematics of a fuel cell . . . . . . . . . . . . . . . 5

1.5 Most investigated fuel cells with operation conditions [14] . . . . . . 6

1.6 Overview of a redox flow battery system . . . . . . . . . . . . . 12

1.7 Overview of a vanadium redox flow battery system . . . . . . . . . 16

1.8 Schematic of the Fuel Cell Bio Reactor [32] . . . . . . . . . . . . . . . 18

1.9 Schematic of the Redox Fuel Cell [33] . . . . . . . . . . . . . . . . . . 20

1.10 Schematic of the Bifunctional-RFB $[34,35] \ldots \ldots$. . . . . . . . 21

1.11 Schematic of a Mixed Reactant Direct Liquid-RFB [36] . . . . . . . . 22

1.12 Issues in membrane development for vanadium redox flow batteries . . 24

1.13 Expected water and ion transfer for anion and cation exchange mem-

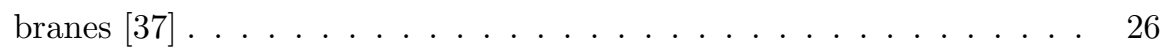

1.14 Nafion chemical structure . . . . . . . . . . . . . . . . . . . 29

1.15 Redrawn schematics of the microstructures of Nafion and a sulfonated poly ether ketone $[50] \ldots \ldots . \ldots . \ldots . . \ldots 30$

1.16 Layer by Layer surface modification . . . . . . . . . . . . . . . . . . 32

2.1 Electrochemical cell . . . . . . . . . . . . . . . . . . 46

2.2 Redrawn schematic representation of a cyclic voltammogram of $\mathrm{Pt}$ in acidic media $[4]$. . . . . . . . . . . . . . . . . . 47

2.3 Redrawn schematic representation of a CO stripping cyclic voltammo$\operatorname{gram}[6] \ldots \ldots \ldots \ldots \ldots \ldots$ 
2.4 Current respond in impedance spectroscopy . . . . . . . . . . . 50

2.5 Nyquist plot of a capacitor and a circuit consisting of an $\mathrm{R}-\mathrm{C}$ element

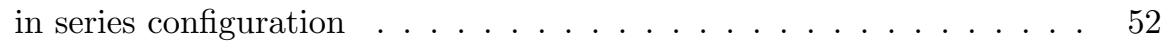

2.6 Nyquist plot of a $\mathrm{R}-\mathrm{C}$ circuit in parallel configuration $\ldots \ldots \ldots . .52$

2.7 Equivalent circuit used to fit impedance data $[7] \ldots \ldots \ldots$

2.8 Scheme of cell for electrochemical impedance spectroscopy . . . . . . 54

3.1 Reactions inside the electrochemical cell of the Modular Vanadium/Air-

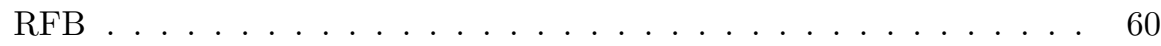

3.2 Schematic of the Modular Vanadium/Air-RFB system . . . . . . . . 62

3.3 MEA for the charging procedure of the Modular Vanadium/Air-RFB . 63

3.4 MEA for the charging procedure of the Modular Vanadium/Air-RFB . 64

3.5 SEM picture of sintered titanium electrode . . . . . . . . . . . 64

3.6 Open Circuit Potential of the Modular Vanadium/Air-RFB . . . . . . 65

3.7 Charge-Discharge behavior of the Modular Vanadium/Air-RFB . . . . 66

4.1 Schematic of the Unitized Vanadium/Air-RFB system . . . . . . . 70

4.2 SEM pictures of high surface area electrodes . . . . . . . . . . . 72

4.3 Open circuit potential of the Unitized Vanadium/Air-RFB . . . . . . 74

4.4 Discharge behavior of the Unitized Vanadium/Air-RFB . . . . . . . 75

4.5 Fast charge and slow discharge behavior of the Unitized Vanadium/Air-

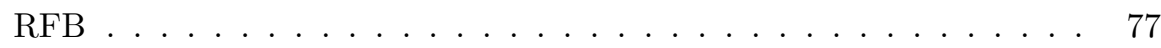

4.6 Unitized Vanadium/Air-RFB charged and discharged at the same cur-

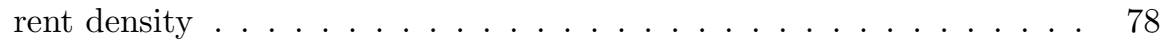

5.1 Chemical structure of Poly Ether Ether Ketone (PEEK) . . . . . . . 83

5.2 Chemical structure of Sulfonated Poly Ether Ether Ketone (SPEEK) . 83

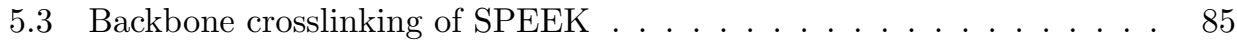

5.4 Chemical crosslinking of SPEEK proposed by Feng et al. [22] . . . . 86

5.5 Schematics of a diffusion cell _ . . . . . . . . . . . . . . 89

5.6 Crosslinked and non crosslinked SPEEK . . . . . . . . . . . . . 90

5.7 FT-IR of non crosslinked and crosslinked SPEEK . . . . . . . . . . 91

5.8 Electrochemical impedance spectra of crosslinked SPEEK series . . . . 93

5.9 Conductivity of crosslinked SPEEK . . . . . . . . . . . . . 94

5.10 Conductivity dependency of crosslinking temperature . . . . . . . 95

5.11 Crosslinking positions of the 1,4 Benzyl-di-methanol $\ldots \ldots \ldots \ldots$

$5.12 \mathrm{VO}^{2+}$ crossover through proton conductive membranes $\ldots \ldots . .99$ 
6.1 Proposed chemical structure of crosslinked Sulfonated Poly Ether Ether Ketone . . . . . . . . . . . . . . . . . . . . 102

6.2 Down field H-NMR-MAS spectra of SPEEK . . . . . . . . . . . . . . . 103

6.3 Down field H-NMR-MAS spectra of crosslinked SPEEK . . . . . . . . 104

6.4 TGA spectra of SPEEK membranes . . . . . . . . . . . 106

7.1 Cracked mud structure of a Pt/Ir catalyst . . . . . . . . . . . 113

$7.2 \mathrm{CV}$ of $\mathrm{Pt} / \mathrm{Ir}$ and $\mathrm{Pt} / \mathrm{Ir} / \mathrm{V} \ldots \ldots \ldots \ldots . \ldots \ldots 117$

7.3 XRD patterns of different catalysts . . . . . . . . . . . . . . 119

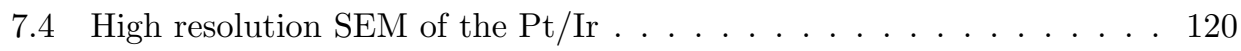

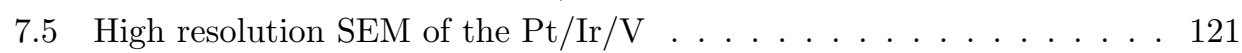

7.6 Accelerated life time test . . . . . . . . . . . . . . . 122

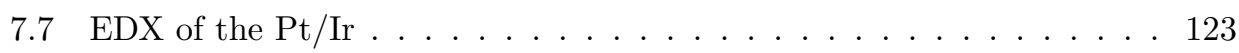

7.8 EDX of the $\mathrm{Pt} / \mathrm{Ir} / \mathrm{V} \ldots \ldots \ldots \ldots \ldots \ldots$

8.1 Hydrogen evolution $\mathrm{CV}$ of $\mathrm{Pt} ; \mathrm{Pt} / \mathrm{Ir}$ and $\mathrm{Pt} / \mathrm{Ir} / \mathrm{V}$. . . . . . . . . . 129

8.2 CO stripping voltammograms of $\mathrm{Pt}$. . . . . . . . . . . . . . 131

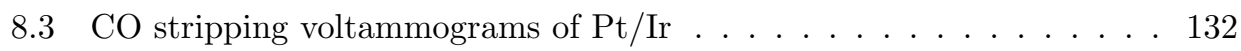

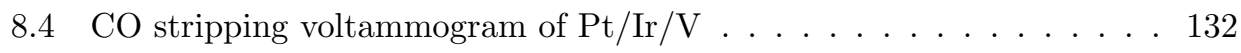




\section{Samenvatting}

De laatste decenia is de interesse voor electrische oplsag systemen substantieel gegroeid. Door de groeiende vraag naar energie, de eindige voorraad fossiele brandstoffen en de toename van vervuiling veroorzaakt door deze fossiele brandstoffen, zijn de industrie, wetenschap, maar ook de samenleving aangespoord om de opslag van energie uit hernieuwbare bronnen te ontwikkelen en te verbeteren. Energieopslagsystemenkunnen gecategoriseerd worden in drie grote groepen: a) mechanische, b) capacitatieve (geen redox koppel nodig ) en c) elektrochemische systemen (Table 9.2) waar alleen de elektrochemische sectie geïmplementeerd kan worden in mobiele en stationaire toepassingen a met grote energieopslagcapaciteit. Toch hebben de huidige systemen grote nadelen die opgelost moeten worden. Nadelen zijn de efficintie van het systeem, het gewicht van het systeem (voor mobiele systemen) en de kosten van het systeem. In dit onderzoek zijn energieopslagsystemen op een andere manier benaderd met verbeteringen voor grote energie opslag systemen maar ook voor mobiele toepassingen.

Table 9.2 Energieopslagsystemen.

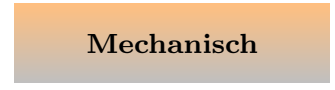

Waterkracht

Perslucht

Vliegwiel

\section{Capacitative}

Super Condensator

Redox Flow Batterijen

Brandstofcell

Hoofdstuk 1 geeft een algemene omschrijving van de energiesituatie en geeft een overzicht van de meest recent ontwikkelde systemen voor verschillende toepassingen. 
Vervolgens richt het hoofdstuk zich op elektrochemische opslagsystemen gebaseerd op polyelectroliete membranen met name voor gebruik in vanadium redox flow batterijen.

Hoofdstuk 2 beschrijft enige elektrochemische analysemethoden die gebruikt worden bij dit onderzoek om bestaande systemen en de ontwikkelde membranen te analyseren.

Hoofdstuk 3 beschrijft de eerste generatie vanadium air redox flow batterij getiteld: Modular Vanadium/Air Redox Flow Battery (Modular Vanadium/Air-RFB). De Modulair Vanadium/Lucht-RFB is een hybride systeem die twee energie opslag systemen combineerd. Namelijk de brandstofcel en de redox flow batterij. De ontwikkeling van zo een systeem is getriggerd door 2 dingen: a) afname van de massa met respect tot het bestaande redox batterij systeem met twee vloeistof opslag containers en b) afname van de kosten van bestaande brandstofcellen door halvering van de benodigde catalysator. Het hoofdstuk beschrijft in detail de systeem eigenschappen en de bereiding van het membraan electrode. Het beschrijft de tekortkomingen van het systeem en hoe deze overkomen kunnen worden. Ten slotte word de prestatie van het Modulair Vanadium/Lucht-RFB systeem bij verschillende condities beschreven.

Hoofdstuk 4 focust op de verbetering van de Modulair Vanadium/Lucht-RFB om het systeem geschikt te maken voor mobiele aplicaties en om de in hoofdstuk drie beschreven tekortkomingen te verbeteren. Hiervoor is voornamelijk gekeken naar de verbetering van de MEA en de optimalisatie van de bedrijfs condities die leiden tot de tweede generatie opslag systeem genaamd Unitized Vanadium/Air Redox Flow Battery (Unitized Vanadium/Air-RBF). Ten slotte wordt de prestatie van de Unitized Vanadium/Air-RBF gedemonstreerd.

Hoofdstuk 5 focust op de ontwikkeling van polyelectroliete membranen voor energieopslag- en energieconversiesystemen. Polyelectroliet gebaseerde membraan opslag- en conversie systemen vereisen veel van de gebruikte polyelectrolieten. Deze kunnen behaald worden door materiaal modificatie, en door de ontwikkeling van nieuwe materialen. Dit hoofdstuk geeft een kort overzicht van interesante materiaal modificatie methoden. Ook beschrijft dit hoofdstuk een een nieuwe methode om gecrosslinked SPEEK te maken. Dit wordt gedaan door een nieuwe crosslinkmethode toe te passen en door de membraan eigenschappen te controleren door de crosslinkcondities te controlleren. Dit levert een nieuw materiaal op dat een stabiel en goedkoop alternatief is voor het veelgebruikte Nafion. 
Hoofdstuk 7 is analyseert de energie consumptie van de Vanadium/Air-RFB en de Unitized Regenerative Fuel 140 Cell en beschrijft de eisen die gesteld worden aan de katalysator van deze systemen. Ook wordt de ontwikkeling van een nieuwe quad gefunctionaliseerde katalysator met verbeterde activiteit voor ORR, OER, HER en CO oxidatie beschreven. Deze katalysator is geanalyseerd met betrekking tot activiteit, stabiliteit op de langetermijn, prestaties bij zware condities en de coating eigenschappen.

Hoofdstuk 8 beschrijft de verdere bevindingen die gedaan zijn tijdens de ontwikkeling van de $\mathrm{Pt} / \mathrm{Ir} / \mathrm{V}$ katalysator. Verder wordt in dit hoofdstuk het gebruik van de $\mathrm{Pt} / \mathrm{Ir} / \mathrm{V}$ katalysator in een breder perspectief geplaatst. Niet alleen door de toepasbaarheid van deze katalysator voor verschillende processen aan te tonen, maar ook om verder onderzoek naar dit type katalysator te stimuleren. 


\section{Acknowledgments}

Now after four years of $\mathrm{PhD}$ its time to thank those, who helped me, not only through this time but also those who supported me much longer than these four years within and sometimes over their own personal limits to make it possible for me to arrive to this point.

My first acknowledgment must go to my promoter and supervisor Prof. Matthias Wessling. A person of which type I have not met much in my life: a great scientist and a man with much experience and always a little tip in times of worry and struggle. He has supervised me during two of the four years of my $\mathrm{PhD}$ studies encouraging me with his special way of motivation to continue. Thank you for trusting in me and never giving up on me, especially when you took over my supervision and during the last period of the thesis.

Secondly I would like to thank one of the most inspiring, honest, modest and warmhearted man and practically my second daily supervisor, Dr. Michel Saakes. Most of the work in my PhD could not have been realized without your great support. You were there for me in times of confusion and despair, no matter when. I have learned a lot from you not only in a scientific point of view but also personally. I very much appreciate your guidance during the last four years. Michel, thanks a lot!

Next I would like to thanks the MTG group staff for the great support and help. Greet, you have always helped me kindly from the beginning of my application until the last period of my PhD studies in all my administrative questions. Without your support I would have gone, most probably, through a very hard time with all the little things from which one never would expect to be such a pain in the neck.

John H., you are a truly amazing man! Looking at you and what you have done for 
me deserves a huge THANKS! There was not one moment, in which you have refused to help me (you even worked during your holidays and weekends on my project!!!) and this shows how unselfish and truly supportive you are. Thank you very much John!

Antoine, the help you have provided me during the last four years deserves a thanks as well. But this is not everything. Antoine, you belong to the persons, which I experienced as a very kind. I always could talk to you freely which was a good feeling and which helped me to relax. Thank you for being so open and friendly.

I also would like to thanks the rest of the MTG-Staff for the support and help: Marcel B., Erik V., Erik R., Herman and Harman.

Special thanks goes to the TCO-Staff Sip Jan Boorsma and Peter Scheeren for the support and building of my experimental set ups.

Furthermore there are some other persons who deserve my thanks for help or many good talks with proper content (not random small talk). These are Anne Corine, Jeroen, Marcel ten H. (thank you for your great work and help), Anna \& Michiel, Murat (thank you very much, especially for the start in Aachen), Sandra \& Juan and Ulrich (one the most motivated dance student).

Looking back in my life I need to mention, that I would not be standing here at this point without a strong and lovely support from different sides. First of all there are my friends, true friends, unselfish and open minded, no matter how reserved I used to be.

Michael, my dear friend, you were my second friend in Germany and you still are a kind of soul mate to me. Looking back it is amazing how much fun we had together, how much we have learned from each other and how much it meant and still means to me to be your friend! Thanks for all your time, all your motivation and inspiration you have brought in my life. Never going to forget the awesome years with you, we rocked. You showed me how to live life differently.

Andreas my friend, this sentence (just classic): Keine Macht den Drogen, das Gehirn wird sonst verbogen! reminds me of so many things and fantastic moments we shared in the past. Looking back I can tell you, that after 1995 you have been one $\mathrm{f}$ the key persons, who gave me strength and motivation to finish the Realschule. You 
have done this with your strong and supporting friendship which I truly appreciate. The time we spent together was always fun, you have broaden my view in different directions and by this helped me to develop my personality. Thank you!

Florian B. one of my "WG-Kochstudio" house mates, a friend who has inspired me with his views, being a better human, and motivated me to finalize what I have started (and I tend to start a lot of things at once). A friend with whom I have shared lots of great moments many of them on our yearly bike trips and a friend who has supported me in my thoughts during my identification process, mutating to a hair ball with two eyes :) Thank you for being there at every hill (in every sense) encouraging me to continue and pushing me to my limits.

Kana (a.k.a. Varatharajan Sivasubramaniam) another dear friend from the most fantastic community ever. You have showed me how diverse life can be. Through all the talks and discussions with you I have learned, that many things in life are not granted as I always thought. You have opened my view and taught my sense for the little things in every days life which I never would have paid attention to. Thank you my friend!

Peter an other kind person and dear friend who has been always a great inspiration for me in many senses. You are by far the calmest person I have ever met. This has inspired me always, although I never could achieve this ease and comfort you radiate, every day. Peter, I thank you for the great time (HC ni semitemos), great discussions and great friendship. The time and discussions with you always meant a lot to me and made some hard day pass faster.

Oliver my friend from the city in the heart of Europe (Nordhorn), would you have imagined the first time we met in Muenster (too early for the first CTA lesson) what we will experience and where we will be in 14 years? My friend I can tell you it was more than a pleasure to met you at this morning. The time with you through all these years was just fun from the weekly cinema visits to the WG-Kochstudio times. You were always up for any action which would add joy to every days life.

Another young man who has become to a dear friend over the past years is Tobias. Tobi, thank you for your patience always when I felt to complain about anything in the community, preferably by SMS at 5:00 AM. Thank you for the talks which I always experienced as sooo relaxing that I could forget for a second about my little 
world and its mostly self-made issues. Thank you for just being there.

Furthermore I would like to thank Florian S. another inspirational source and dear friend. Florian, I would say that if I would not have met you in the Fun-Factory I would have missed one of the greatest joys in my life, namely the dance. You have showed me and inspired me so much in my dance that I will always associate one of my greatest passions with you. But not only in my dance but also in my way of living and the way to analyze certain issues you have showed me new ways and strategies. Talking with you has always been very fruitful for me and jamming with you always fulfilled me with lots of joy.

Myriam \& Gérard I would like to thank you for the support, especially for the moving, for accepting and welcome me immediately as a member of the family and for good times in South France. Tiphaine, also special thanks to you for being always a good partner to talk to and the unselfish attitude.

At this point I would like to thank a very special person. A person from which I have learned so much in a very short time (in any sense) a person who inspires me every day anew, a person who has supported me in one of the hardest times of my life so substantially that I never could have imagined that this could be possible and a person who I love. I would like to thank you Géraldine (my L.O.V.E.), from the bottom of my heart, for being there for me, every day, showing me love and strengthen my back no matter how grumpy, ugly and selfish I am. I would like to thank you for keeping me moving, inspiring me and motivating me repeatedly although this must be sometimes a real pain in the neck. Thank you for taking care about, the one who still would cry for his food, the one who still would dress like a teenager without you, the one who can be sometimes a really annoying smart $a^{* *}$, and the one who likes to live in a mess...thank you for taking care about me and being there always with the cutest smile I have ever seen in my life. You are a true gift from life to me. I Love you!

Finally there is a support which never has given up on me making me strong through my whole life. This goes out to my family!

Liebe Geschwister: Schirien, Schahab und Schura. Würde mich heute einer fragen, ob ich eine gute Kindheit hatte müsste ich diese frage bejahen. Ja, ich hatte sogar eine wunderschöne Kindheit. Ein Grund dafür seid ihr. Ich könnte natürlich jeden einzelnen von euch aufzählen aber das mach ich jetzt mal nicht. Stattdessen will ich ein 
paar von den unzähligen schönen Augenblicken in eure Erinnerung rufen und hoffen ein kleines Lächeln hervorlocken zu können. Danke für all die schönen Augenblicke und euren Support!

- Palmstock: Wer hat da so sehr große Probleme mit den Namen unserer Nachbarn Möller oder doch Schlömmer?

- Überraschungseibasar: Kleine selbstgemachte Poster hängen überall im Haus auf denen geschrieben steht: Flohmarkt bei mir im Zimmer. Fragt sich wer ist "mir", ganz klar oder?

- Michael Jackson, irgendwie hat die ganze Familie einen Bezug dazu. Und das zeigt man auch gern, besonders wenn man im Sauerland auf Zeltlager ist

- Mr. 556, und Fett-Fett-Zilla, ach das waren harte Zeiten

Und nun komme ich zu den wohl zwei wichtigsten Personen in meinem Leben: Meinen Eltern.

Liebe Mama und lieber Papa, vor knapp 23 Jahren wurden Sie mit der Entscheidung konfrontiert, Ihr Leben im Iran- einem wunderschönen, jedoch politisch unstabilen Land- fortzuführen oder ein neues Leben abseits eines Staates, welcher von diversen Repressalien seitens der Regierung heimgesucht wird, zu beginnen. Sie entschieden sich für Letzteres und zugleich dafür, Ihr Leben zu riskieren, um Ihren Kindern hier in Deutschland ein besseres Leben zu ermöglichen. Sie haben nach einer mit Gefahren behafteten Flucht aus dem Iran- Ihrem Vaterland- in Deutschland unglaubliche Strapazen auf sich genommen. In einem fremden Land wieder Fuß zu fassen, sodass Sie uns das Bestmöglichste bieten konnten, hatte und hat noch heute für mich einen unschätzbar hohen Wert. Freilich hatte all dies seinen Preis. Glücklich kann sich jedoch jeder wissen, diese Aufopferung zweier Menschen einmal zu spüren. Deshalb widme ich Ihnen diese Arbeit, um Tribut zu zollen für Ihren selbstlosen und verbissenen Kampf um unser Wohl. Danke für alles!! 


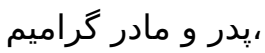

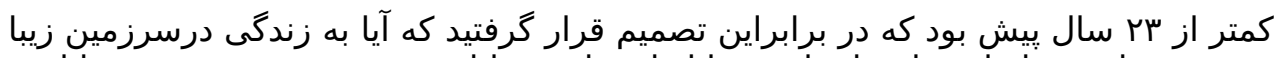

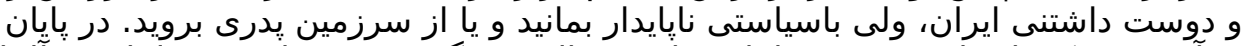

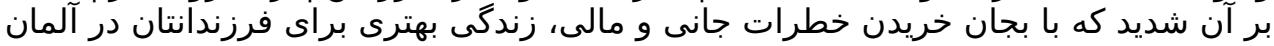

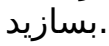
شما با فرار از سرزمين يُدرى كه با مخاطرات گُوناگون و دشوارى هاى بيشمار وغيرقابل

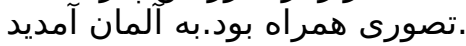

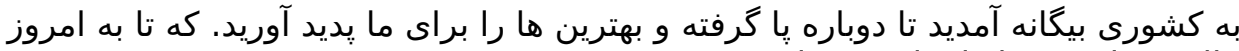

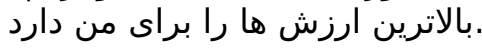

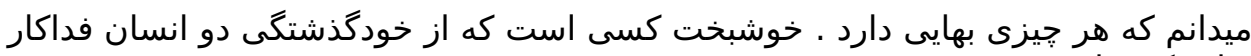

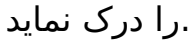
از اينرو اين كار و دسترنج خويش را، همجون يُاداشى ناجيز براى فداكارى و يشتكار در جنكى

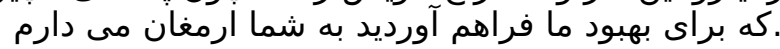

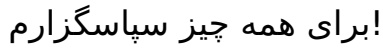

